Ornament is not ArchitectureARCHITECTURE AS ORNAMENT

An exploration of digital fabrication and parametric modelling to reenvisage and revitalise ornamentation in architecture 
The following thesis is part of the Advanced Manufacturing and Prototyping for Design Research Lab. AMPD aims to investigate and define innovative techniques and methods of modern construction applicable to the architecture and construction sector through the use of advanced tools of design, fabrication, and manufacturing. The fourth industrial revolution is core to our research exploring methods of improving information flow from design to fabrication - across the digital continuum - to design architecture that builds wellbeing for people and the planet. We can't keep doing what we have always done- our research questions the status quo by designing and constructing prototypes. You should consider the thesis within the larger body of research that AMPD Research Lab undertakes. Each thesis has focused on an aspect of AMPD's aim.

This research was funded by the 'BRANZ Future Design Thinking for Construction' scholarship.

Thanks to Kirsty Morison for her kindly making the firing of the clay models possible.

$$
\text { ampol }
$$

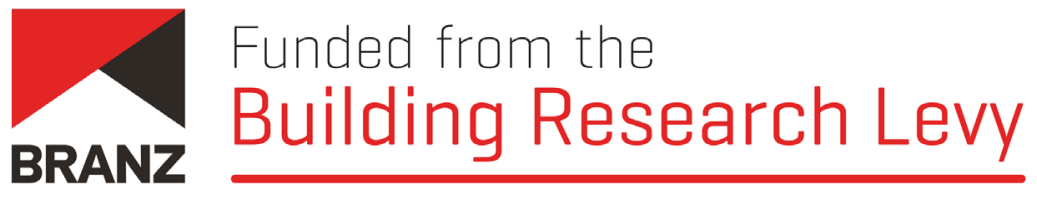

All figures were authors own, unless specified in list of figures. 


\section{ARCHITECTURE AS ORNAMENT}

An exploration of digital fabrication and parametric modelling to reenvisage and revitalise ornamentation in architecture

\section{Kathryn Turner}

A thesis submitted to Victoria University of Wellington in partial fulfilment of the requirements for the degree of Master of Architecture (Professional)

Victoria University of Wellington

2021 


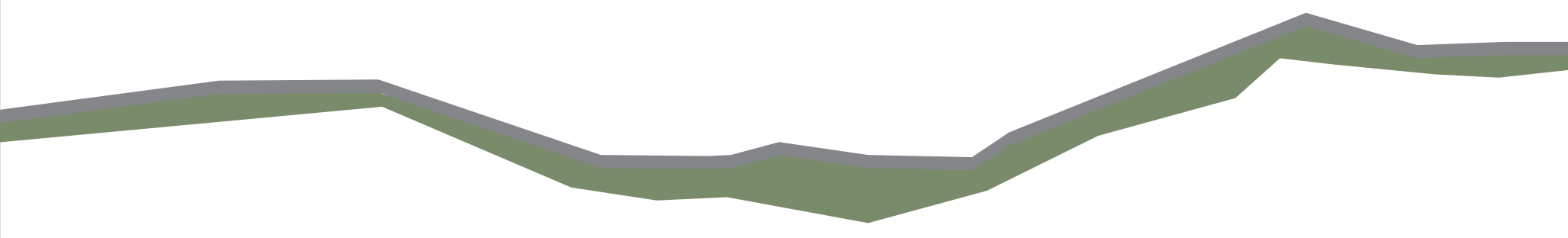

\section{ABSTRACT}

We are currently in the middle of the 4th industrial revolution, where digital technology and fabrication tools have the potential to drastically change the way we think about architecture. Contemporary architectural design is now being driven by an influx of digital tools, including parametric modelling, digital fabrication, and robotics. These tools allow designers to create forms with complexity, creating new textures, patterns and styles, they are however being underutilised. Because the focus of these methods remains on massproduction and efficiency, as they were from the second industrial revolution, architecture has now become sleek and unornamental. When ornamentation is used it is now generally limited to façade design, and the focus is towards ideas such as tessellation and repetition. These styles can sometimes be successful, however they lack the sense of depth and craft that classical ornamentation once had. A variety of social, cultural, technological and historical influences means that contemporary ornamentation no longer holds the significance and importance it once had. This research questions this reality and explores the use of contemporary computational design and fabrication techniques to understand how ornamentation can be revitalised and reimagined in contemporary architecture.

By building upon literature and case study analysis, this research uses the architectural column as a design mechanism, and parametric modelling to redefine the place that ornamentation has in contemporary architecture. By using a process of visual scripting and digital modelling, these techniques are used to explore how digital tools and the influence of history can reimagine ornamentation. This research process begins with small-scale digital tests which then translate into small-scale prototypes through the use of additive manufacturing. After an evaluation and critical-reflection of these prototypes, these ideas are translated into clay prototypes by using robotic fabrication. To further refine and finalise the designs the research is then applied to an architectural design context, and a final large-scale column is robotically fabricated. This final stage works to clearly show the design intent, to understand not only how traditional ideas and nature can be translated into contemporary designs, but also how the process of parametric design can create design variation, rather than identically replicated components. This research found that there is an immense amount of potential for using these visual scripting tools and methods of digital fabrication for revitalising ornament, creating mass-customisable architecture, not mass-replications. 


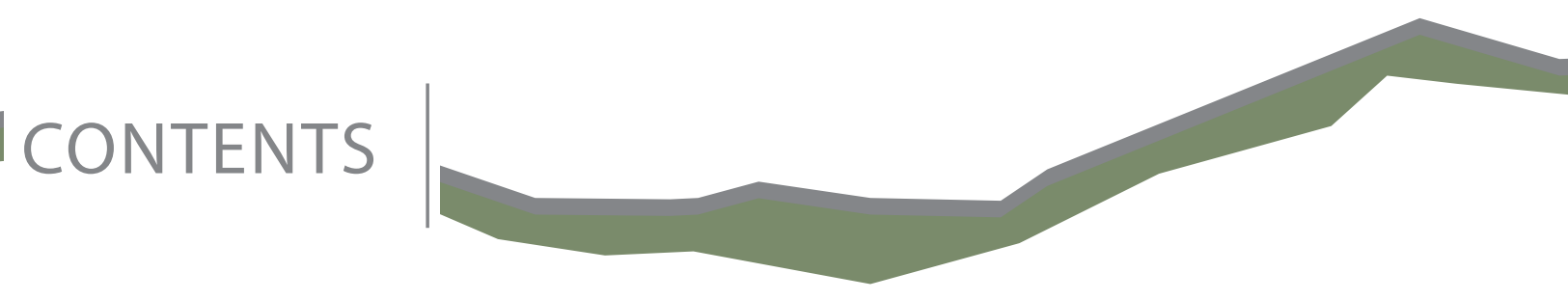

abstract

CHAPTER ONE

1.0 Introduction

1.1 Aims and objectives

1.2 Scope

1.3 Methodology

CHAPTER TWO / Literature Review

2.1 Literature Review

2.2 Case Study Review

2.3 Reflection

3.1 Design Software \& Process

3.2 Influences for Initial Designs

3.3 Initial Prototyping

3.4 Reflection

4.1 Clay Printing

4.2 Case Study: Building Bytes

4.3 Robotic Fabrication

4.4 Fabrication Process

4.5 Script Organisation

4.6 Printing Design Iterations

4.7 Reflection

4.8 Design Reflection 
5.1 Returning to Nature as Design Influence

5.2 Application to Architectural Context: Brief

5.3 The Site: Wellington Waterfront

5.4 Explanation of Final Designs

5.5 Final Design: Fabricated Column

6.1 Limitations 


\section{TERMINOLOGY}

MASS CUSTOMISATION "a technique that makes manufacturing processes flexible enough to produce products according to precisely what the customer wants while keeping costs at a low level. This concept makes the most of both personalization and mass production, which leads to a cost-efficient manufacturing system." (Zhang, 2020)

MASS PRODUCTION "the manufacturing of large quantities of standardized products, often using assembly lines or automation technology" (Banton, 2020) 
"No longer distracting or restricting the creativity of the making process, computer software, digital technologies and tools that were once the sole domain of large scale manufacture are instead being democratized and applied in unconventional ways to enhance and assist it, enabling the crafting of extraordinary, artistic forms that would have previously been all but impossible" (Johnston, 2015, p. 7).

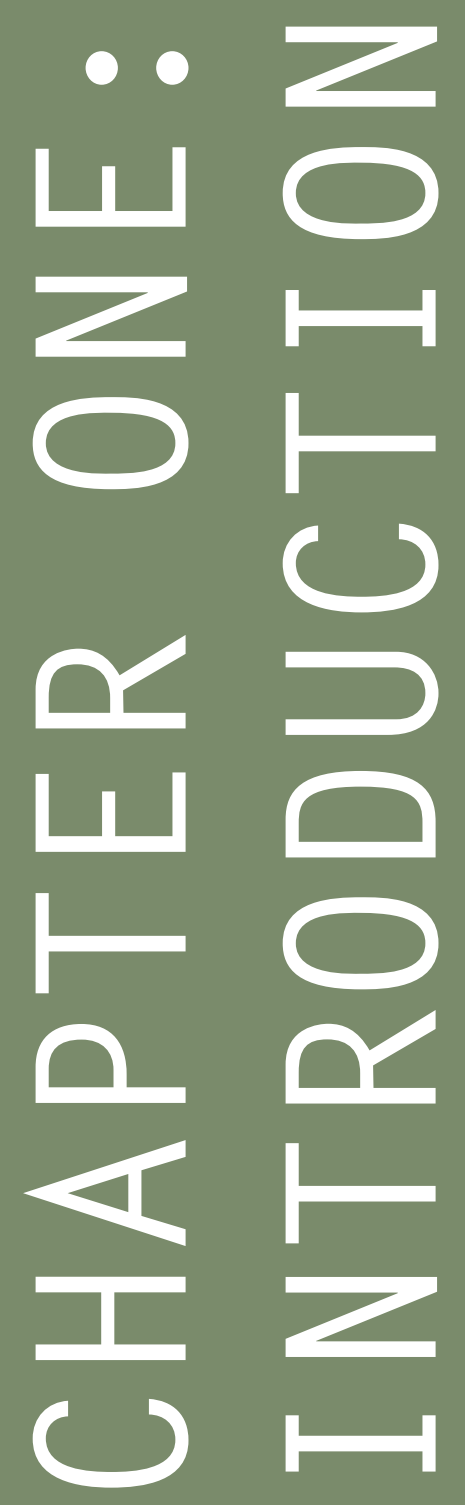




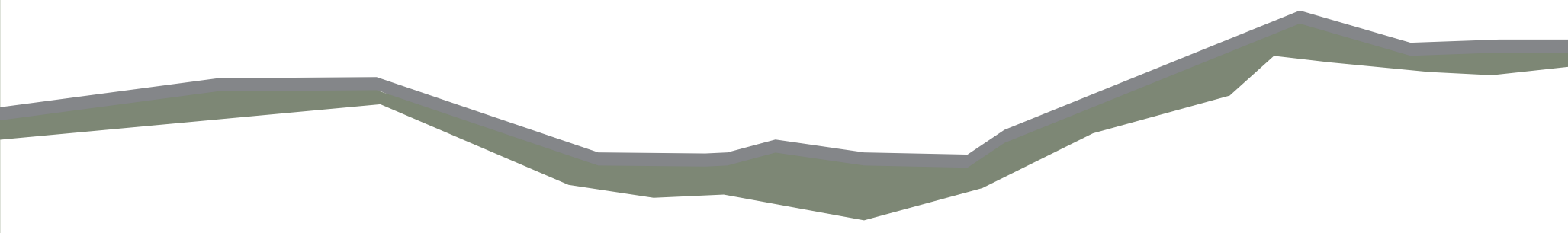

\subsection{INTRODUCTION}

Ornamentation is integral to creating a sense of craft in architectural design. In classical architecture, ornamentation was the key component to constructing buildings that symbolised a sense of beauty as well as expressing social values, hierarchy and order (Picon, 2013, p. 11). Throughout time this classical definition of ornament has evolved, with each architectural movement adding influence to its meaning. Social, cultural, technological, and historical conditions have significantly impacted ornamentation, and the second industrial revolution was a defining moment for this. During this period, in an effort to reduce cost and increase efficiency, mass-production became a primary focus for construction (Retsin et al., 2019, p. 8). Although these technological advancements were integral in developing the construction industry, the push for mass-production meant the focus was removed from detail and craft, and therefore ornament was no longer seen as a necessity to design.

Now, in contemporary architecture, there is an immense amount of new fabrication technology, including additive manufacturing such as 3D printing, subtractive manufacturing such as Computer Numeric Controlled (CNC) fabrication, and robotic fabrication. The availability of this technology means architecture is no longer bound by the limitations of mass-production, bringing forward new opportunities for contemporary architecture to be redefined, and in turn to redefine ornament. "fabrication and construction are increasingly challenging the historic relationship between architecture and its means of production" (Kolarevic, 2005, p. 4).
This research focusses specifically on the use of additive manufacturing technology, driven by the use of computer-aided design (CAD) and parametric software, to understand how these innovative digital tools can be used to bring ornamental craft and detail back to contemporary architecture. By using the architectural column as the design mechanism for this research, this work explores ideas of complexity, texture and variation to show how the abilities of these tools have the potential to transform architecture. The designs are influenced by historical precedents, specifically components of classical architecture and nature. This thesis does not argue that there is a singular solution to the revitalisation of ornament, but rather highlights how this technology can be used in ways that allow for a multitude of possibilities in producing craft and intricacy. With computational design it is no longer necessary to mass-replicate, and this research argues that this needs to be utilised, so these tools to be used to their full creative potential. 


\subsection{RESEARCH QUESTION}

How can contemporary computational design and fabrication techniques reinvigorate and reimagine the use of ornamentation in contemporary architecture?

\subsection{AIMS \& OBJECTIVES}

This research aims to use digital fabrication and parametric design to create a design series of unique ornamental columns. These will show how ornamentation can be reimagined in contemporary architecture, and the benefits that mass-customisable designs have to the construction industry.

1. Research existing classical ornamentation, and how construction technology and social implications have influenced the transition from its classical definition to its contemporary place in architecture. Identify the disconnection between ornament and the capabilities of digital fabrication. Understand how ornamentation can be reintroduced and redefined, and the methods in which to do so.

2. Use visual scripting and parametric design to create digital models that are customisable. Fabricate iterations of small-scale physical models to test these methods.

3. Robotically fabricate prototypes to test material quality and limitations. Use findings to refine fabrication methods.

4. Apply findings to an architectural context and produce a design series and coinciding script that represents the potential for mass-customisation, and how it can be used to revitalise ornamentation in the construction industry. 


\subsection{SCOPE}

This research focusses on designing a methodology through the use of parametric design and visual scripting to create ornamental and mass-customisable columns. The research focusses specifically on the architectural column; however the findings of the research are intended to be able to be utilised in future research at a wider scale, including the application to full buildings and other architectural elements. The research is addressing the underutilisation of using digital fabrication to create intricate, ornamental architectural components. By using nature and elements of classical ornament, specifically the architectural orders as a design influence, this research works to show how methods of mass-customisation can be used to achieve democratisation without compromising quality. The design focus has been specifically kept to these areas in order to maintain a concise body of research. The designs were explored using visual scripting and $A M$, including the use of robotics and 3D printing to test and explore design possibilities. Structural testing lies outside the scope of this research due to access and time constraints. 


\subsection{METHODOLOGY}

This thesis was formed with a research through design approach. This was an important process that allowed for the essential understanding of the parametric software and the digital fabrication technology. It allowed for an iterative and adaptive process which let the fabrication workflow constantly be improved and adjusted, strengthening the research, and allowed insight into the feasibility of an application to the industry.

The research process began with a literature review, which analysed key architectural periods and the relation that ornament and technology had on them. These were the classical period, specifically Greek architecture, with a focus on the architectural orders and the influence of nature; the second industrial revolution and modernism; the digital revolution; and contemporary architecture. This analysis was essential as it identified key characteristics of classical ornament, giving an insight into how these ideas could be reinterpreted successfully for ornamentation to re-emerge. The analysis also identified construction and computation technology, which showed the influence that not only social and cultural aspects have on architectural style, but also the influence that technology has on the evolution of it. The current technology and digital fabrication tools were assessed and understood in order to decide which specific methods would be most valuable to pursue in the design phase. A clear disconnection was found between the capabilities of digital technology and the current contemporary construction process, and it was made clear that mass-customisation is a critical point in the industry for ornamentation to hold its redefinition and re-emergence.

After the literature and case study analysis was completed, and critical reflections were made on the findings, digital prototyping could begin. By using parametric modelling through the use of Rhinoceros and Grasshopper, design iterations were created with initial influences from the classical orders. These initial prototypes provided an understanding of the software, and how the different components and plugins could be used to successfully create pattern and complexity, as well as identifying how the scripts can be manipulated to create masscustomisable forms. Selected models from these different design series were then fabricated into small prototyped models, through the use of 3D printing.

After a critical refection of these initial prototypes, these models were then further developed with new design ideas tested. These were then translated into larger-scale models, which were then robotically fabricated with a clay extruder attachment. An iterative process of evaluating, adjusting, fabricating and reflecting was undertaken which helped to refine the process further. Any errors in either the printing or the script were modified and adjusted, and then re-tested.

To further refine and finalise the designs, the research was applied to an architectural design context. This included a design brief of the creation of a column series architectural intervention. This final design stage worked to clearly show the design intent and outcomes of the research, to understand not only how traditional ideas and nature can be translated into contemporary designs, but also how the process of parametric design can create design variation, rather than replicated components. Critical reflection of these designs included the identification of the potential for masscustomisation, and how these scripts could be applied to other architectural elements and further developed through different influences. This reiterated where this research could fit into the industry, and how the research objectives were achieved. 


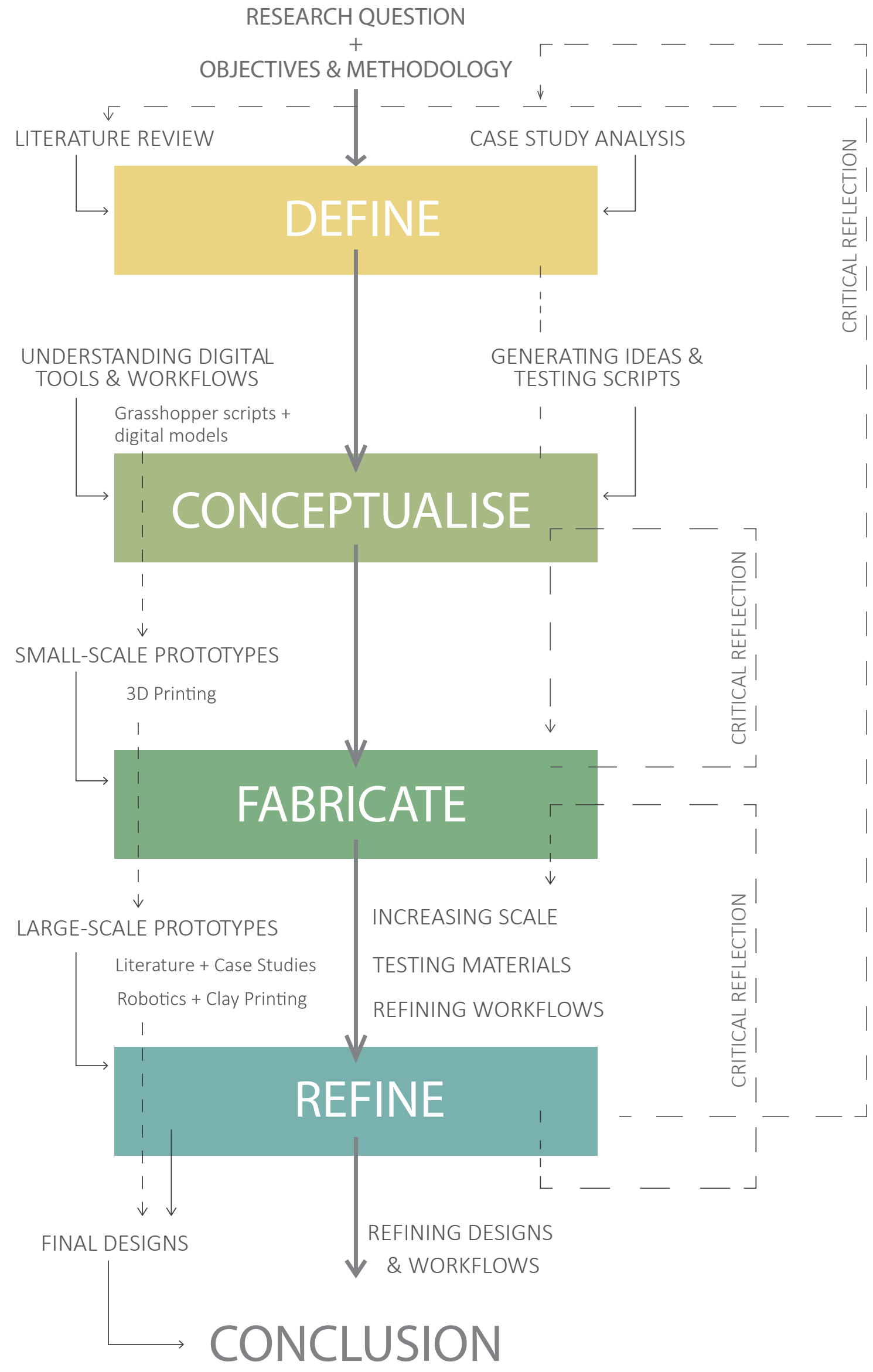




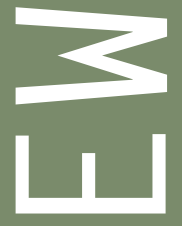

I

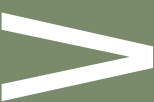

L

• ع

$\ddot{\circ}$

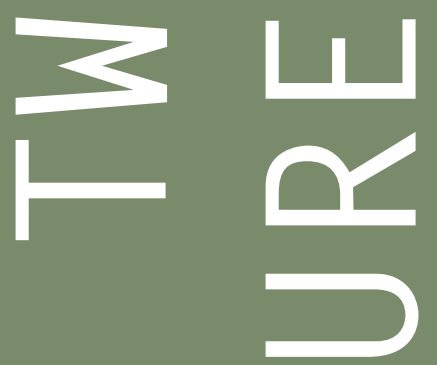

$\propto$

$w \varangle$

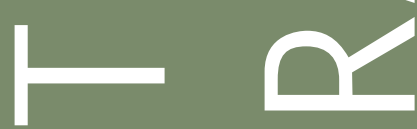

Q لـ

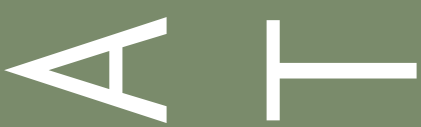

a

$\bar{U}$ 


\subsection{INTRODUCTION}

The following chapter consists of a literature review and case study analysis in order to provide a background and justification for this research. Classical ornamentation, specifically in Greek architecture, has been used as the starting historical basis in order to provide a specific design basis and scope for the research. The chapter begins with an analysis of the architectural orders, and the influence of nature to ornament during this period. The analysis then moves to modernism, and then to postmodernism, through to contemporary design. An overview of the current digital tools and technologies available and the potential they have for architectural ornamentation is also provided. The following categories have been researched and discussed:

- Classical Greek ornament and nature

- The Architectural orders

- Modernism and the 2 nd industrial revolution

- Ornamentation beyond modernism

- Parametric design

- Digital Fabrication

- Additive Manufacturing

- Robotic Fabrication

A review of case studies was then completed, and then a reflection of the literature and research was produced in order to provide a grounding for where this research will proceed. 


\subsubsection{CLASSICAL ORNAMENT \& THE INFLUENCE OF NATURE}

Ornament played a critical role in classical architecture. In Greek architecture, ornamentation was a key component of the design of buildings. Ornamentation provided a sense of beauty, but it also was responsible for the expression of social values, hierarchy and order, as well as conveying vital information about the purpose of buildings and the rank of the owners (Picon, 2013, p. 11). The laws of composition in Greek ornament were taken from nature (Ward, 1896, p. 40). "The three great laws which we find everywhere in nature - radiation from the parent stem, proportionate distribution of the areas, and the tangential curvature of the lines - are always obeyed" (Jones, 2016, p. 93). Examples of this can be seen through the use of stylised plants, one of which being the use of the anthemion, a flowerlike cluster of foliage resembling a honeysuckle, which was often used in friezes, alternating with lotus buds or palmettes (Jones, 2016, p. 102). As well as with the laws of nature, human proportion also informed the development of structures, this can particularly be seen in columns (Bloomer, 2000, p. 111).

\section{"The connection between the expressions inherent to our bodies and the articulation of construction was brilliantly achieved. Embedded in the proportions and shape of the Greek column is the combined image of the human body and the upright post" (Bloomer, 2000, p. 111).}

In ancient Greek culture, the initial role of ornamentation was to represent religious sacrifice, as well as to tell war stories, and to symbolise various Greek gods and goddesses (Hersey, 1988, p. 11). Each Greek God and Goddess had their own tree associated with them; Zeus with the oak tree, Aphrodite with the Myrtle tree, and Apollo with Laurel (Hersey, 1988 , p. 14). To show these symbols of worship and sacrifice, trees were often trimmed into the shape of primitive columns (Hersey, 1988, p. 14). The larger public structures and temples were developed into stone imitations of these wooden structures (Weston, 2011). Although now most that are left of these are ruins of white stone and marble, they were originally covered in brightly coloured painted ornament (Jones, 2016, p. 94). The system of layout and organisation across this classical architecture can be described as:

"a system by which the geometry of each part is related to the geometry of the whole, giving a harmonious balance and response to the entire façade, or total building, or both" (Curl, 1992, p. 13).

Principles of the style include ideas of "geometrical arrangement, proportion, stability, repetition, contrast, symmetry, radiation, tangential junction, repose, variety, subordination, balance, unity, series, growth, superposition, fitness" (Ward, 1896, p. 41). The architectural design, and in turn the ornament, was defined by several rules, which depicted their architectural style. 


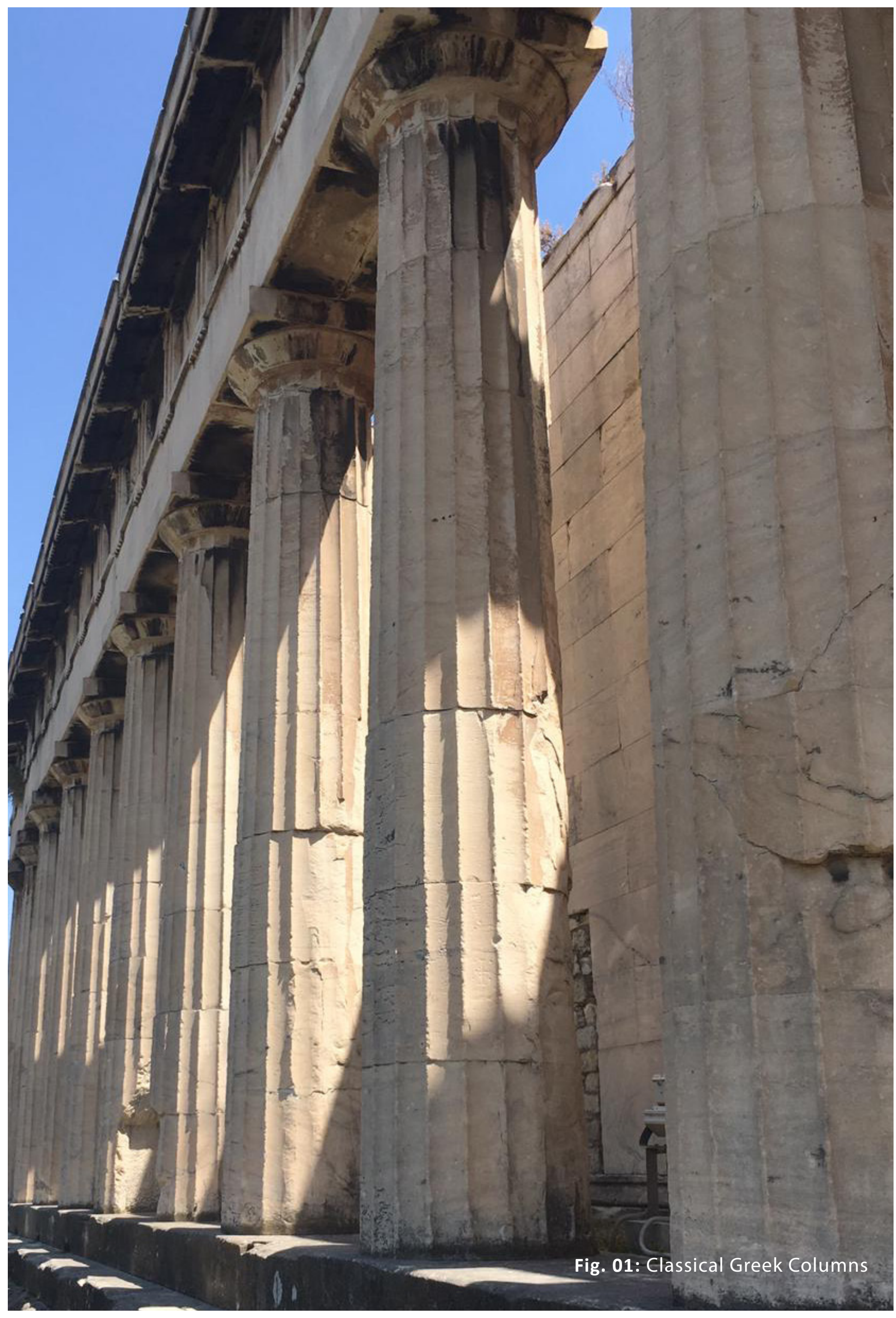




\subsubsection{THE ARCHITECTURAL ORDERS}

The architectural orders are a significant example of the use of ornamentation in Greek architecture. The orders refer to the makeup of classical columns and their individual rules of proportion, order, and variance in style and ornamentation associated with them. The three Greek orders are the Doric order, the Ionic order, and the Corinthian order (Trilling, 2003, p. 104). An order is "an assembly of parts consisting of a column, with base (usually) and capital, carrying an entablature, proportioned and embellished in consistency with one of the Orders" (Curl, 1992 , p. 16). Over a period from about 700BC, the Greek orders were evolved (Chitham \& Loth, 2004 , p. 29). Their evolvement was influenced by human proportion and nature, and each held either masculine or feminine qualities, with associations to different places or ethnic groups (Trilling, 2003, p. 104). The Ionic and Corinthian held representations of luxury; and Dorian for strength and fighters, with their masculine and feminine associations determining their use for either interiors or exteriors of buildings (Trilling, 2003, p. 104). They were used to accepted conventions, to give character or a sense of decorum, appropriate to a buildings' status and purpose (Weston, 2011).

\section{THE DORIC ORDER}

The Doric order was the simplest of the architectural orders, being the only order without a base (Ward, 1896, p. 147). This order was used in the early Greek temples from 600 B.C. and culminated in the Parthenon in 438 B.C. (Glazier, 1899, p. 9). This order was said to be inspired by the Dorians, who were fighters, therefore the column held masculine proportions (Trilling, 2003, p. 104). This meant that the shaft had a larger diameter to align with the male figure. The capital resembles an echinus (sea urchin) moulding, with deep channellings, and a square abacus above (Ward, 1896, p. 149). The columns have no base, with a height of between four and six and a half times the diameter, with the circular form of the shaft generally having 20 concave flutes separated by arises (Curl, 1992, pp. 18-22). Due to the seafaring nature of the Greeks, and their inhabitancy of the sea-shore, a lot of ornamental influence was said to have come from their familiarity with the forms of sea and shells (Ward, 1896, p. 149).

\section{THE IONIC ORDER}

The Ionic Order, named after Ionia (Trilling, 2003, p. 104), holds feminine qualities and therefore differs from the Doric by holding more slender proportions (Ward, 1896, p. 151). Unlike the Doric order, the Ionic order has a base (Curl, 1992, p. 24). The order is distinguishable by the volutes on its capital - the coiled form inserted between the abacus and the ovolo (Summerson, 1980, p. 124), and is said to have been derived from shells, rams' horns, or stylized scroll forms evolved in Egyptian art and used decoratively in ancient times (Curl, 1992, p. 24). Caryatides were occasionally introduced into this order; they were female figures clad in drapery having vertical folds which re-echoed the flutings of the Ionic column (Glazier, 1899, p. 9). These caryatides supported the entablature in place of the columns (Glazier, 1899, p. 9).

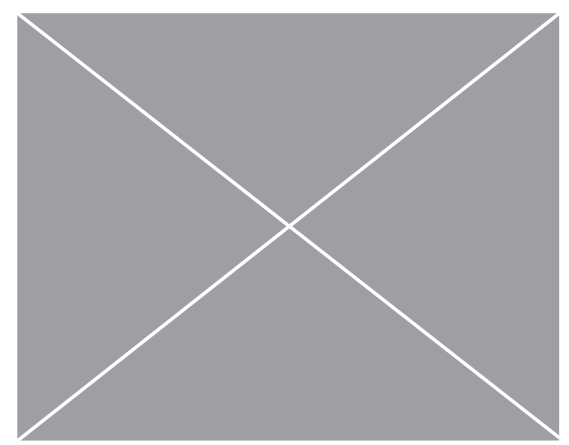

Fig. 02 : Greek ornament 


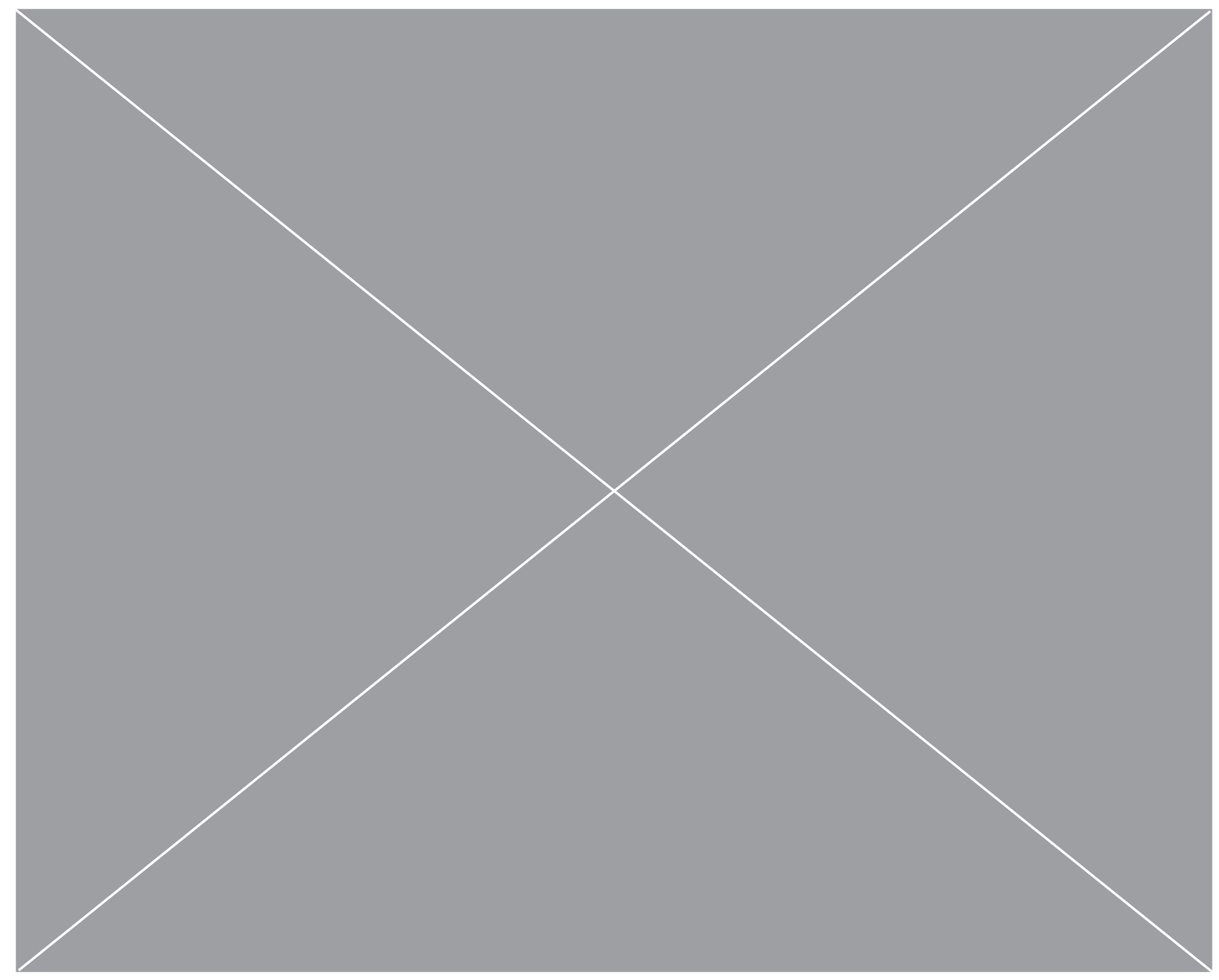

Fig. 03: Greek Doric Order

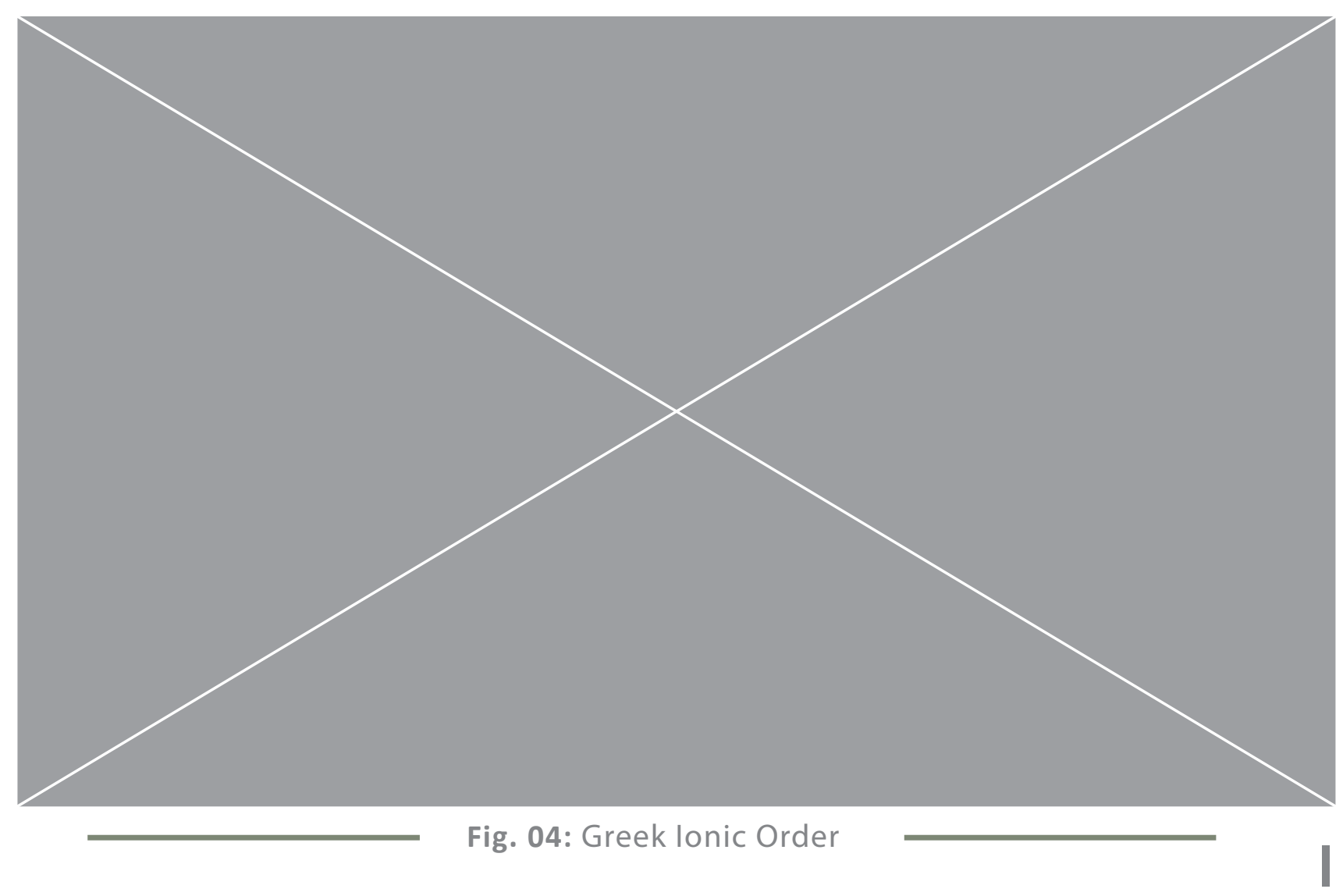




\section{THE CORINTHIAN ORDER}

The Corinthian order is another feminine order and is said to be influenced by the story of a young maiden from Corinth who passed away (Trilling, 2003, p. 104). According to Vitruvius, Callimachus was the original designer (Vitruvius, 30-20BCE/2014, p. 209), and he was inspired by seeing the belongings of this maiden placed on top of a monument in a wicker basket, which an acanthus plant grew around, thus creating the visual inspiration for the Corinthian capital (Vitruvius, 30-20BCE/2014, p. 209). The Corinthian order holds details from both the Doric and Ionic order, and has been said to be the daughter of the two orders (Hersey, 1988, p. 67). It is one of the more detailed orders, and is distinguished by the decorations of the ranks of the acanthus leaves, with the fern-like stems reaching out to the corners of the abacus (Summerson, 1980, p. 124). The Corinthian order was used less by the Greeks, however when used they clearly showed "refinement and delicacy of details" (Glazier, 1899, p. 10).

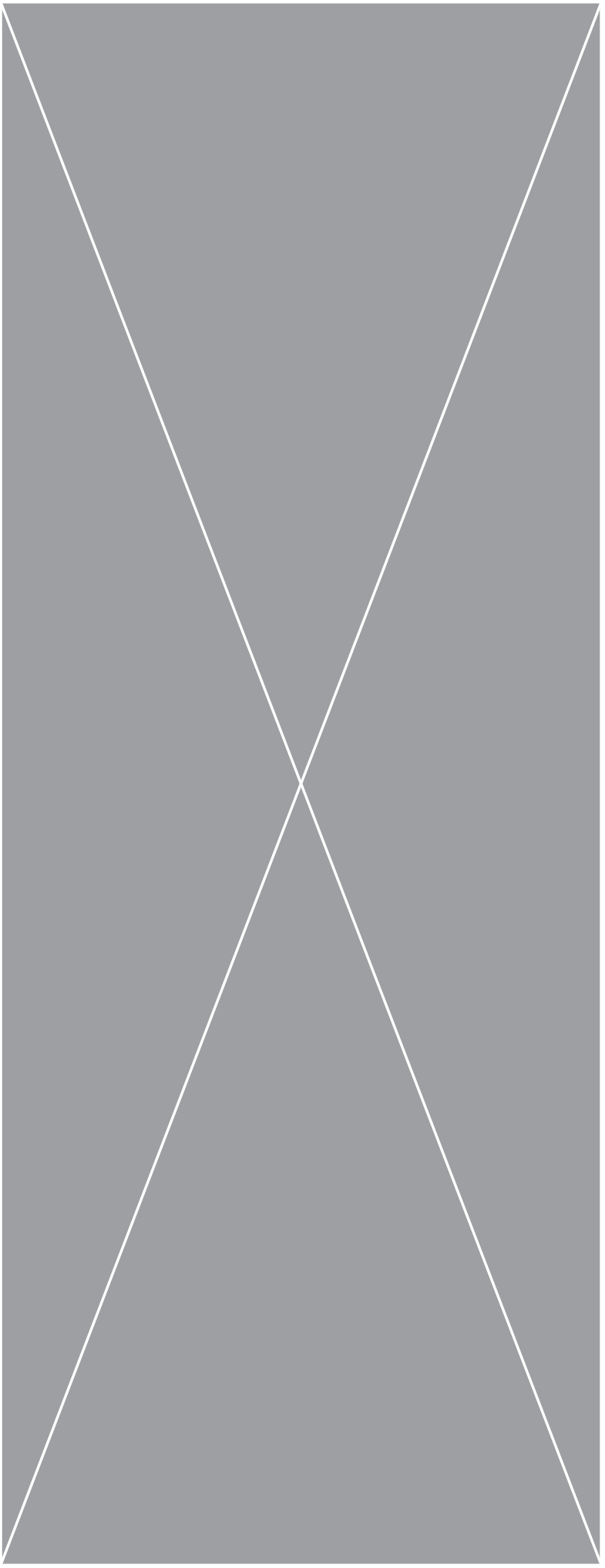

Fig. 05 : Greek Corinthian Order

Fig. 06 : Caryatids on Porch of Maidens

Fig. 07 : Corinthian Capital 

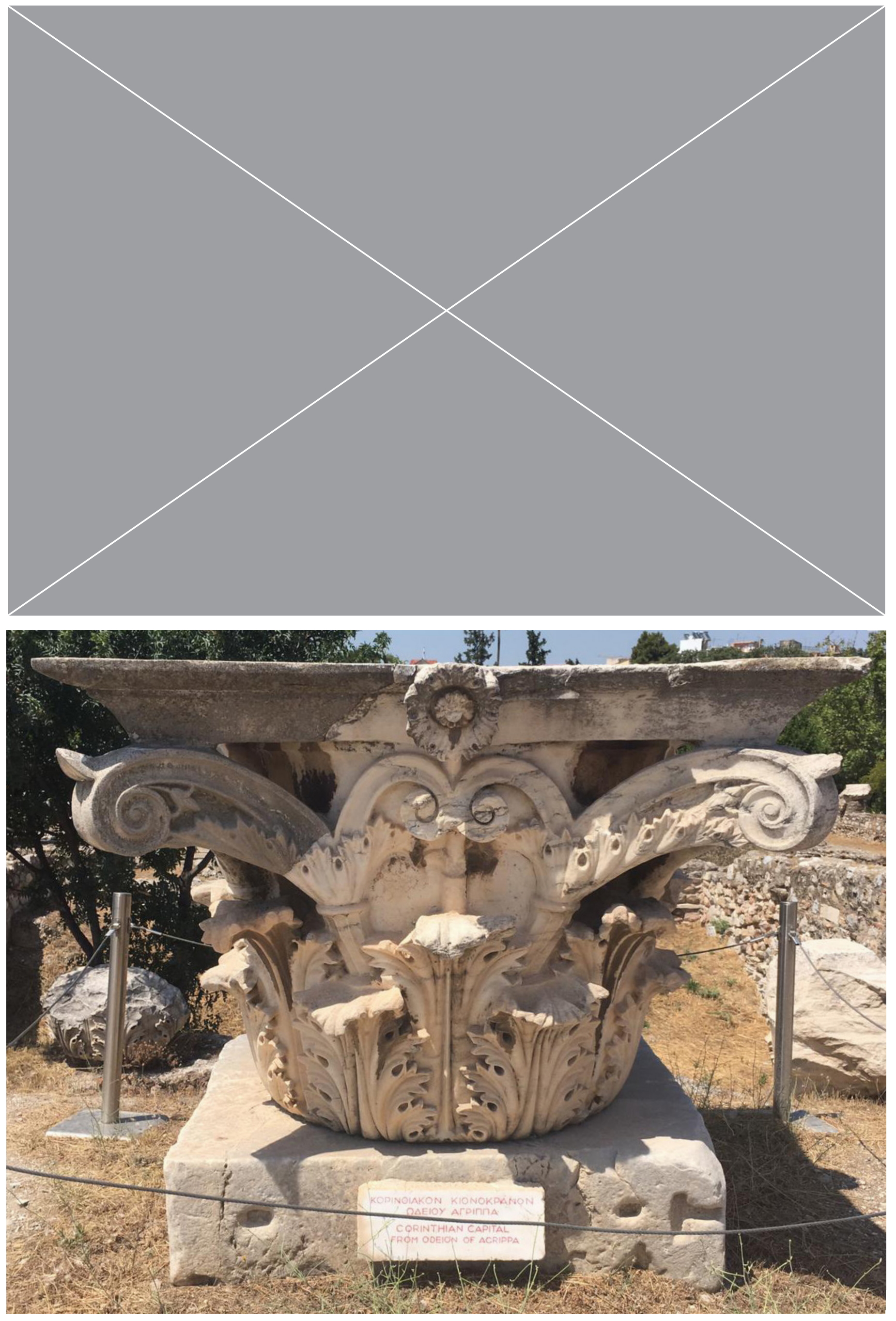


\subsubsection{DESIGN \& CONSTRUCTION}

Classical Greek architecture was defined by a clear set of rules and ordering and had a prominent use of ornamentation and décor. Greek ornament is distinguished by the use of "composition and perfect symmetry, simplicity of line, refinement of detail and radiation of parts" (Glazier, 1899, p. 17). Although there were tremendous changes in building technique associated with monumental architecture in Greece during the second half of the seventh century, this technical development decreased rapidly, and the system of post-and-lintel structure executed in large, dressed stone blocks continued for the next millennium (Coulton, 1977, p. 140). Nature and human form had a clear impact on interpreting ideas of proportion and symmetry within the architecture, and this can clearly be seen across different monuments. 


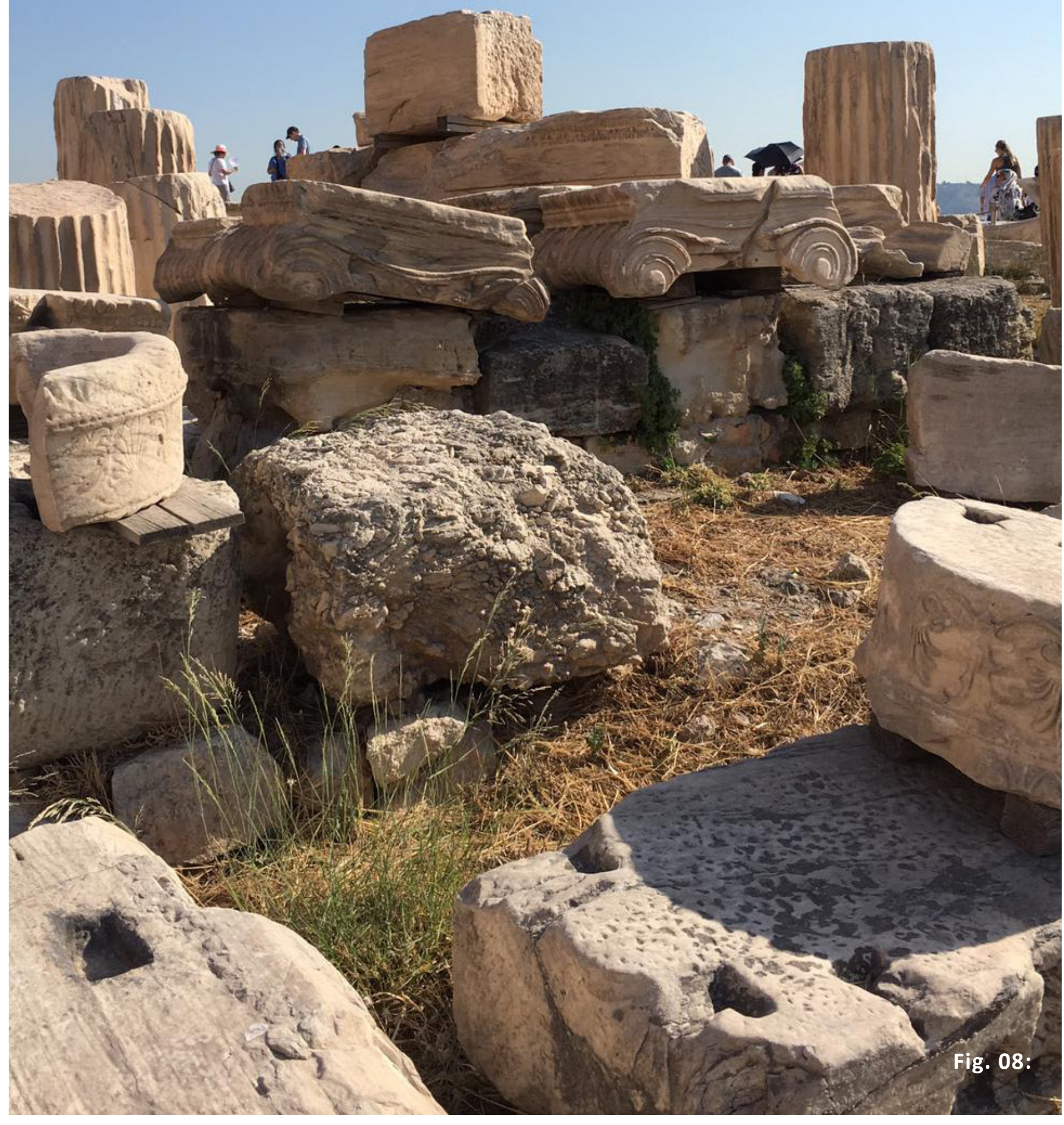




\subsubsection{MODERNISM \& THE SECOND INDUSTRIAL REVOLUTION}

\begin{abstract}
"Style is identity. Ornament has always been a powerfultool of ethnic and culturalself-definition. Modernism, in contrast, is cosmopolitan. Rejecting the past, it set itself above traditional identities. The widely proclaimed twilight of modernism coincides with a worldwide political and social fragmentation." (Trilling, 2003, p. 3)
\end{abstract}

Design trends are influenced by several components. Cultural and historical aspects have a significant impact on how architectural trends develop, including the development of both successes and shortcomings to develop architectural style (Picon, 2013, p. 14). The modernist design movement saw an immense change in the relationship between ornament and architecture. "The decorative arts were no longer an integral part of the design process, but were required, after construction was completed, to fill interior spaces with furniture and self-sufficient works of art" (Mitrache, 2012, p. 567). During this design transition, modernist architects during the 19th century such as Adolf Loos saw ornament and décor as something of an abomination, as opposed to a thing of beauty (Picon, 2013, p. 11). These views meant that traces of ornament and décor were limited to the furniture, rather than the architecture itself. These views sparked social changes, which in turn fundamentally transformed cities, and promoted the emergence of new building typologies alongside the influence of manufactured materials such as steel and glass (Achten et al., 2020, p. 317). A significant difference between classical architecture and modernism, is the removal of the relationship to human form, "Classical architecture stresses the relationship of a building's proportions and scale to those of a human body. Modernist architecture breaks with this tradition" (Hell et al., 2010, p. 48). Through the denial of traditional styles, modern architecture refused naturalbased ornamentation (Abondano, 2013, p. 269), and the result of this found very sleek, and unembellished architecture.

This shift that modernist architects had in removing ornament from architecture in reality saw a redefinition and reintroduction in itself. Robert Venturi and Denise Scott Brown describe this in their "duck vs decorated shed" analogy (Venturi et al., 1977, p. 163), stating that when modernists promoted space and articulation over symbolism and ornament, in reality what they designed is an ornamental building in itself (Venturi et al., 1977, p. 163). "They substituted for the innocent and inexpensive practice of applied decoration on a conventional shed the rather cynical and expensive distortion of program and structure to promote a duck" (Venturi et al., 1977, p. 163). Michiel van Raaij describes this concept as the emergence of "building as ornament" (Raaij, 2014, p. 34). "In the search for a new visual language for architecture, images from outside architecture were woven into architecture. In the rejection of ornament on a small scale, ornament on the scale of the entire building was introduced, albeit unintentionally" (Raaij, 2014, p. 34). Even if ornament attempted to be removed from architecture, there is always some element of it still there, even if it is completely redefined.

\footnotetext{
"Architecture is partly based on the mediation of its former achievements as well as shortcomings. Modernism did not break with this self-reflexive stance, and now modern architecture itself has become a legacy that must be reinvested with new meaning" (Picon, 2013, p. 14).
} 


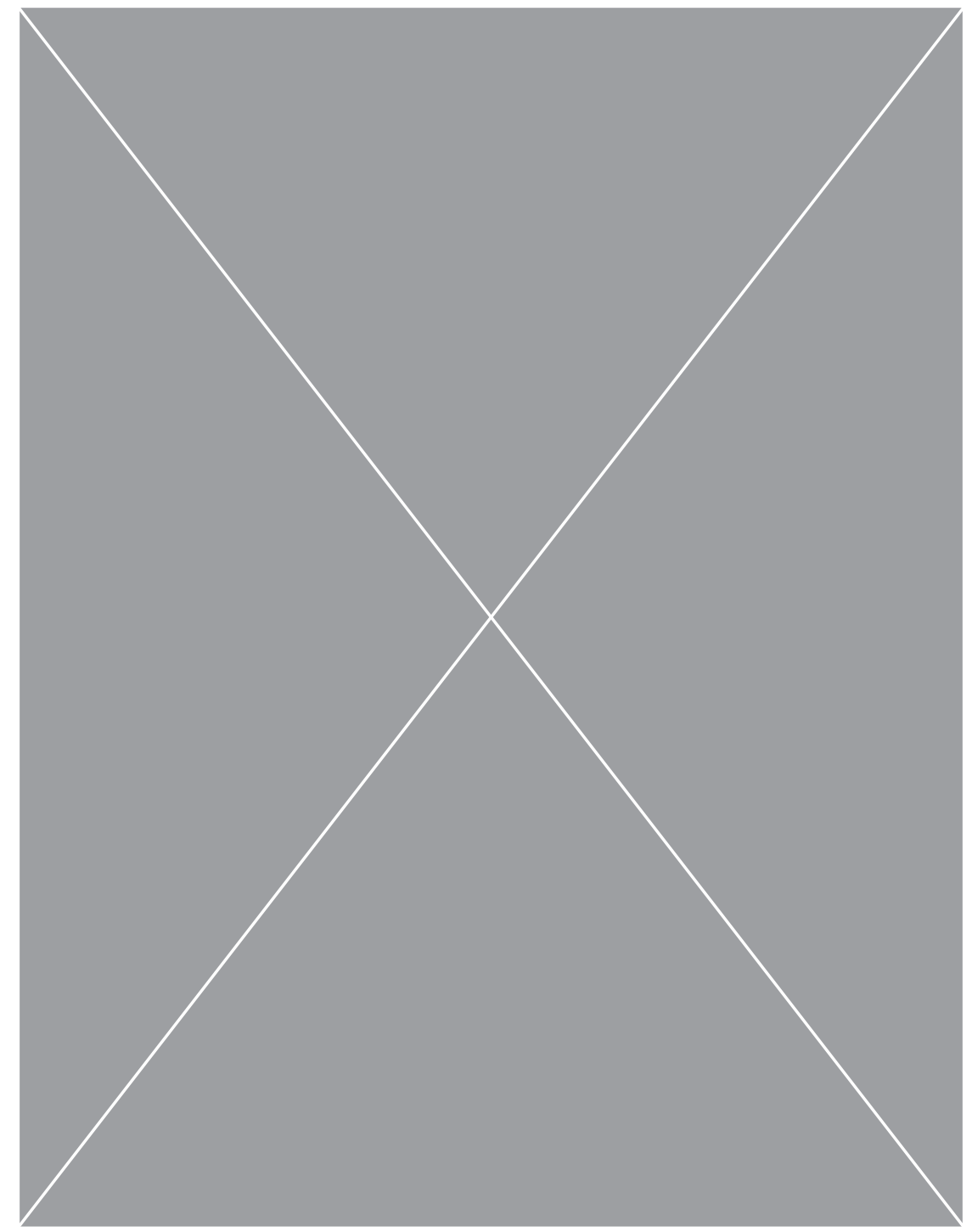

Fig. 09 : Venturi \& Scott Brown's ‘Duck vs. Decorated Shed' 
Mechanical and technological advancements also have a significant impact on architectural trends. With a change in methods, tools, and materials, there comes a change in the output of form. This change was evident particularly during the second industrial revolution. Whilst the first industrial revolution introduced the replacement of manual labour with mechanical tools, the use of electricity and engineering marked the second industrial revolution, therefore "triggering the origination of mass production systems, affecting the core of the construction industry" (Achten et al., 2020, p. 317). With the use of the factory and the production line, there was a focus on producing products cheaper and faster, with the economy therefore predominantly driving the design, rather than the designer.

"Along with the denial of history and the exclusion of ornamentation, the refusal of nature by modern architects also implied a shift in the production system due to the fact that natural principles such as efficiency or optimization, essential to form-making processes in nature, started to be understood as industrial demands related to the costs of production" (Abondano, 2013, p. 269).
Mass-production during this time became a large part of the construction process, with the added push for efficiency. Because most of these technologies are matrix-based through moulds, casts, dies or stamps, it became standard to print out as many identical copies as possible in order to decrease the expense of production (Retsin et al., 2019, p. 8). This consequently meant that architectural objects became repetitive, and with the mechanised mass-production of things such as doors, wall panels, and windows, the importance and availability of traditional craftspeople was reduced, of which their manual skills majorly contributed to shaping the historical definition of ornament (Bloomer, 2000, p. 137). "Even the allure of timeless ornament became diminished by a fascination with the polish of new technology" (Bloomer, 2000, p. 137). 

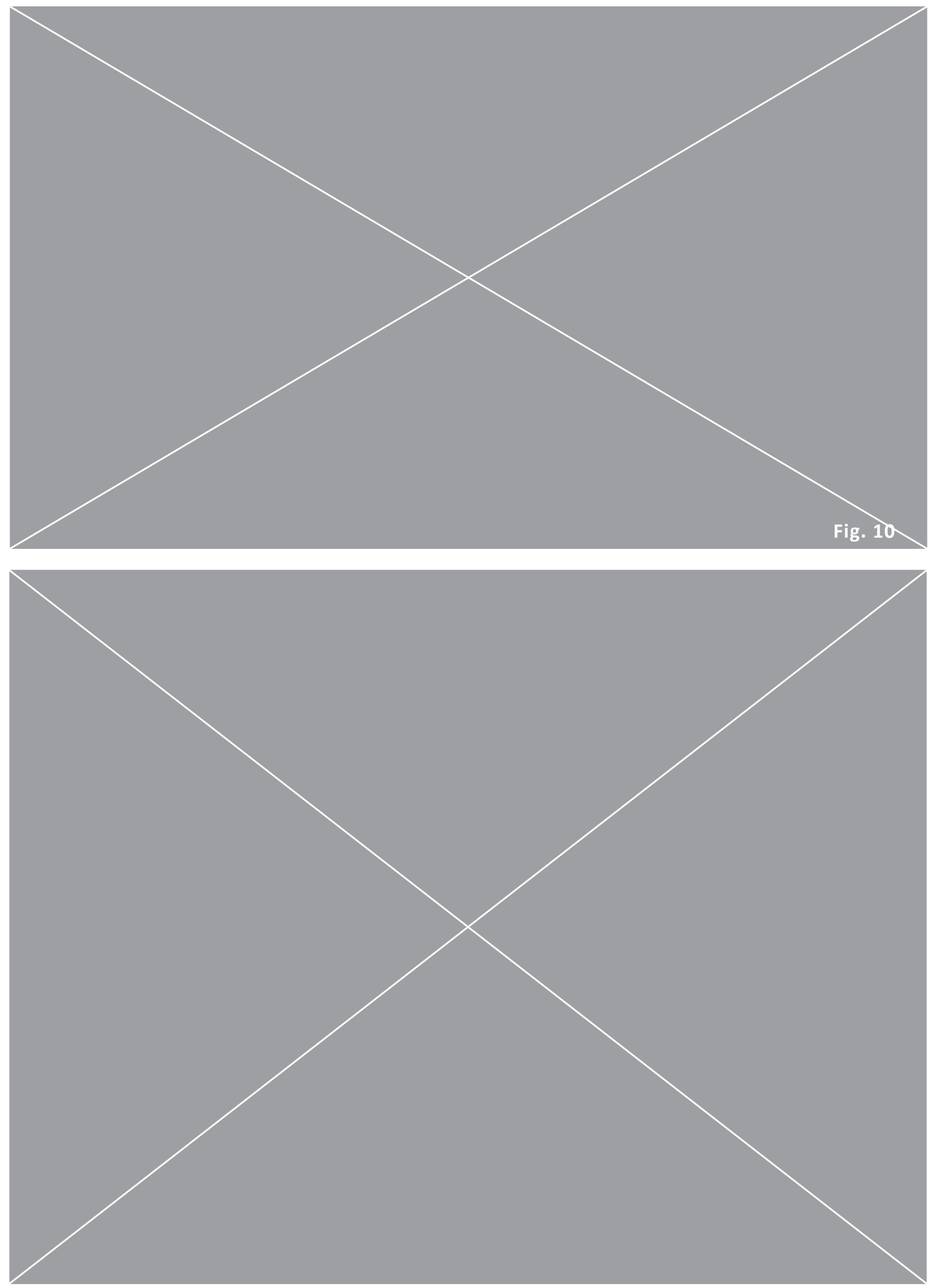

Fig. 11: Seagram Building 1958 


\subsubsection{ORNAMENT BEYOND MODERNISM}

\begin{abstract}
"Pleasure and beauty, rank and prestige, communication and knowledge: this triadic structure has not yet fully returned with contemporary architecture, and this incompleteness may allow us to understand better what remains to be achieved to foster the re-emergence of a true politics of ornament" (Picon, 2013, p. 53).
\end{abstract}

Through postmodernism and various other architectural styles moving through to contemporary architecture, trends have continued to develop, however ornament has been seen in very different ways to its classical definition. Postmodernism sought to bring emphasis to the use of symbolic signs (Jencks, 1991 , p. 42), "Postmodernism triggered a resurgence of ornamentation not only as means of embellishment, but most importantly as a conveyor of meaning" (Mitrache, 2012, p. 567). Venturi and Scott Brown were two architects that pushed for the use of designing the "decorated shed" (Venturi et al., 1977, p. 163). Venturi argued that the "decorated shed" was much stronger, as they communicated more effectively (Jencks, 1991, p. 42). "The duck is, in semiotic terms an iconic sign, because the signifier (form) has certain aspects in common with the signified (content). The decorated shed depends on learned meanings - writing or decoration - which are symbolic signs" (Jencks, 1991, p. 42). These shifts in culture brought through continued ideas of iconography, of characteristic images from outside architecture to explain the nature of the building (Raaij, 2014 , p. 27). These ideas saw architecture being designed as a whole, rather than through the use of hierarchy and order that have clearly been used in classical design, which in turn has created an entirely different aesthetic output that is still used today. Although the views seen by postmodernists showed a strong distaste towards modernism, the movement itself did not last long (Jencks, 1991, p. 15), as Jencks notes "as long as architecture is produced on the run, in too great volume, it will suffer these problems of over-production (Jencks, 1991, p. $15)$. With the pressed production, the cultural shift moved forward to a new design trend, and therefore another change in the definition of ornament.

In the late 1980s and early 1990s, amongst other design trends such as brutalism, there formed a turning point (Raaij, 2014, p. 37). "this was a time when the old models stalled, but a new recipe had not yet clearly emerged" (Raaij, 2014, p. 37). This was largely impacted by the advancements of new digital technology, "the newly acquired cultural freedom and the emergence of market thinking coincided with the introduction of the first computers in the design process" (Raaij, 2014, p. 40). This new development with technology was a main influence in the formation of contemporary architecture. "A fascination with new technology - stemming in large part from innovations in the automobile, aviation, and ship-building industries - and a return to the questions of the nature and role of architectural excess as a central rather than peripheral condition of contemporary practice" (Pell, 2010, p. 16). Raaij argues that although computer-aided technology was not a prerequisite for building as ornament becoming so prominent, that the development of this technology nevertheless accelerated the process (Raaij, 2014, p. 40). "The media in which architects work - manual sketches, models, drawing software - partly determine their way of thinking, and thus what kind of designs they make" (Raaij, 2014, p. 40).

Contemporary architectural ornamentation has continued with this trend of new technology as with previous design movements, however "the fourth industrial revolution is yet to make as great a leap as the industrial revolution did with modernism" (Retsin et al., 2019, p. 12). Ornament 


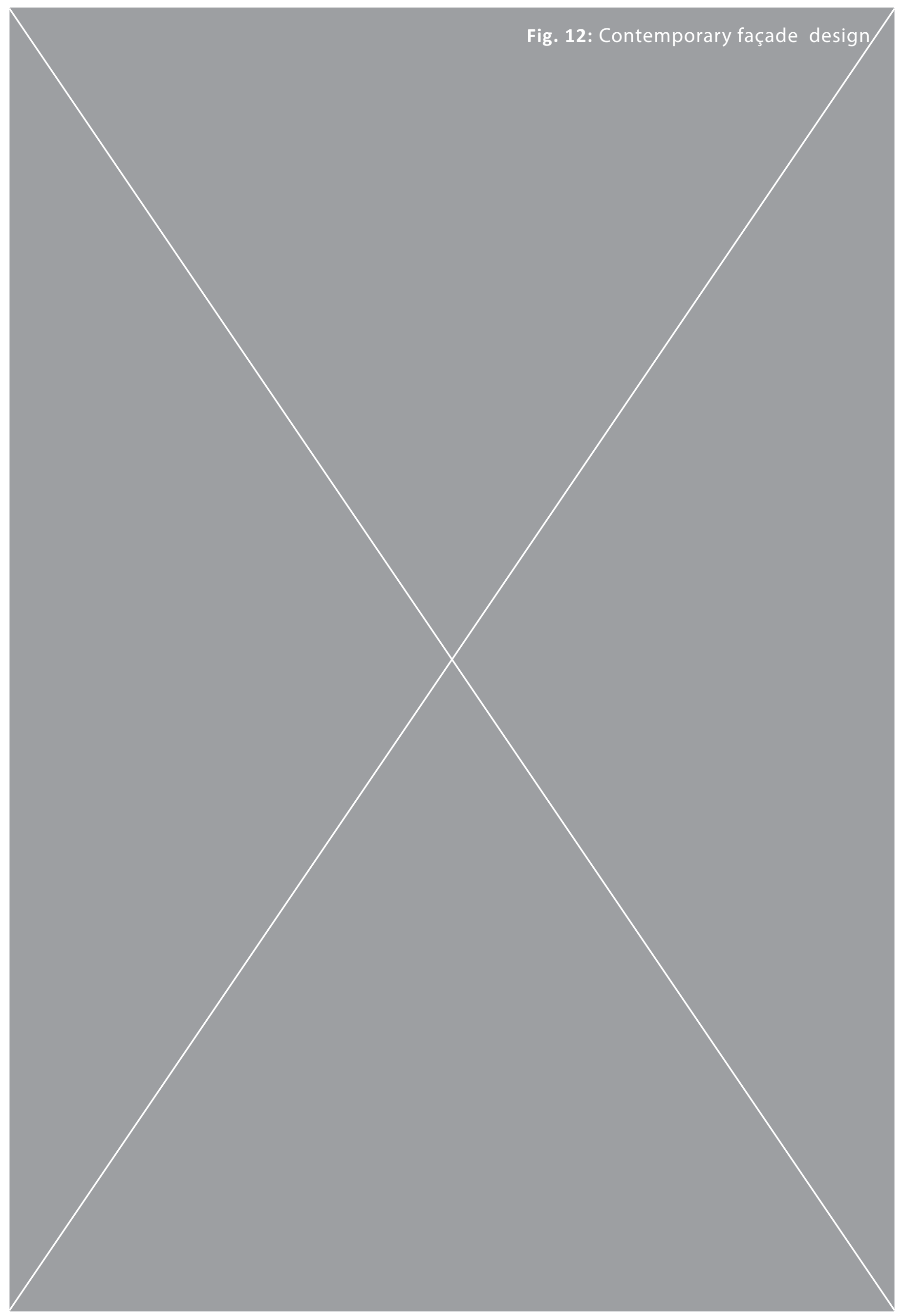


is now based on a lot of examples of patterning and tessellation (Picon, 2013, p. 30), and computational tools are being used in some ways, but to limited extents, and with limited influence from historical precedents. The second industrial revolution and modernist design issues surrounding efficiency, cost, and budget restrictions are still prominent in contemporary design. This in turn has meant that the use of decoration and ornament has quite often been limited to the façade, rather than the entirety of the building.

"Today, the budget of the client and mutual settlements with the architect determine the limits for creating spectacular and astonishing façades. The ornamental dimension is developed as an extension of constructing a brand image and sign exchange value ... Ornament becomes a symbol of prestige and an instrument of power, in addition to being a representation of building function or program." (Balik \& Allmer, 2016, p. 168).

In some instances, to make the use of décor more affordable and accessible, the design of façade systems that have decorative effects built-in has been achieved (Mitrache, 2012, p. 569). Providing more democratisation and access to expression and design in lower budget projects is one success of this method, however as Mitrache states,

"there are hidden pitfalls to this liberalization of ornamental-art-derived-architectural decoration: the slightest of changes in shape, colour or proportion can turn the dial of associated aesthetic values from chic to kitsch, and there is always the possibility of decorative excess" (Mitrache, 2012, p. 569).

It is clear that care in ordering and balance of pattern and texture, as well as attention to the influence of culture, history and technology are key considerations to creating successful ornament. 


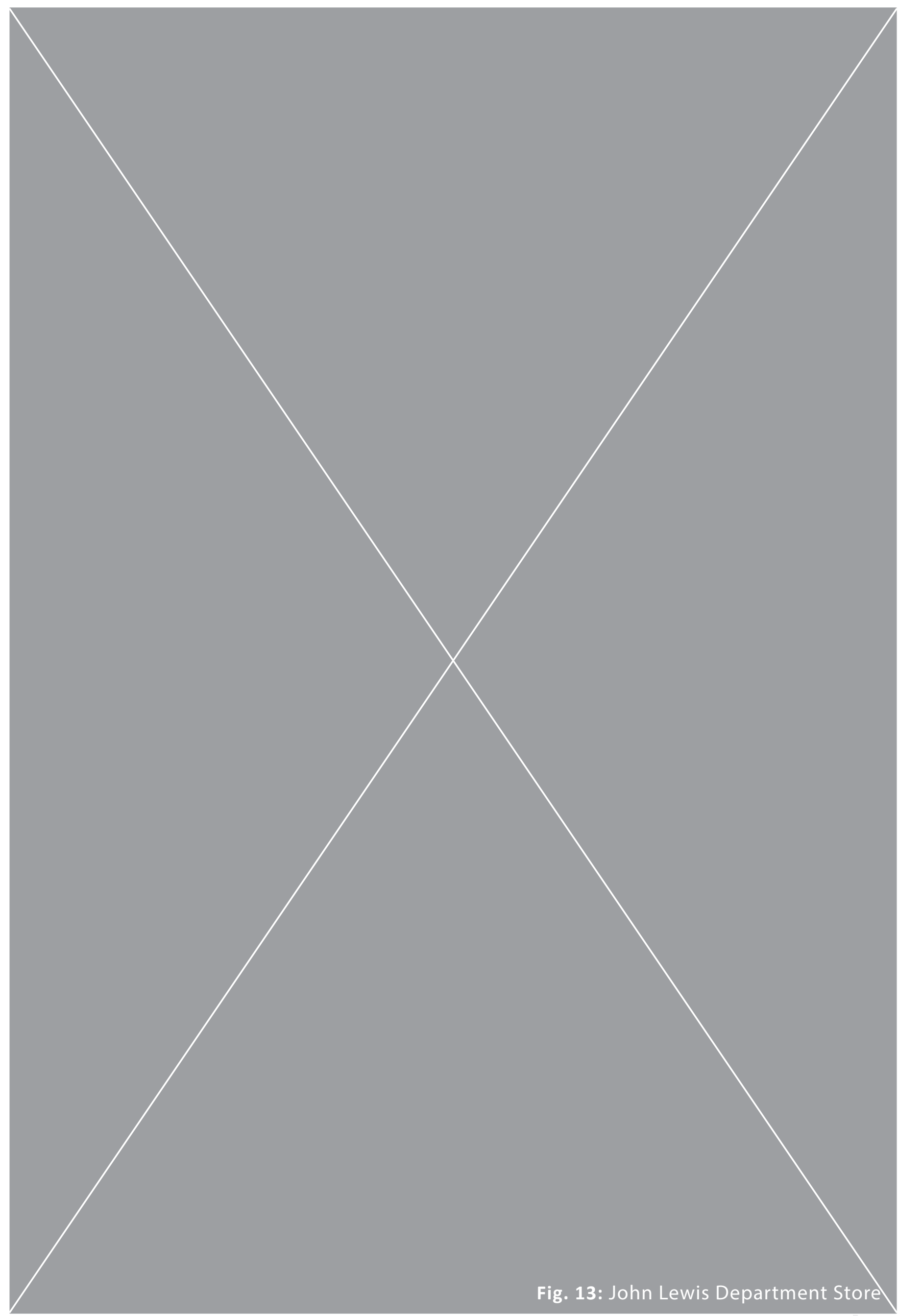




\subsubsection{DIGITAL FABRICATION \& PARAMETRIC DESIGN}

Digital fabrication and parametric design allow for great potential in architecture. Digital fabrication is "a method using digital data to direct a manufacturing process" (Dunn, 2012, p. 18). Emerging over recent decades, digital fabrication has the ability to change architectural practices significantly (Kolarevic, 2005, p. 3). The use of these tools allows for more flexible methods of designing, with the opportunity for added detail as well as efficiency, and with the influence of history in mind, they open up wide possibilities for new and exciting forms able to be created, ones not possible through manual construction methods.

"The digitalisation of building processes has overcome many of the limitations of industrial mass-fabrication: it allows a large degree of customisation, paired with high efficiency and customisation" (Dillenburger \& Hansmeyer, 2014, p. 93) 


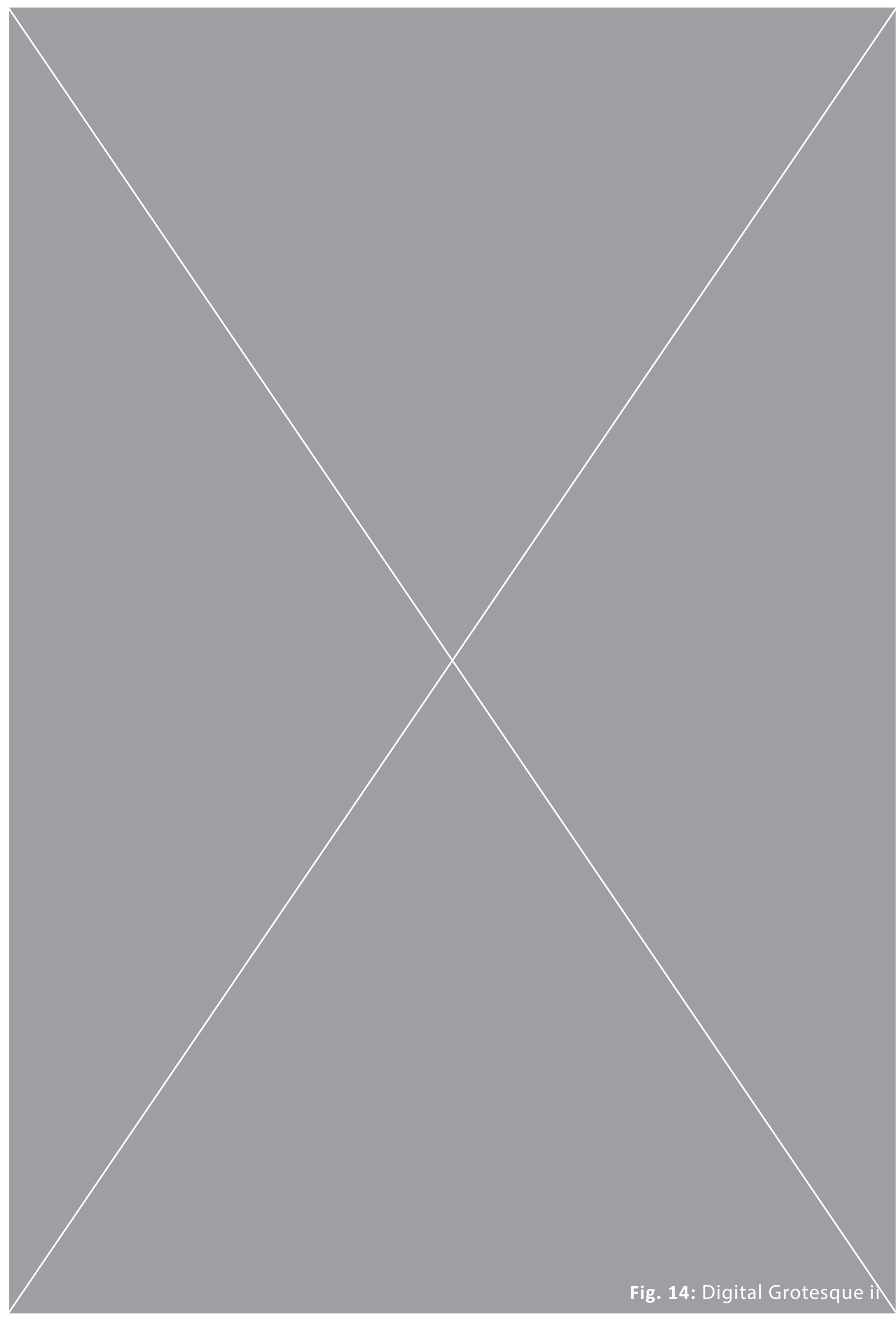




\subsubsection{PARAMETRIC DESIGN}

Generative and parametric designing are widely developing computational methods in Architecture. Bringing forward a new way of designing, these "offer new design paths to architects by breaking with predictable relationships between form and representation in favour of computationally generated complexities, thus enabling the development of new topologies" (Agkathidis, 2015, p. 8). The terms describe the process of using computational software, and rules or algorithms to generate digital models. By defining a basic set of rules, specific parameters and constraints, these rules can then be translated into a digital model, and then adjusted and adapted in realtime within the software.

"Often building on parametric concepts, generative design transforms the computer from a modelling assistant to a generator through the use of a defined set of production, or grammar, "rules". Generative systems are aimed at both sparking new design ideas and solving difficult tasks, both of which provide design assistance and extend designers' current capabilities." (Shea et al., 2005).

Standard computer-aided design (CAD) tools allow digital models to be made and visualised, however the nature of this non-parametric software means that consequently the vast majority of these models are built in a way that means they are difficult to modify interactively (Jabi, 2013, p. 9). When creating more complex models without parametric software, changing simple aspects of a digital form usually requires an extensive amount of low-level modifications to many of its other parts (Jabi, 2013, p. 9).
Parametric design however removes this limitation; by adjusting specific parameters the model will then react and update accordingly, allowing for the optimisation of the process, whilst reducing the amount of time it takes to do so (Jabi, 2013, p. 9). These methods can be effective in architectural design, with the ability to provide new variables and possibilities (Kolarevic, 2005, p. 17).

"Using parametrics, designers could create an infinite number of similar objects, geometric manifestations of a previously articulated schema of variable dimensional, relational, or operative dependencies. When those variables are assigned specific values, particular instances are created from a potentially infinite range of possibilities" (Kolarevic, 2005, p. 17).

Parametrics are one of the key tools that have the potential to make ornament and decoration more dynamic, rather than static. In façade design, the use of these tools means that "façade-wide ornamental art is now kinetic, kaleidoscopic and reactive, either in response to external stimuli (sunlight, temperature, wind pressure or human presence), or according to carefully designed, computer-controlled algorithms" (Mitrache, 2012, p. 569). The development of these techniques brings new possibilities to how ornamentation could be redefined. 


\subsubsection{MASS CUSTOMISATION}

The digital fabrication technology emerging internationally is now bringing forward a new movement in architecture and design. Being described as the "digital industrial revolution" (Johnston, 2015, p. 7), technology such as robotics, and both additive and subtractive manufacturing, are being driven through the use of parametric design bring through new possibilities for design and architecture. Now, instead of mass production technologies and their previous limitations with variation, cost and efficiency, digital fabrication now allows for "copies" to become "new originals" (Retsin et al., 2019, p. 9), meaning there is no longer a necessity to mass-replicate to reduce cost. With these limitations no longer needing to drive the industry, the potential for creative freedom becomes much wider.

"The synergy between the digital modelling and the use of prototyping machines can easily transform virtual models into actual object, anticipating the change in production process and industrial manufacturing" (Rossi \& Buratto, 2018, p. vii)

The use of mass-customisation with digital tools has been used in design and product manufacturing for some time, however "the transfer of non-standard technologies from the small-scale of product fabrication to the largescale of building and construction remains to this day a major design issue" (Retsin et al., 2019, p. 9). Despite technology in other disciplines speeding ahead, buildings have been designed in a very similar way since the industrial revolution (Retsin et al., 2019, p. 44). In the late 1990s, Computer Numeric Controlled (CNC) fabrication was introduced, a subtractive manufacturing method which "further enabled the realisation of complex digital work with an assortment of computer-guided, flat cutting processes, multiaxis mills, and routers, among other traditional workshop devices given new flexibility through the addition of CN control" (Pell, 2010, p. 11). The limits of early CNC technology however involved size and application by the dimensional and material constraints of available fabrication technologies (Pell, 2010, p. 11). This meant that consequently many explorations of digital fabrication tended to focus on the design and production of complex surfaces, however not yet at a full building scale (Pell, 2010, p. 11).

\footnotetext{
"With the 3D printing, the innovation concerns especially the process, leading the way to further changes that on one hand give life back to old practices, on the other hand link the designer and maker. A new crafts age opens after the crisis that afflicted the industrial age" (Rossi \& Buratto, 2018, p. vii)
} 


\subsubsection{ADDITIVE MANUFACTURING}

Additive manufacturing (AM), "3D Printing", or formerly known as "rapid prototyping", are terms that describe the production process where an object is produced additively, usually layer-by-layer (Molitch-Hou, 2018, p. 1). "A digital model, made using computer-aided design (CAD) software or with 3D scanning, is sliced into individual layers, which then supply the toolpath code for a 3D printing machine. Depending on the exact technology, the machine implements a specific process to recreate the model in the physical world from the base slice to the top, until the object is complete" (Molitch-Hou, 2018, p. 2). AM has many different benefits when compared to other manufacturing processes, including the costeffectiveness and efficiency of the process (Gurr et al., 2017, p. 10213), compared to subtractive manufacturing such as CNC machining, AM is less wasteful in both construction material and replacement machine tools, and enables the use of more complex internal substructures and undercuts (Gurr et al., 2017, p. 10214). There are many types of machines and methods of $3 \mathrm{D}$ printing, with the ability to work with a variety of different materials and techniques. They generally however work using the same principle process (Bandyopadhyay \& Bose, 2016). First, a CAD model is made, which is then converted into an STL file and then uploaded to the selected printing program, or into a visual scripting software such as Grasshopper. The system then slices the model on the computer into several contours or layers, and then, depending on the method of printing, deposits or binds the material layer by layer, until the model is complete (Bandyopadhyay \& Bose, 2016, pp. 6-7).

\section{HISTORY OF ADDITIVE MANUFACTURING}

AM processes began developing in the mid to late 1980s, when in 1983 Charles W. Hull invented stereolithography (stl. file), and then subsequently co-founded 3D systems in 1986 to market the first commercial 3D printing technology (Hull, 2015, p. 25). Since the inception of this technology, there has been a surge in the production of 3D printing, with major printing companies creating their own 3D printers. There was a clear advantage of being able to quickly prototype models at a much earlier stage, without having to go through a complex manufacturing process (Retsin et al., 2019 , p. 39). A benefit of this is that it becomes easier and faster to fix potential issues in earlier stages of the manufacturing process. In the 1990s, AM reached a point where it was ready to be implemented for industrial use, and the advantages of the technology over traditional manufacturing methods interested most industries (Bandyopadhyay \& Bose, 2016, pp. $6-7)$. The layer-by-layer system meant that it gave the ability to create complex geometry that could be built relatively easily out of a variety of materials, and it allowed for parts to be made that otherwise couldn't through other technology (Bandyopadhyay \& Bose, 2016, pp. 6-7). Other advantages include the ability for the technology to be used across a large amount of applications, and it has been used successfully in industries such as art, aerospace, and medicine (Bandyopadhyay \& Bose, 2016).

AM is now used heavily in design and product manufacturing, as well as in household 3D printing, however it is still very limited in its use in architecture and building. This is largely due to issues regarding the transition to largerscale manufacturing from small product design, and the different material and structural considerations that emerge (Leach, 2017, p. 80). Majority of existing large-scale 3D printers can also only print highly simplified designs, as highresolution technologies have issues regarding limited print spaces, high costs, or materials that limit structural use (Dillenburger \& Hansmeyer, 2014, p. 93). This has been one of the shortfalls in the construction industry catching up with the technology, added research into how these small-scale tests translate into largescale is essential in order for these methods to successfully progress. "The potential of additive manufacturing is thus far from being utilised" (Dillenburger \& Hansmeyer, 2014, p. 94). 


\subsubsection{ROBOTIC FABRICATION}

Robotic fabrication is providing even more innovations to the construction and technology industry, bringing added benefits of precision and flexibility, as well as the cost-effectiveness of the process - the use of parametric and robotic tools means that "it often costs the same to mass-customise the manufactured products as it does to mass-produce the same quantity of identical products" (Jabi, 2013, p. 10). The use of robotics has worked to further enhance existing digital fabrication tools, "Over the past decade, robotic fabrication in architecture has succeeded where early digital architecture failed: in the synthesis of the immaterial logic of computers and the material reality of architecture where the direct reciprocity of digital designs and full-scale architectural production is enabled" (Gramazio et al., 2014, p. 14). Industrial robots have been around since the 1960s, but "it is only now that we are witnessing a robotic revolution that extends beyond industrial production plants and into all walks of our lifeworld" (Daas \& John Wit, 2018, p. 28). A key benefit with industrial robots is their ability to work with virtually any tool, whether analogue or digital (Daas \& John Wit, 2018, p. 31). By the attachment of different components, and a reconfiguration of hardware, the abilities of robotics is expanded even further.

"Milling, drilling, cutting, carving, welding, printing, photographing, bending, brick-laying, sewing, folding, fastening, forming, assembling, weaving, spraying, dynamic casting and any number of other pre-existing or innovative tasks can be accomplished through the implementation of different effectors" (Daas \& John Wit, 2018, p. 31).
The ability to apply robotics to a wide variety of tasks through the use of different components vastly increases the potential that these tools have in architecture. By using a visual scripting tool such as Grasshopper, code is exported to the robotic system to provide a toolpath for the robot to follow. Robotic arms also have the ability to use 6-axis rotation, allowing for further freedom and flexibility in production, in comparison to other fabrication methods such as standard 3D printing.

"Digital fabrication and robotic production are two points along technological and chronological continuums, yet they are points with overlaps and differing trajectories. One does not replace the other. Robotic production builds off digital fabrication technologies and provides degrees of freedom that open up new avenues of making" (Daas \& John Wit, 2018, p. 28) 


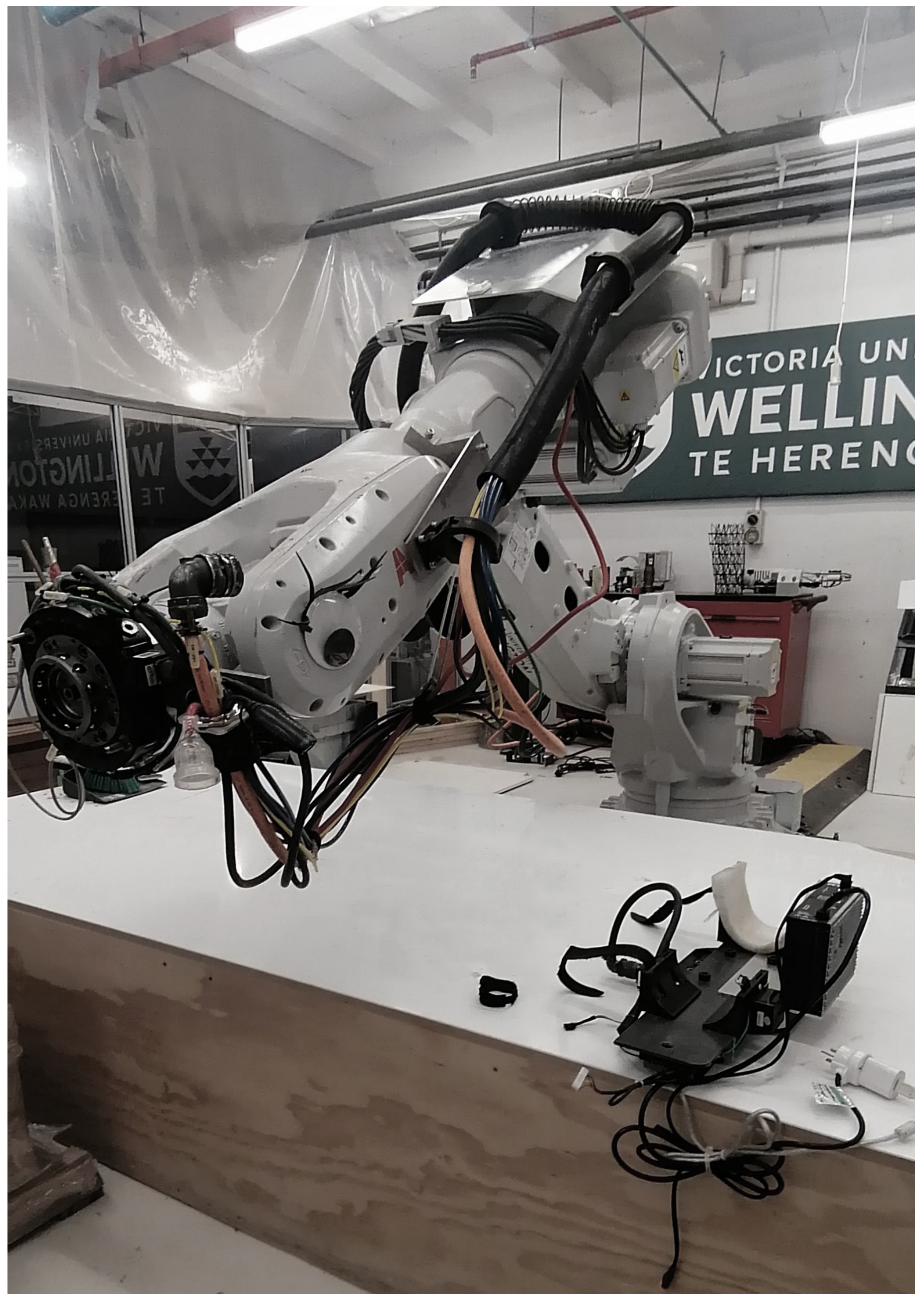

Fig. 15: ABB Robotic Arm at Victoria University 


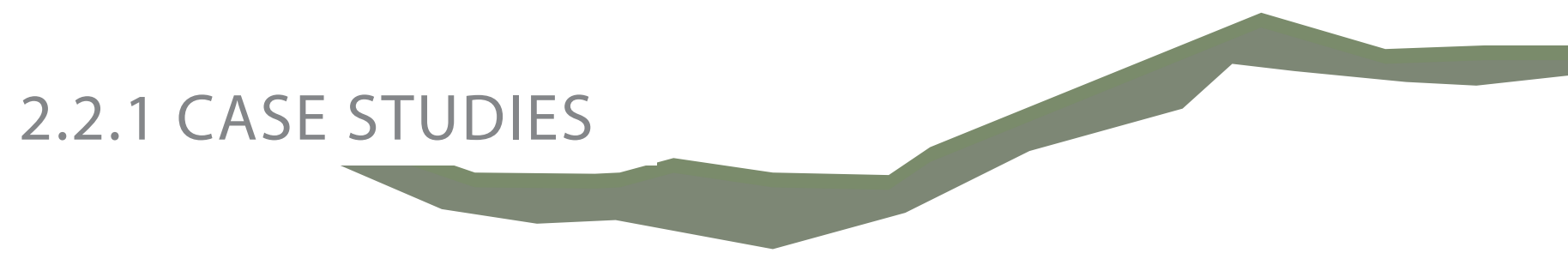

\section{MICHAEL HANSMEYER / BEN DILLENBURGER}

Michael Hansmeyer is a computer scientist and architect who uses computation and algorithms to generate new architectural forms (Szita, 2011, p. 229). The project "subdivided columns" works with his own software, using algorithmic scripting to embellish and define an abstracted Doric column (Hansmeyer, n.d.). The original column was fabricated by laser cutting $1 \mathrm{~mm}$ sheets of grey board individually, and then manually stacking together each sheet to create a $2.7 \mathrm{~m}$ column at (ETH) Zurich in 2010 (Hansmeyer, n.d.). To further progress this research, four CNC-milled ABS columns were produced for the Gwangju Design Biennale in 2011, and then again the project was developed further in 2017 (Hansmeyer, n.d.). The results of this research outline the level of complexity and intricacy that this kind of computational technology has to produce new levels of ornamentation, as well as the potential that using historical style as a design driver can have. It does also however highlight the disconnection that can sometimes occur during the design and fabrication process (Retsin et al., 2019, p. 45). By using a subtractive manufacturing process such as laser cutting, although the time in design and fabrication can be reduced significantly and the level of detail able to be achieved is high, there is still the need for a large amount of manual labour to compile the parts (Retsin et al., 2019, p. 45). CNC and laser cutting being subtractive processes also mean a lot of wastage is produced through the creation of the final products, due to the techniques of cutting and milling away excess materials.

The subdivided columns projects have produced an interesting perspective on the adaptation of classical ornamental techniques through the use of computational design and fabrication. The level of detail and precision in the explorations are high and give insight into the best ways of using subtractive technology. The projects also outlined the issues around using subtractive methods, especially in regards to wastage and the manual labour still required in compiling the columns. There is not however a focus or interest on mimicking nature or organics, and rather the primary focus of the designs is "using simple processes to produce complexity" (Szita, 2011); which is misaligned with the underlying influences this thesis has presented.

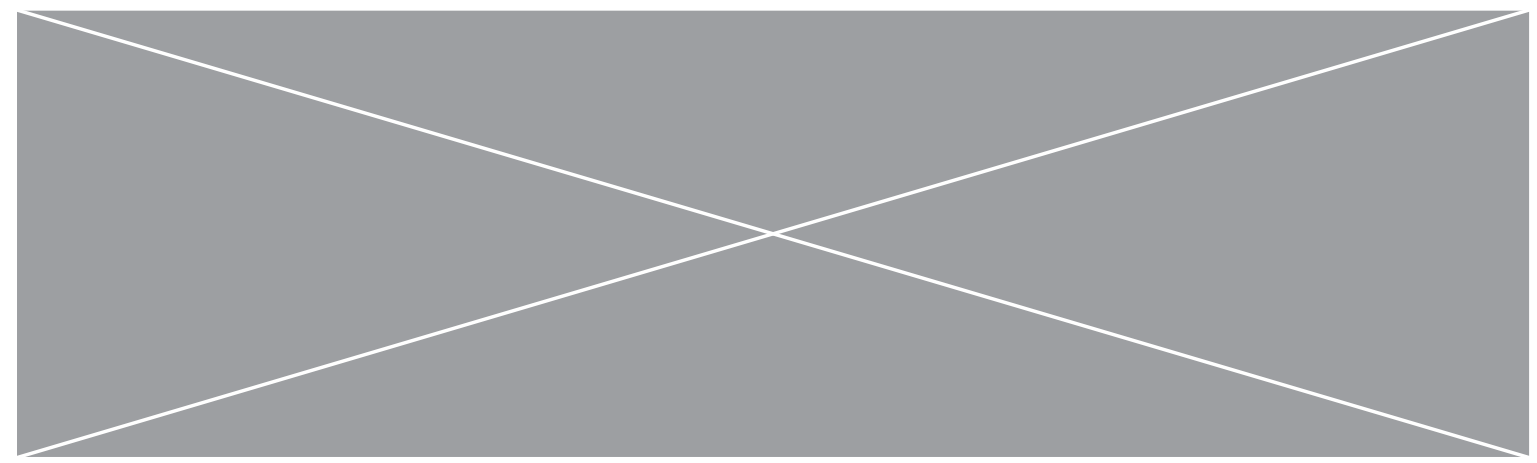

Fig. 16: Interior of grey-board column 


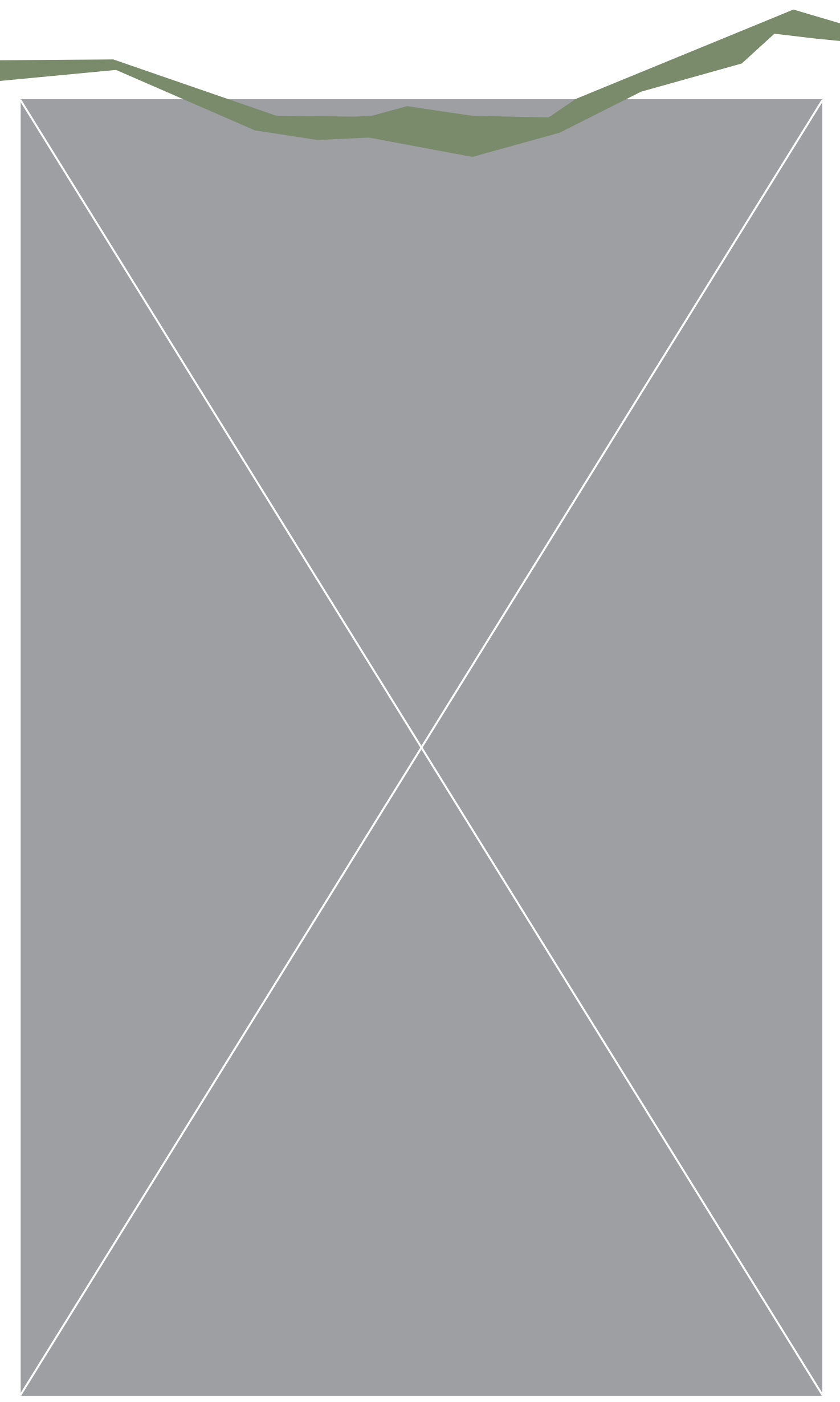

Fig. 17: Subdivided column 1 at ETH 


\subsubsection{CASE STUDIES}

\section{MICHAEL HANSMEYER \& BEN DILLENBURGER: DIGITAL GROTESQUE I \& II}

The Digital Grotesque projects are further computational design research projects produced by Hansmeyer and his research team, now using AM technology and the application of sand-printing at an architectural scale (Dillenburger \& Hansmeyer, 2014, p. 93). The research intent of this technology was to overcome the limitations of complexity, cost and resolution that came with other AM techniques when printing at an architectural scale (Dillenburger \& Hansmeyer, 2014, p. 93). Beginning with Digital Grotesque I, the research is the "design and fabrication process of a highly complex immersive space that is entirely built of structural 3D printed elements" (Dillenburger \& Hansmeyer, 2014, p. 93). Digital Grotesque II was a second project in the grotto series, a full-scale 3D printed grotto, which premiered at Centre Pompidou's Imprimer le monde exhibition in 2017 (Hansmeyer, n.d.). By using binderjet printing, "hundreds of square meters of surface are compressed into a $3.5 \mathrm{~m}$ high block that is brought to life as a seven ton, 3d printed sandstone structure" (Hansmeyer, n.d.). The technology in this research project operates by glueing thousands of small particles of sand together in order to create the form (Retsin et al., 2019, p. 45). As Dillenburger and Hansmeyer state, "3D printed elements are within reach, not only as façade modules, but also as construction systems" (Dillenburger \& Hansmeyer, 2014, p. 97). The projects produce a high level of detail and resolution, however they are still requiring further research into areas such as material properties, surface quality, structural optimisation, weight reduction, and the development of joints and assembly (Dillenburger \& Hansmeyer, 2014, p. 97). 

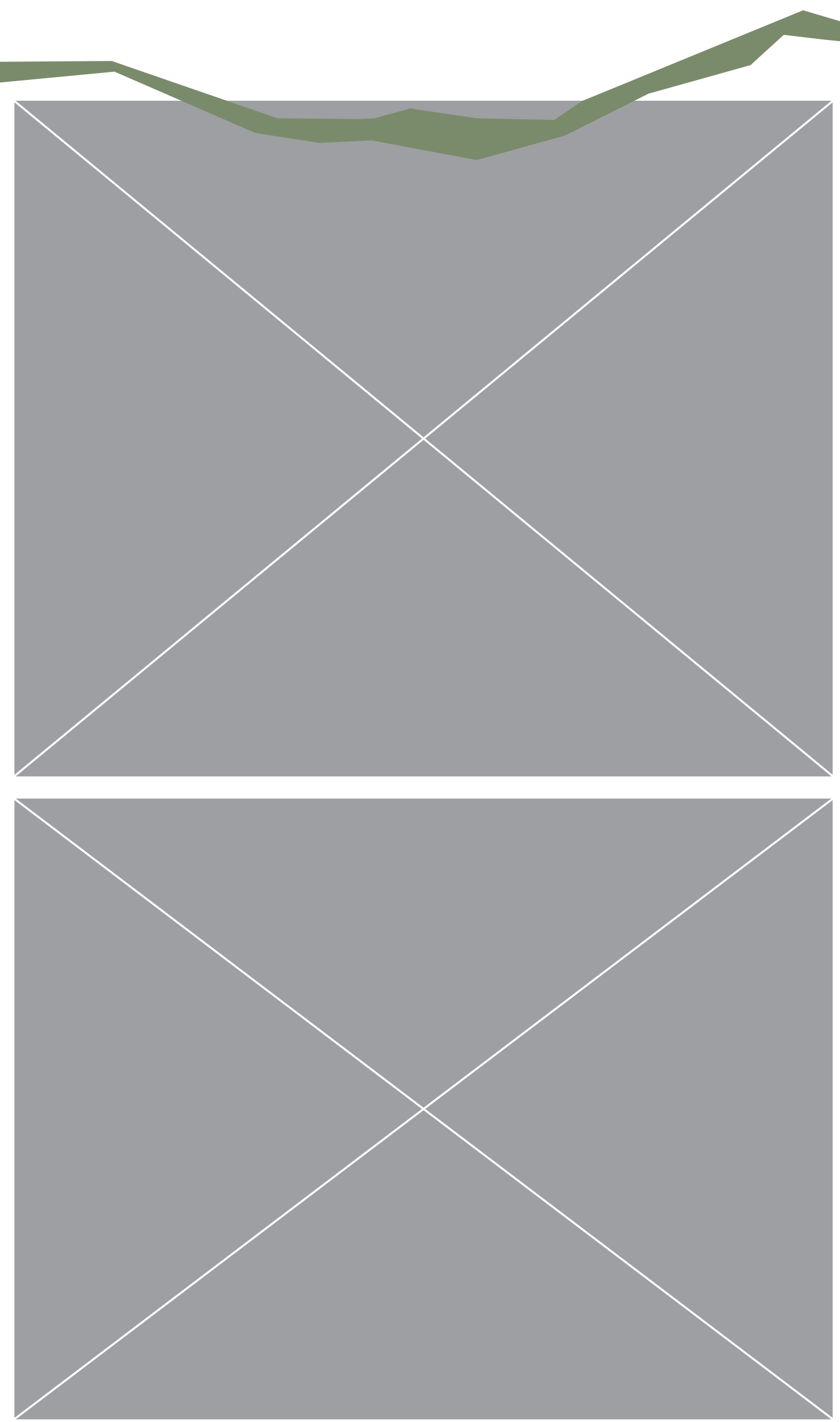

Fig. 18: De-sanding of printed elements

Fig. 19: Digital Grotesque ii 


\subsubsection{CASE STUDIES}

\section{MĀORI ORNAMENT: TE NOHO KOTAHITANGA MARAE}

Although this research is primarily focussed towards a European perspective, it is important to consider its impact towards Aotearoa, New Zealand. Māori architecture in New Zealand and its associated ornamentation and decoration hold a high level of symbolic, traditional and culturally significant craft and values. Traditional carvings and design are associated heavily with nature and history, "the close relationship between Māori and their natural environment is used to inspire the imagination" (Walters, 2014, p. 10). Examples of this can be seen to be represented in traditional meeting houses and marae. "Meeting houses are today normally conceptualized as complex representations of ancestry." (Sissons, 2010, p. 372). The design and construction of this type of architecture requires a high level of cultural consideration, of local iwi and traditional values, with a master carver often leading or being heavily involved in the craft process. Te Noho Kotahitanga Marae opened in March 2009, and is located at the Mt Albert campus at Unitec, in Auckland (Unitec, 2019). The main centrepiece is the whare whakairo (carved meeting house) 'Ngākau Māhaki', which was built and designed by Te Arawa master carver Dr Lyonel Grant (Unitec, 2019). This was the first whare whakairo in nearly a century that has been created using traditional architectural approaches (Unitec, 2019). Described as " 'He tāpiri taketake he tauira o tōnā wā tonu' - Blend of classic and contemporary design" (Unitec, 2019), the Marae design was designed by combining traditional techniques and modern media together (Unitec, 2019).
"The carvings may be traditional in format, but each element has been remodelled to fit modern society and to reflect its influences. This marae is a culmination of the past 30 years of my career. It is a legacy to those from whom I have learned," - Grant (Unitec, 2019).

Māori carvings can be presented in a variety of different ways. Te Noho Kotahitanga Marae is an example of translating modern design styles with traditional techniques, but these methods vary across different works of architecture, including using more traditional styles and methods of craft. "The construction of meeting-houses itself clearly follows a nontimeless, historical transformation" (Meijl, 2006, p. 215).

Although the values behind the craft, and the influences of nature in Māori architecture hold strong relevance to the ideas presented in this research, the use of them being applied to parametric and generative processes of designing pose some risks. The development of Māori carving and architectural design requires a deep understanding and knowledge of the history and craft in order to provide successful and respectful designs. Without the deep knowledge and understanding of local iwi and Māoritanga, there is a risk of being disrespectful to the architecture and culture of Māori architecture, and therefore for the purpose of wanting to be inoffensive, this particular area of research has not been the continued focus for this thesis. 

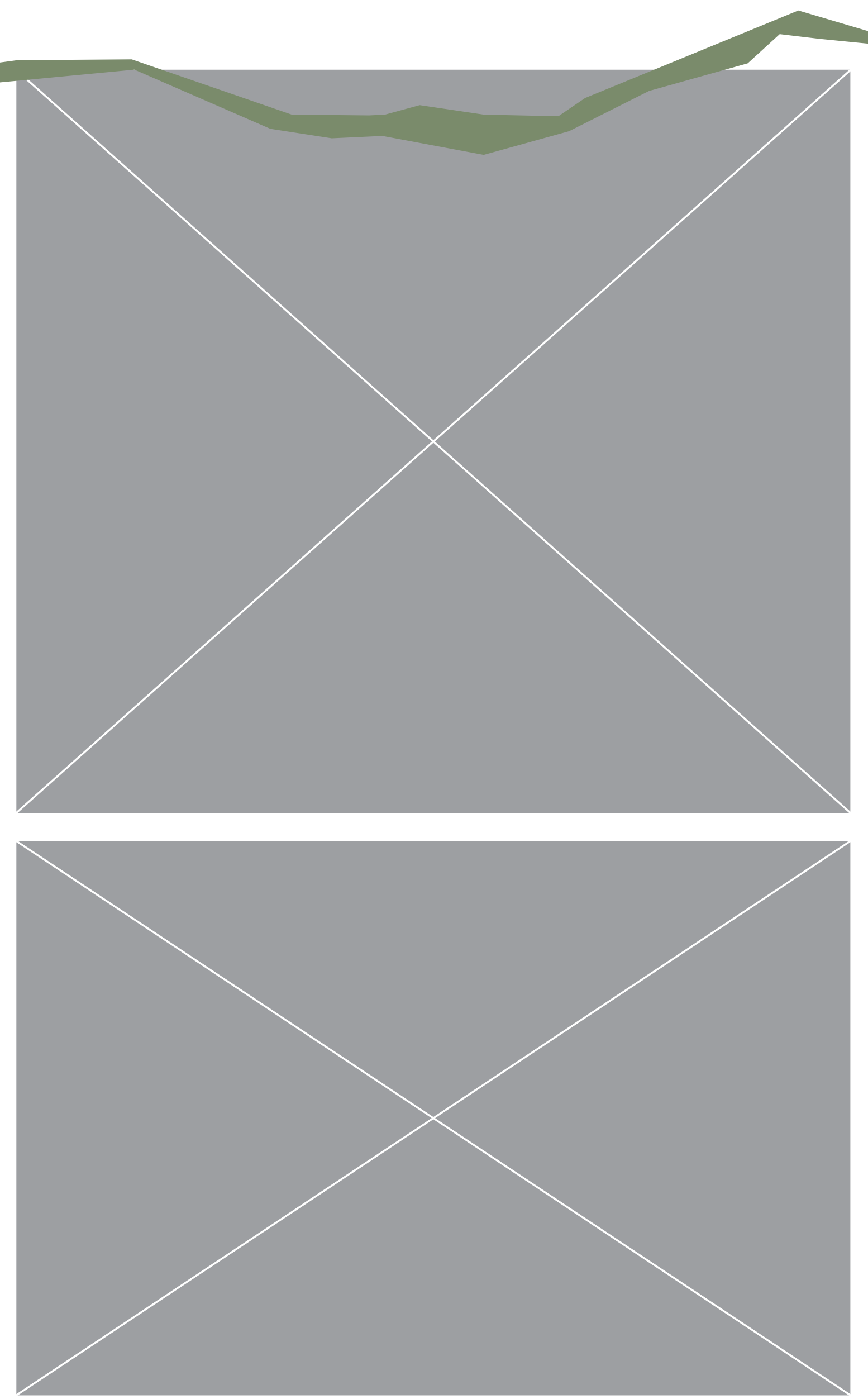

Fig. 20 \& 21: Carvings on marae 


\subsubsection{CASE STUDIES}

\section{NERI OXMAN, CHRISTOPH BADER \& DOMINIK KOLB: WANDERERS}

Neri Oxman, alongside her team of designers and scientists, have worked on a variety of different projects within the field of Material Ecology (Oxman, 2018). 'The Wanderers' is a research project that was part of the exhibition 'The Sixth Element: Exploring the Natural Beauty of 3D Printing' on display at EuroMold, Frankfurt, Germany (MIT, n.d.). The research was done in collaboration with Christoph Bader and Dominik Kolb (Oxman, 2018), and is a project that involves the creation of "biologically-augmented 3D printed Wearables" (Mediated Matter Group, n.d.).

This project was a highly technological project, which involved a lot of scientific research on ecology and growth. Although this is well outside the scope of the research being undertaken in this thesis, 'Wanderers' is a clear example of how the use of organic form in conjunction with digital fabrication, computational design, and $3 \mathrm{D}$ printing can all work to creating some meaningful and influential designs.

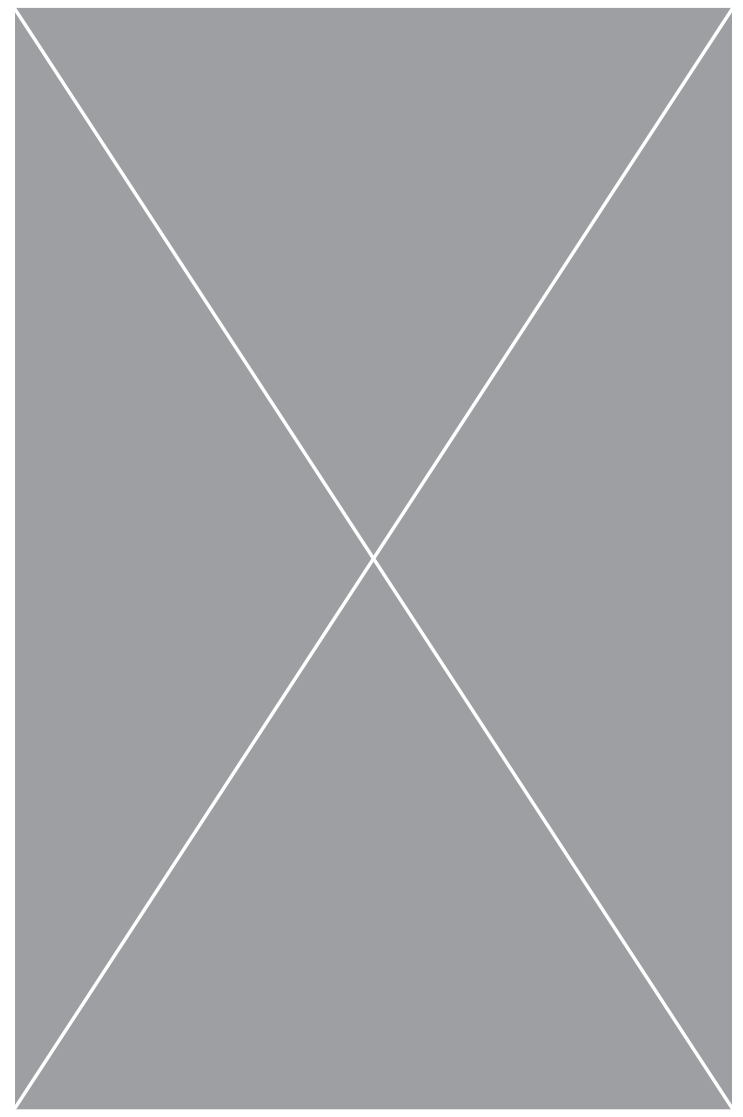

Fig. 22: 3D Printed Wearable 

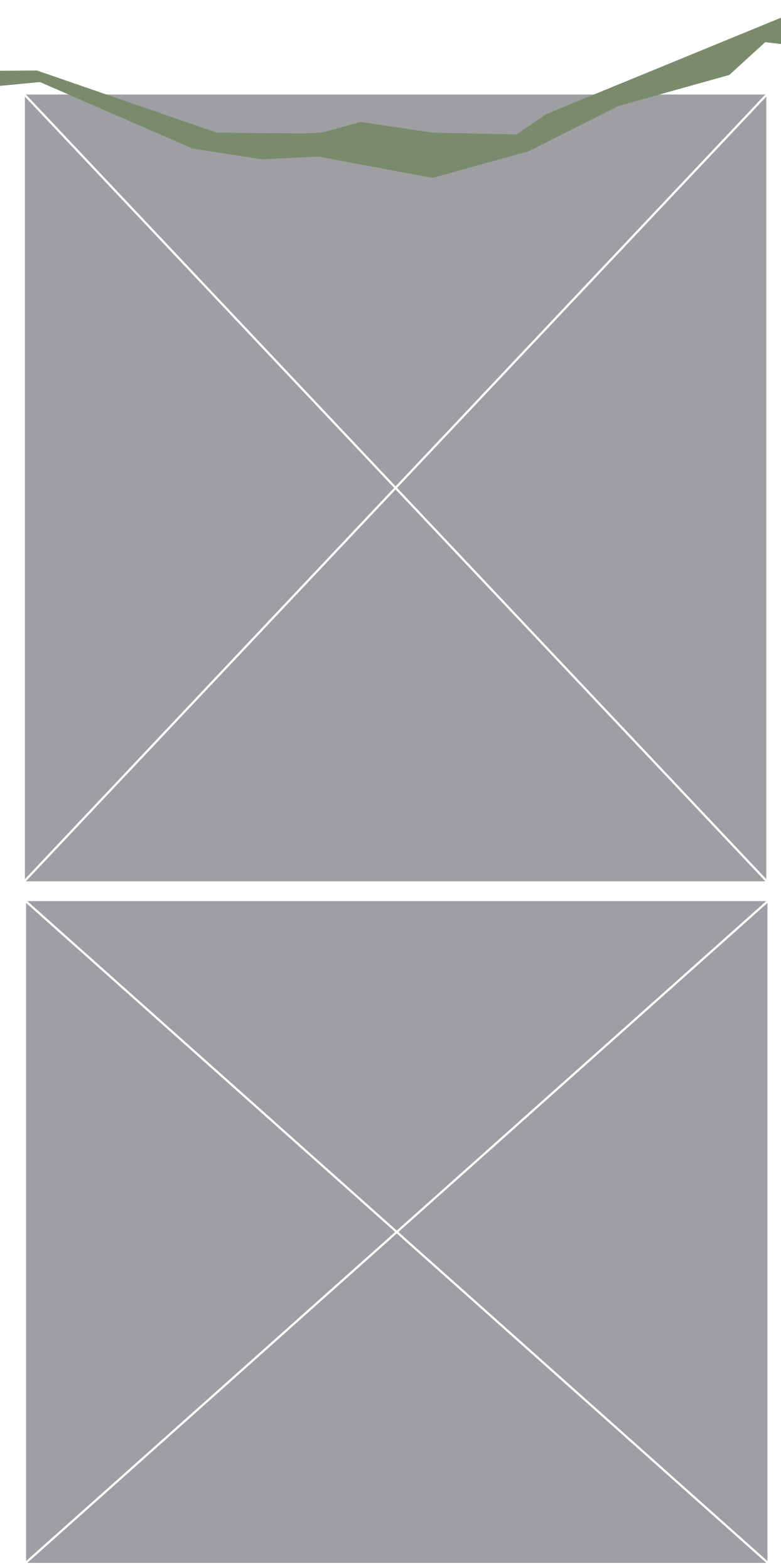

Fig. 23 \& 24: Digital Renders 


\subsubsection{CASE STUDIES}

\section{ETH ZURICH: CONCRETE CHOREOGRAPHY}

An interdisciplinary research team of students and teachers at ETH Zurich's Master of Advanced Studies in Digital Fabrication and Architecture were part of the project 'Concrete Choreography' (Anton et al., 2020, p. 286), which produced an installation in collaboration with the Origen Festival, in Riom, Switzerland (Walsh, 2019). The installation produced the first robotically $3 \mathrm{D}$ printed concrete stage, with nine $2.7 \mathrm{~m}$ concrete columns fabricated without formwork (Walsh, 2019).

This research project was able to build upon previous research from ETH Zurich, such as Hansmeyer and Dillenburger's previous projects, as mentioned above. The main research aim of this project "was to demonstrate the remarkable architectural qualities achievable through $3 D C P$, but impossible with any other printing method or conventional casting technique" (Anton et al., 2020, p. 286). 'Concrete Choreography' holds similarities to the kinds of research this thesis seeks to investigate, including the material properties and methods of using robotics for architectural scale printing. This project differs however, as the focus is primarily on the fabrication technique, rather than having a historical influence to the methods of the designs. 


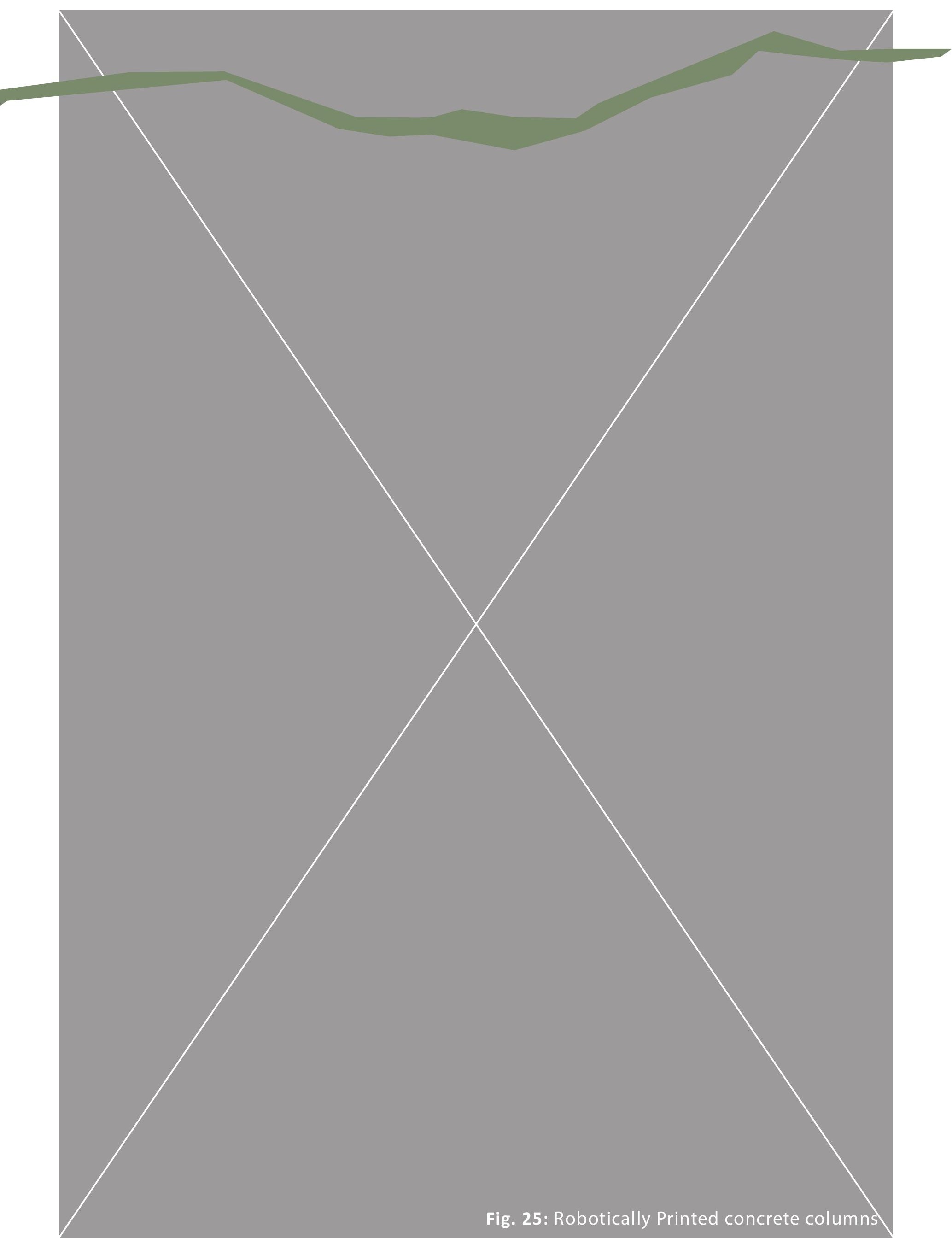




\subsection{REFLECTION}

The literature review has reinforced that the development and transition of ornamentation from classical ideas through to contemporary is complex, and requires the consideration of a variety of different factors, including social, cultural, historical and technological conditions. In classical architecture, ornament held a strong level of symbolic values, which held information on status and rank. The architectural orders were clear examples of the rules of geometry and order that assisted in forming the classical definition of ornament. The review of ornament in regards to modernism and technology offered insight into how these different cultural and technological influences transitioned its definition through different architectural trends, and highlighted that neglect of history and its influences can have a negative effect on ornament developing. The investigation into the different digital fabrication technologies outlined the benefits of different techniques, including robotics, AM and SM, as well as identified some of the key considerations needed when moving to large-scale manufacturing. The literature has made it clear that there is a disconnection between history and technology when it comes to ornaments position in architectural design in contemporary architecture. Reintroducing ornamentation into contemporary design in an effective and meaningful way is not a simple process of replicating classical principles, but rather requires a method of realigning the fabrication technologies in an architectural sense, with cultural and historical implications kept in mind as well.

The review of case studies has highlighted a mixture of different advanced technologies and projects that are investigating this area of fabrication, however there are very few examples of industry examples of architectural projects in contemporary architecture using these design methods and ideas, identifying a clear gap in the industry. Investigation into Māori architecture has shown key design influences and inspiration, but also highlighted the delicacy and level of complexity and knowledge of Māoritanga required in order to create successful and meaningful outcomes and therefore because this research is being directed towards generative and parametric design techniques, that area has not become a focus for this research. Works from Hansmeyer and Dillenburger are some of the projects that show the potential that additive manufacturing techniques have in this area, and have also identified some potential design issues that could occur in terms of the production process. From the literature, it is clear that robotic fabrication in alignment with AM techniques have the potential to provide intricate and crafted ornamentation, and therefore they will be a key driver in the progression of this research. 



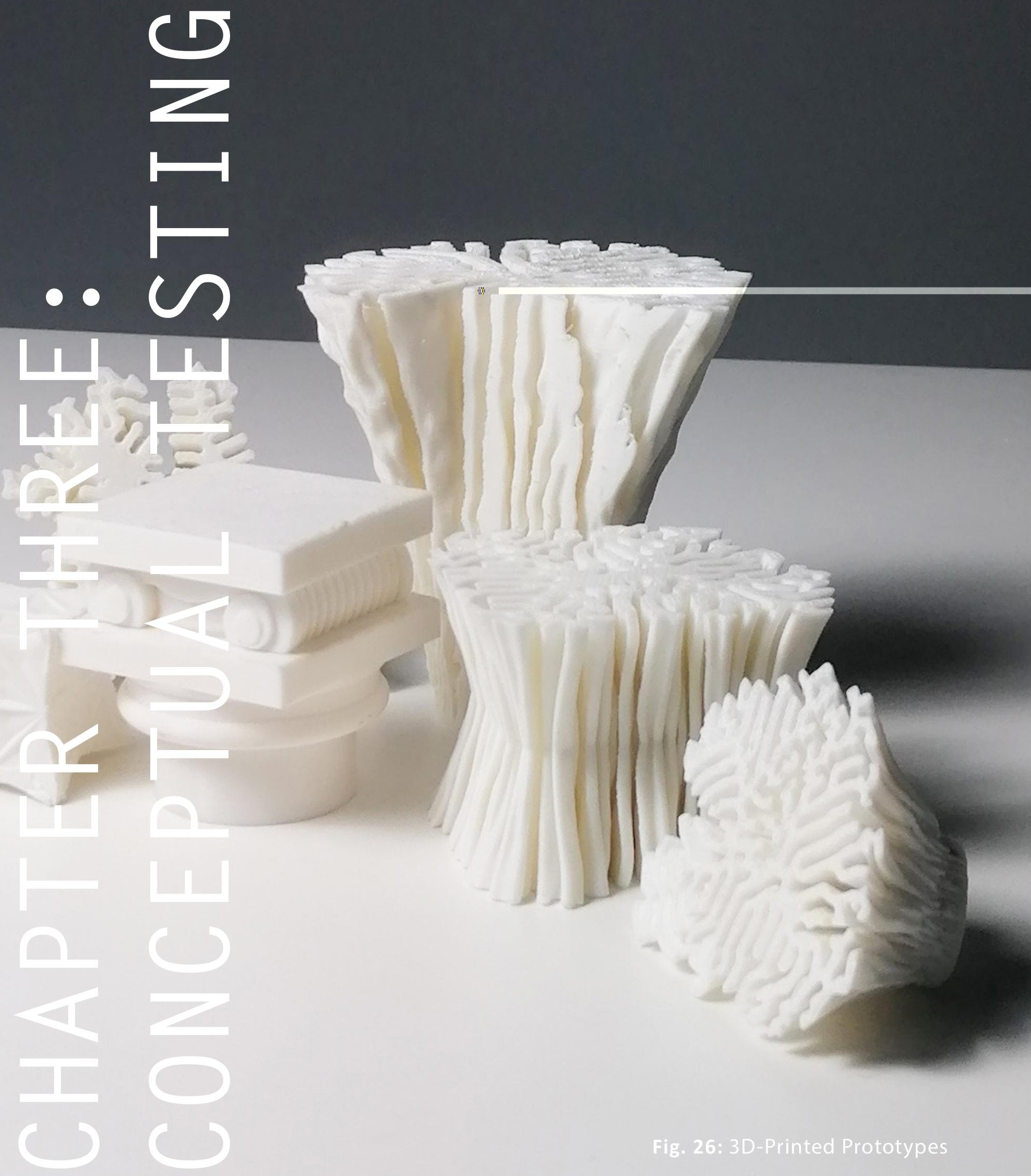




\subsection{INTRODUCTION}

The following chapter begins the design and investigative stages of this research. By using the literature and case study analysis outlined in the previous chapter, this chapter uses Grasshopper and Rhinoceros, as well as an influence from classical ornamentation to create design iterations. This stage starts with the identification and understanding of the computational tools, and then, by using the classical orders as a design influence, works to produce design iterations that are continually evaluated and critically reflected on. After the initial digital iterations were created, the connection to the digital fabrication process was instigated, which involved the prototyping of small-scale models using 3D-Printing out of ABS plastic. After each design series, a critical reflection was made in order to adjust and analyse the strengths of each stage, and to identify the best direction for the research to progress further. 


\subsection{DESIGN PROTOTYPING: SOFTWARE \& PROCESS}

From the literature, it was found that generative and parametric design tools were effective computational techniques that would work well in developing this research. Grasshopper, the visual scripting add-on to Rhinoceros is the primary software that has been used to undertake the visual scripting process to develop the digital models, alongside the implementation of selected plug-ins. 'Plug-ins' are additional pieces of software developed by designers that are downloaded to become part of the design environment (Davis \& Peters, 2013, p. 126). "Each plugin emerges to address a specific problem or opportunity that an architect has identified in their work, thus widening the digital design environment around the desires of the individual designer" (Davis \& Peters, 2013, p. 126).

By using Grasshopper and Rhinoceros together the digital model can be updated through the script easily and represented in the Rhino window in real-time. This allows for a much smoother workflow, allowing for added benefits of precision and control and a much more dynamic and iterative workflow. The visual nature of the software also makes the process much more user-friendly, when compared to standard written scripting processes. Once a script is successfully produced, iterations are then created through the adjustments of 'sliders' or additional 'components' in the script, and these can be solidified in Rhino by using the 'bake' command, creating a design series.

This stage largely involved the understanding of this technology, and the tools and associated plugins. This meant that the initial explorations were focussed on understanding the workflow, surface qualities, and creating interesting forms and adding complexity, whilst exploring the best methods for adjusting scripts, and therefore creating mass customisable models. The process began with the use of exploring 2D shapes, which were then translated into 3D forms. Once a base script was successfully produced, the key areas of the script that allowed for iterations and variations were identified, and these were adjusted and 'baked' out in succession to allow for design iterations. Components such as 'orient' and 'rotate' were also applied to add variation.

Once a design series was generated, selected models were then 3D-printed using ABS plastic filament and UpBox 3D-printers to produce small-scale prototypes of the models. This stage was essential in understanding how AM and digital fabrication processes fit in with digital prototyping, which in turn helped to establish an effective workflow. This stage helped to identify any issues with the scripts or models themselves in the early stages, before the commencement of moving into larger prototypes in the later stages of this research.

A critical reflection of the effectiveness of the script and method, the ease of use in adjustments, and the ability and level of customisation was applied to each design series, as well as identification of the strengths and weaknesses of the prototypes, and the steps needed to improve and refine them. 

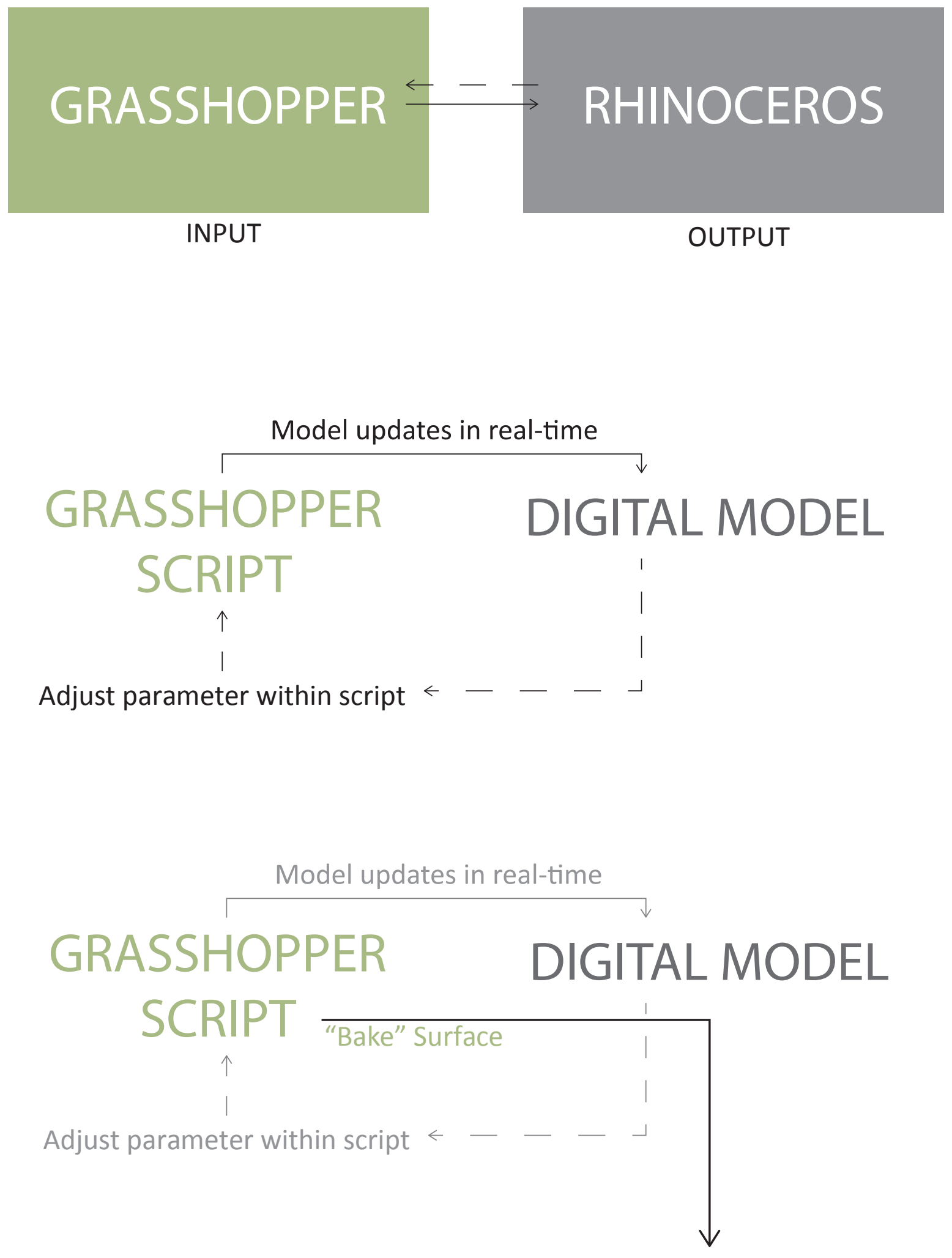

Digital design Iterations + Files ready to export for fabrication 


\subsection{INFLUENCES FOR INITIAL DESIGNS}

The 3 Greek architectural orders, as well as inspiration from nature and organic forms were used as a design influence to the iterations. After the initial 2D explorations which worked to understand the software; a particular idea, theme or style was taken from one of the orders, which was then translated into an idea from nature, and then into a digital representation through a script. The intention of this stage was not to provide a clear replication of classical ornament, but rather to take a simple concept or component from a historical precedent, and understand how digital fabrication and mass customisable properties were able to reenvisage and redefine what ornament could look like to be effective in a contemporary context.

\footnotetext{
"Contrary to what one might imagine, history reveals itself more productive when the present does not appear as a mere extension of the past but seems, rather, to stem from a complex reinterpretation of some of its elements, a reinterpretation in which continuities and discontinuities need to be carefully sorted and weighted" (Picon, 2013, p. 14)
} 


\section{HISTORY + THEORY}

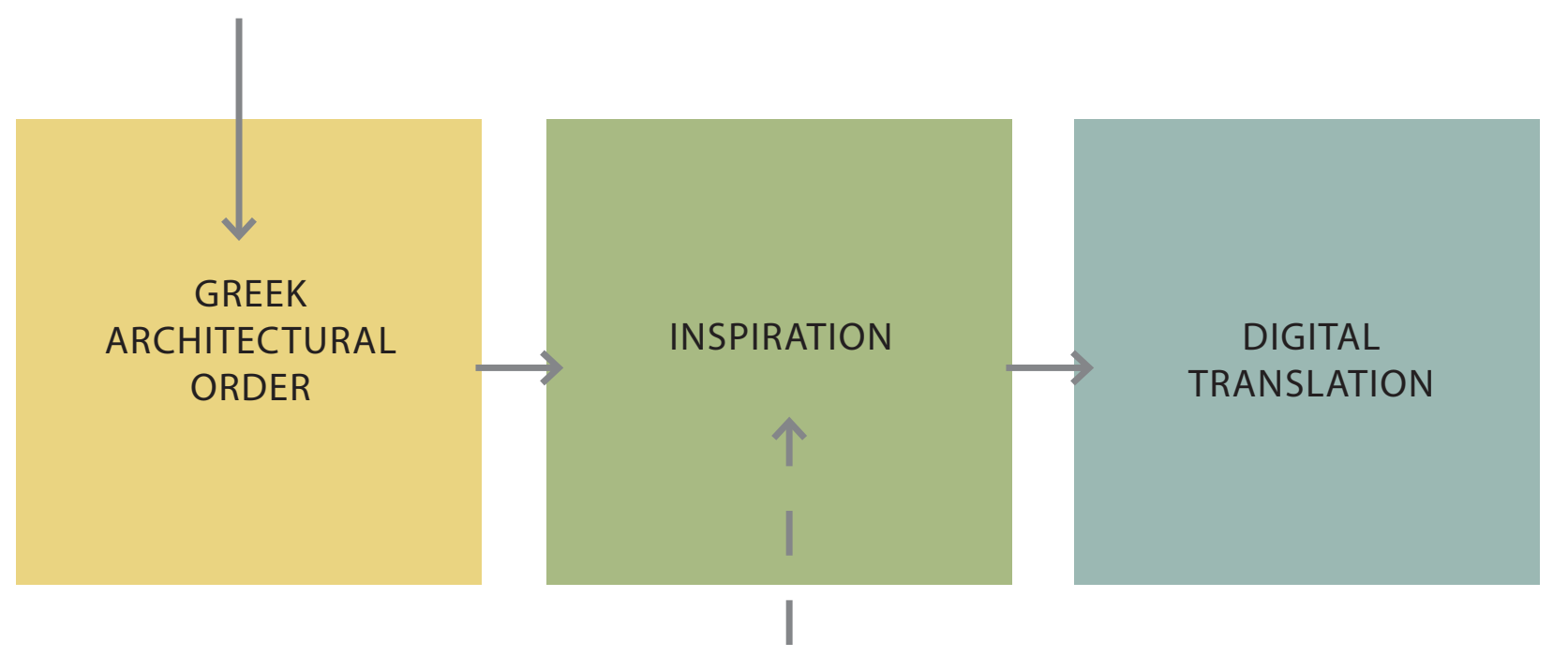

NATURE
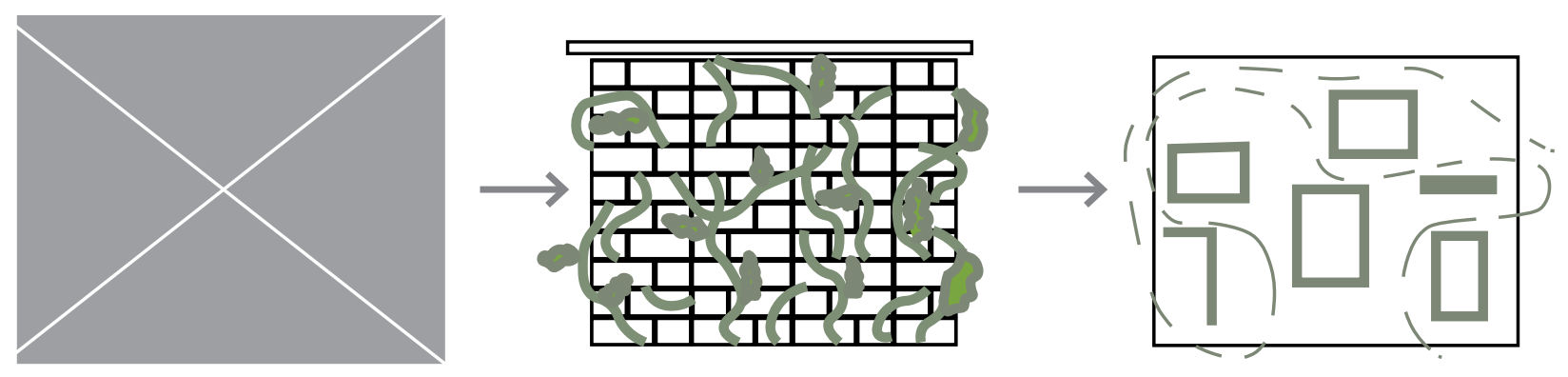


\subsection{INITIAL PROTOTYPING}

\section{DORIC ORDER - CORAL FORMS - CURVE EXPANSION}

This design series was influenced by the Doric order, in particular the way that the sea urchin (Echinus) and seashells were reflected on the design of the column capitals. This 'coral growth' design series uses a method of curve expansion to simulate a 'growing' form. The base script worked by starting with a closed curve, which was then divided into segments, and then the script expanded the curve using the "kangaroo 2 physics' plugin, creating a squiggled line that was not allowed to cross over itself. The results were then moved vertically and then lofted together to create a complete surface.

Once the base script was completed, the key aspects that provided the most manipulation and adjustments were modified to create customised designs.

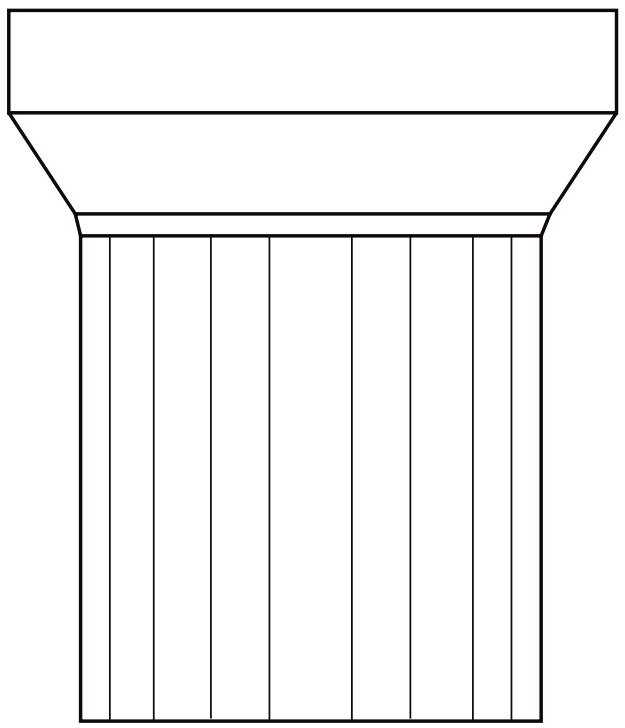

Fig. 32: Doric Capital 


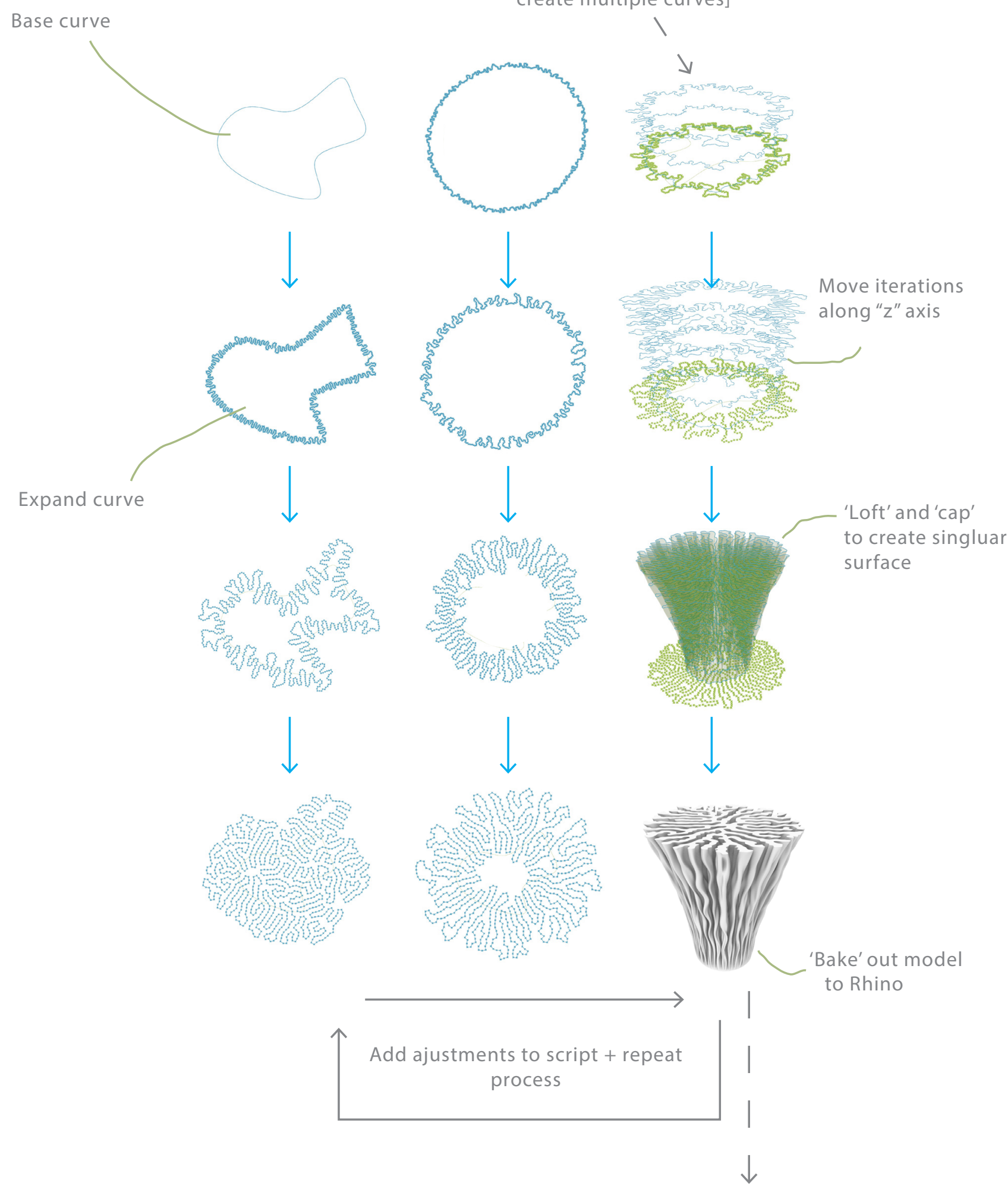

[Script repeats process to

create multiple curves]

Export to stl. file for 3D printing 


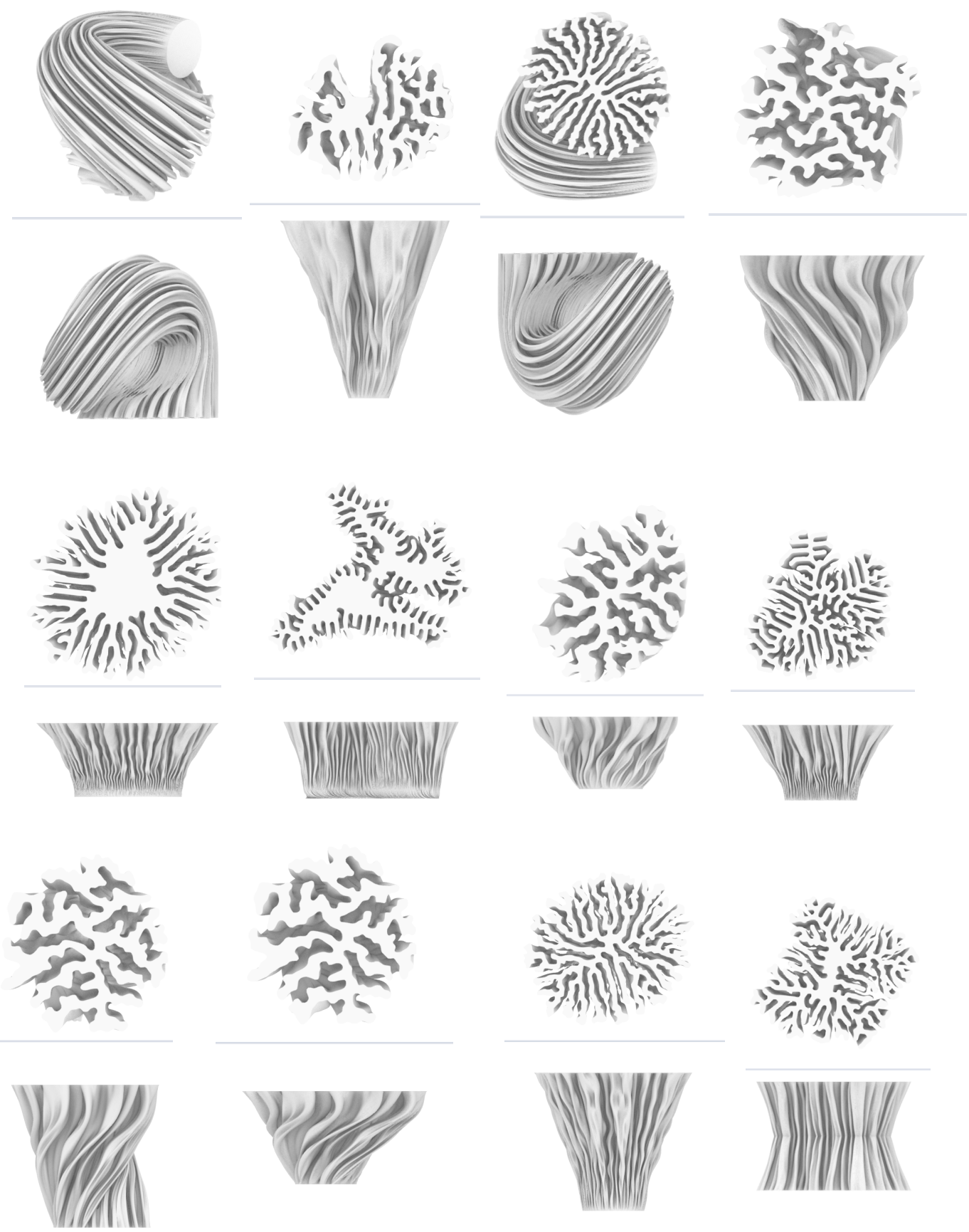

Fig. 34: Rhino digital models

\section{REFLECTION}

The models created from this design series created some complex and interesting surface qualities. By using adjustments such as 'rotate' and adjusting the divisions, a lot of variation was able to be created. The main level of pattern was mainly seen from the top of the form rather than the sides, so some adjustments to bringing more surface qualities to the sides was something to be explored in further iterations.
Rating of script/method: 7/10

Ease of use: $6 / 10$

Level of customisation: $7 / 10$ 


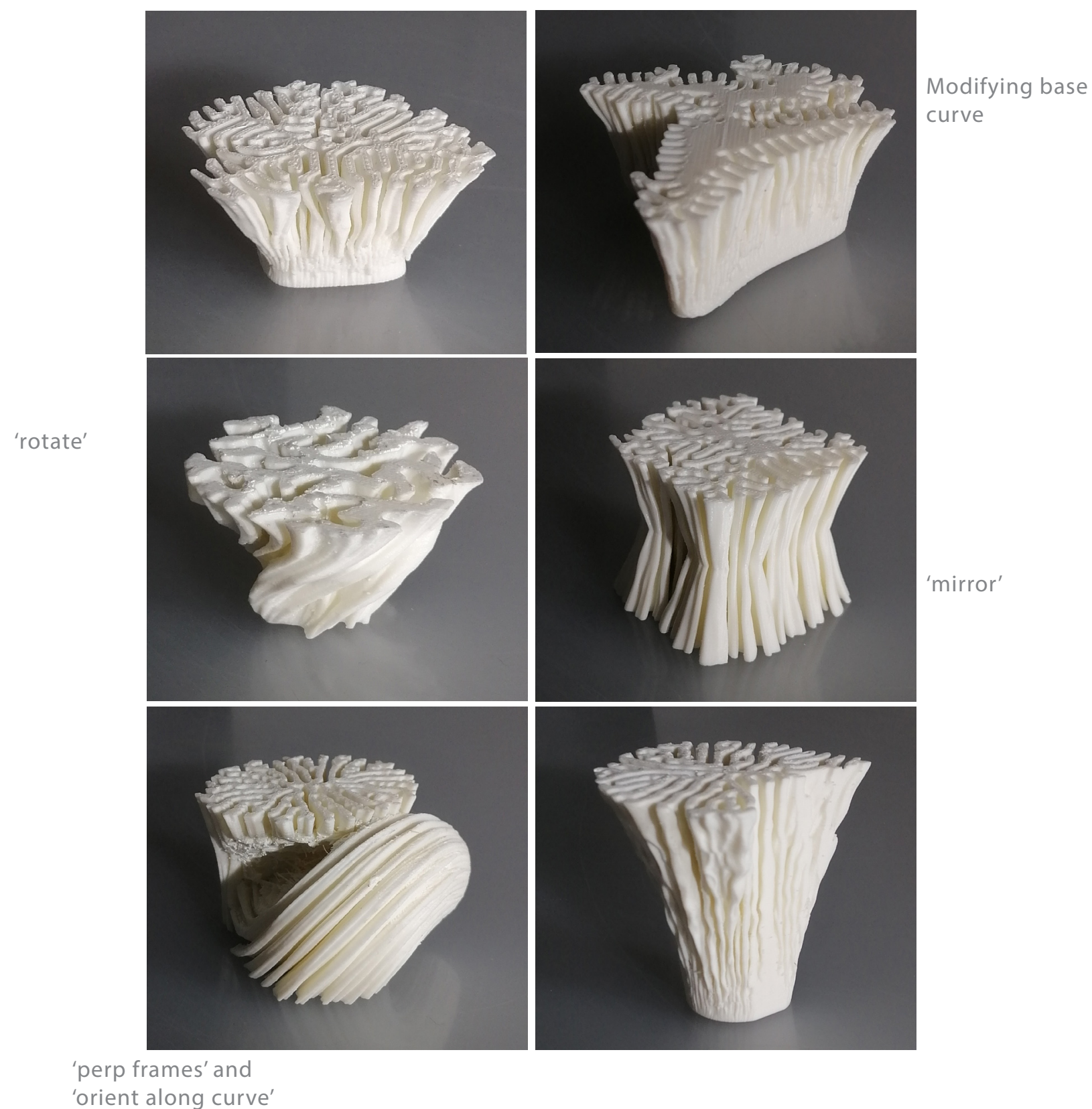

Fig. 35: 3D-Printed prototypes

\section{FABRICATION}

When moving into the 3D printing of these forms, it became evident that there was a lot of overhang in some of the models. This caused issues as it required extra printing of removable scaffolding to print them successfully. This meant there was added waste. Although for the smaller prototypes it was not a major issue, it was clear that it would become very wasteful in large scale prints, as well as would provide added difficulty when moving to other materials. 


\subsubsection{INITIAL PROTOTYPING}

\section{IONIC ORDER - CURVATURE - EXPANDING SPHERE}

Continuing with ideas of 'growing' and 'expanding' from the previous series, these iterations took inspiration from the curves and spirals seen in the lonic order. The base script began with a spherical object, and then expanded the area of the surface, creating an organic form. The script used the 'Anemone 0.4' Grasshopper extension, developed by Mateusz Zwierzycki in 2015, which enables the creation of script loops in Grasshopper (Food4Rhino, n.d.).

Each iteration was creating by adjusting the level of surface expansion applied to the spherical shapes.

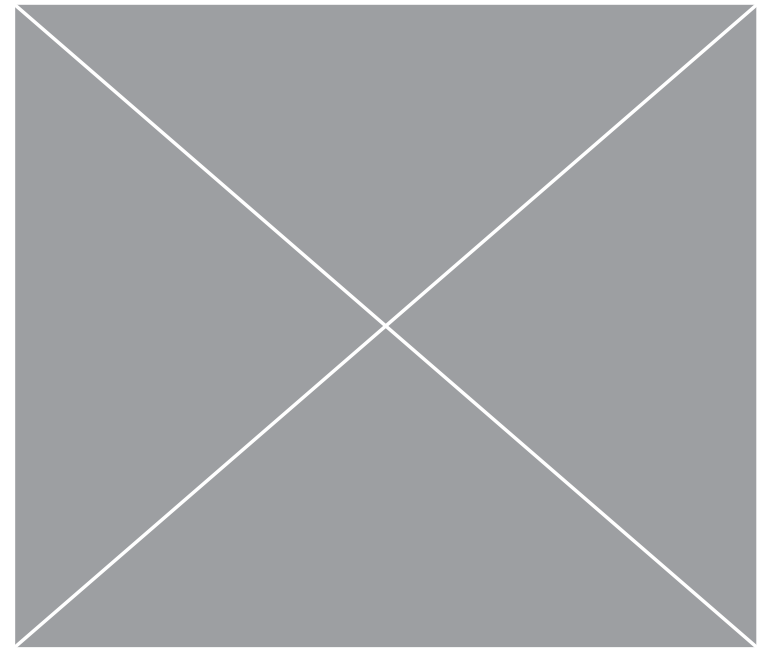

Fig. 36: Ionic capital 

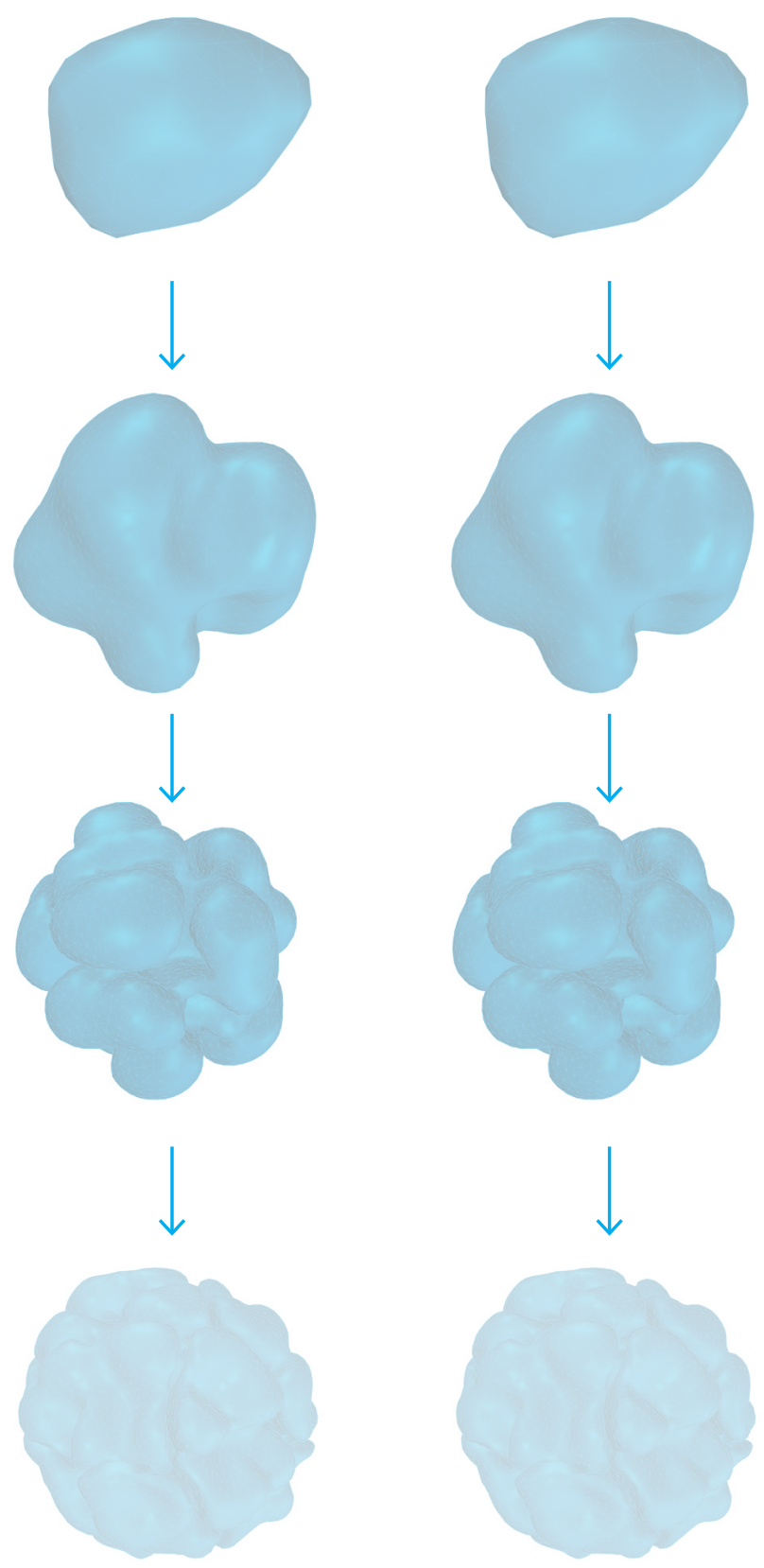

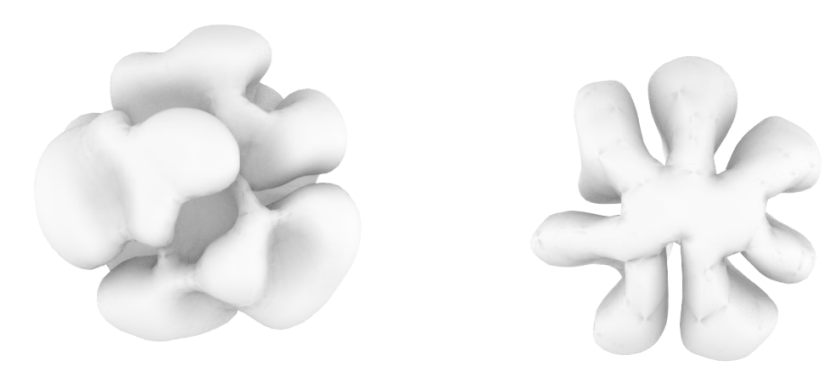

Applying script to
cylinder form instead
of sphere
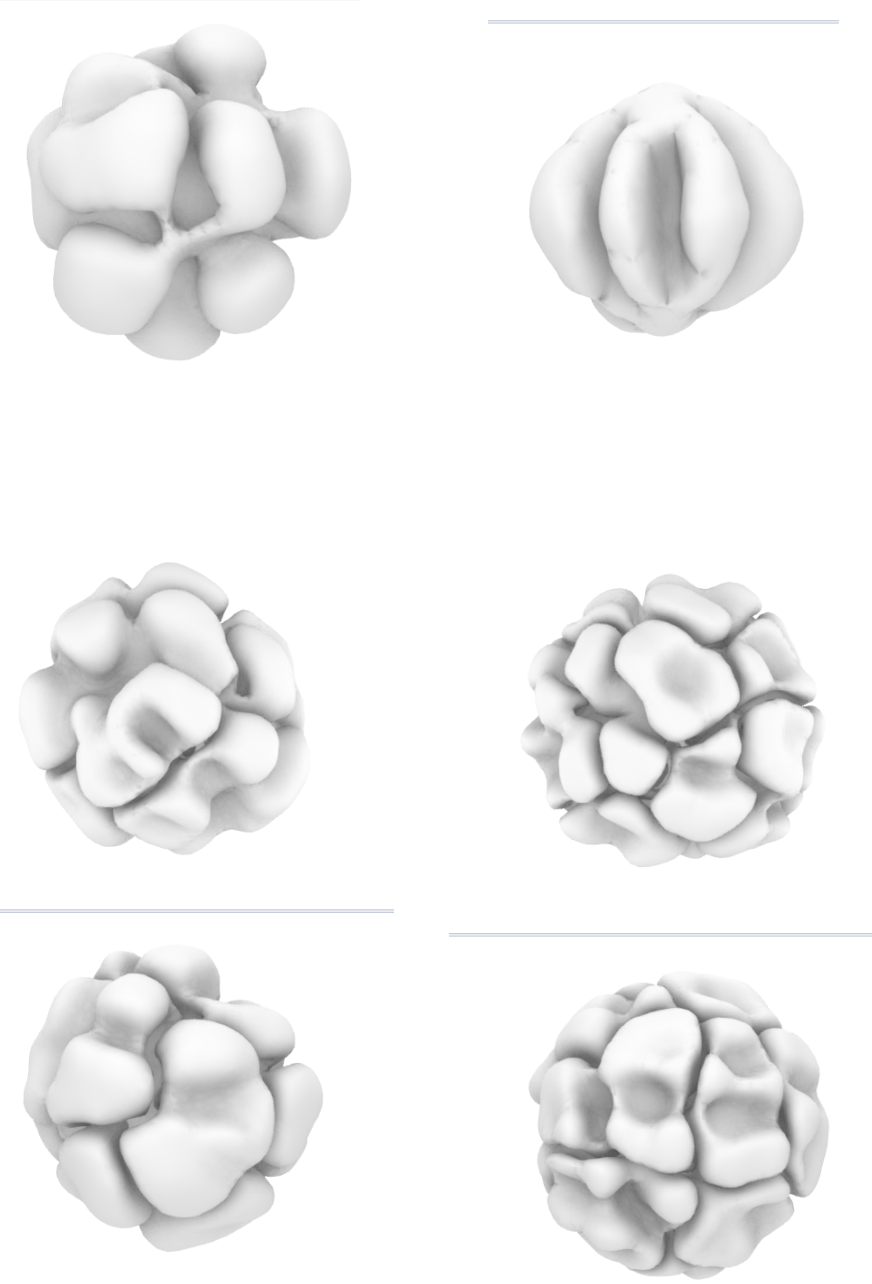

Fig. 38:

\section{REFLECTION}

This design series created some organic textures, however there was a lot of limitations to how easily the forms could be adjusted and customised. Very little variation was able to be achieved beyond increasing the surface area. Using a base form other than a sphere was not very successful. The forms were interesting, however they did not entirely reflect on the desired design influence from the lonic column.
Rating of script/method: $5 / 10$

Ease of use: $4 / 10$

Level of customisation: $2 / 10$ 

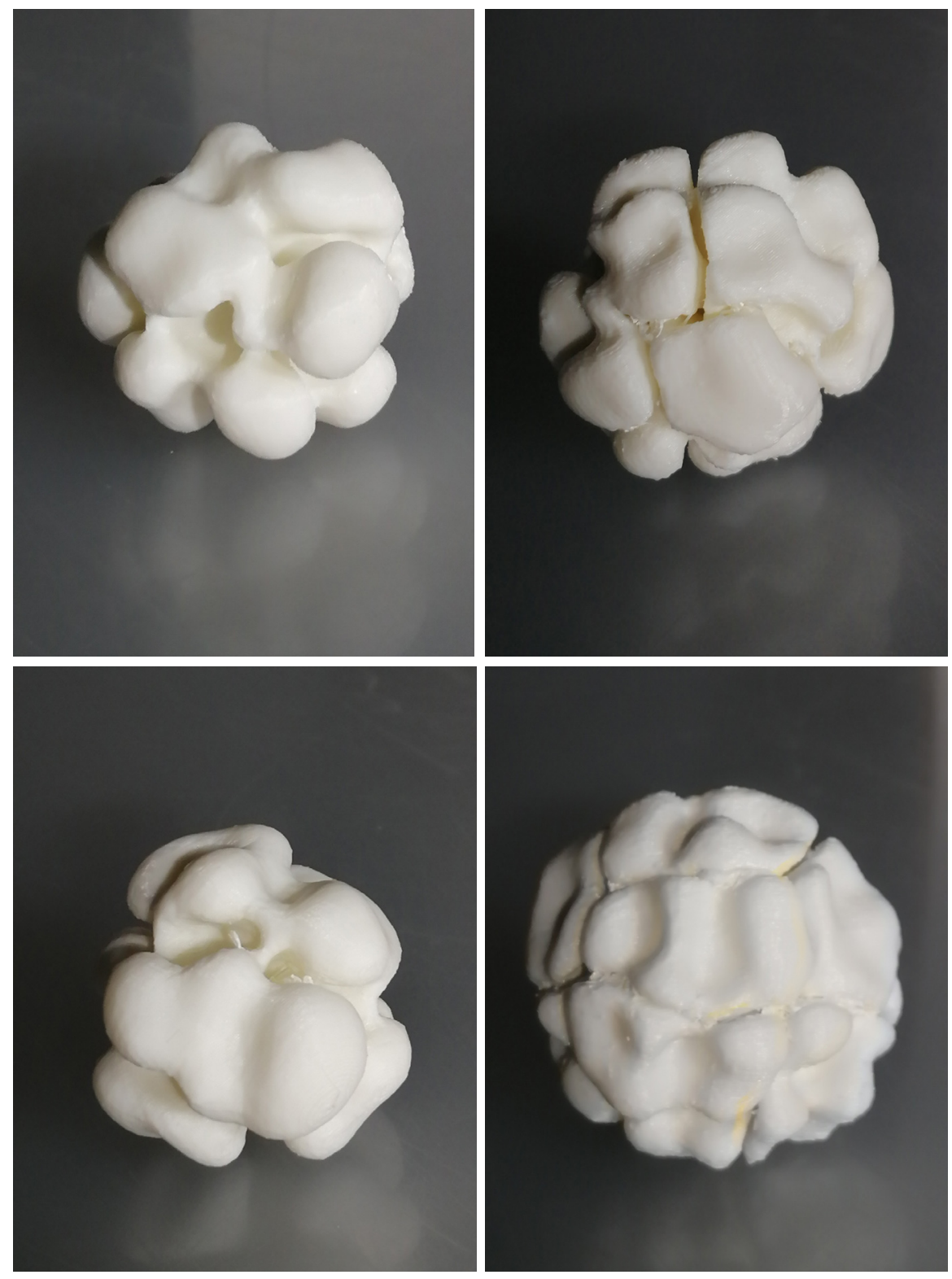

Fig. 39:

\section{FABRICATION}

These forms printed across effectively, however much like the first series, there required a lot of scaffolding, and therefore waste. Although they were interesting shapes, the practicality of them turning into architectural columns was limited. 

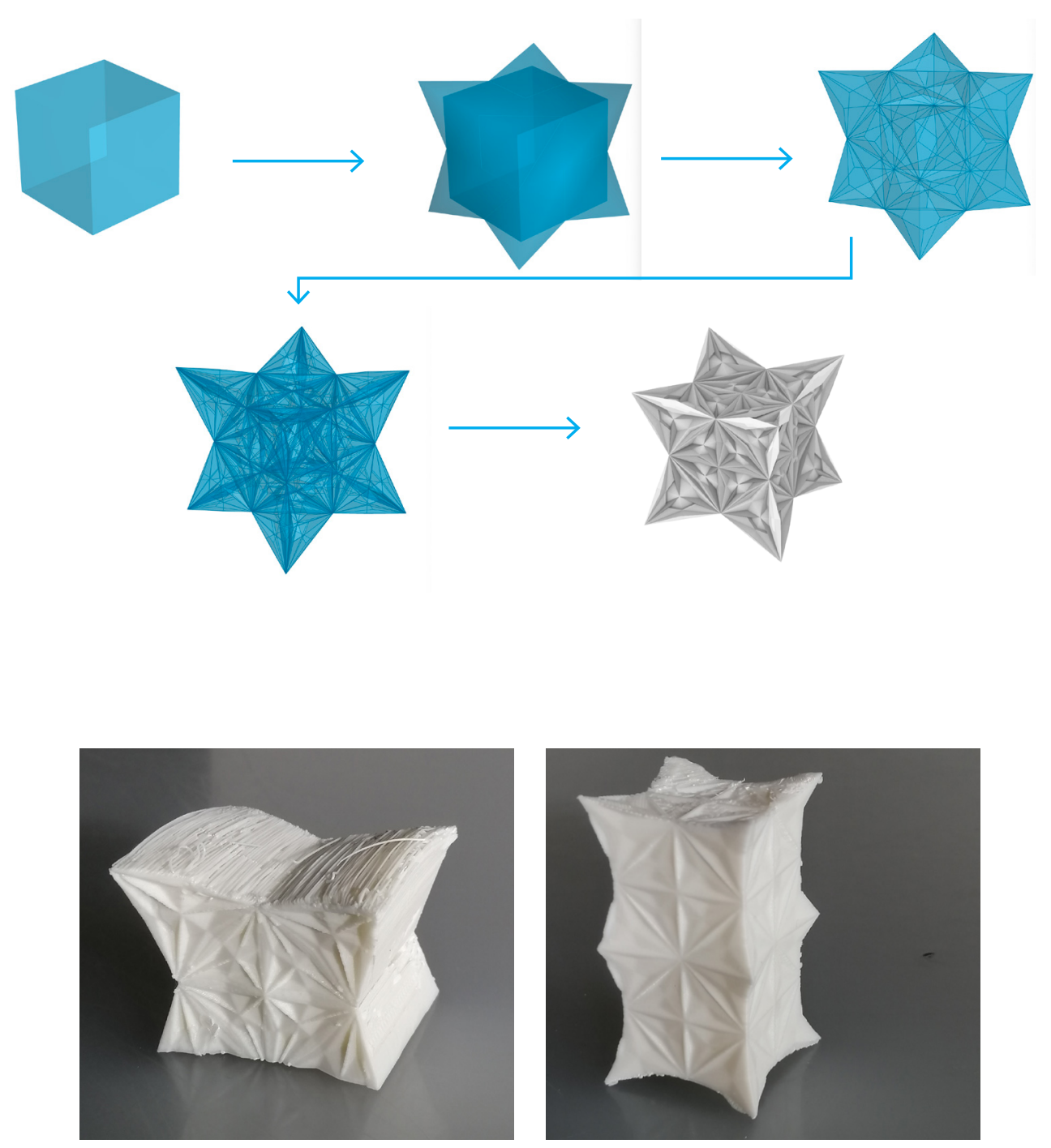

Fig. 40 \& 41

FABRICATION

Mesh Subdivisions - This test had inspiration taken from Michael Hansmeyer and Ben Dillenburger's works, as shown in the case studies in chapter two. The script used an iterative process of dividing cube forms in order to create complex geometry. Although it did create a high level of complexity to the surface, they were difficult to manipulate to create the desired more organic and classically inspired
Rating of script/method: 5/10

Ease of use: $6 / 10$

Level of customisation: 4/10 

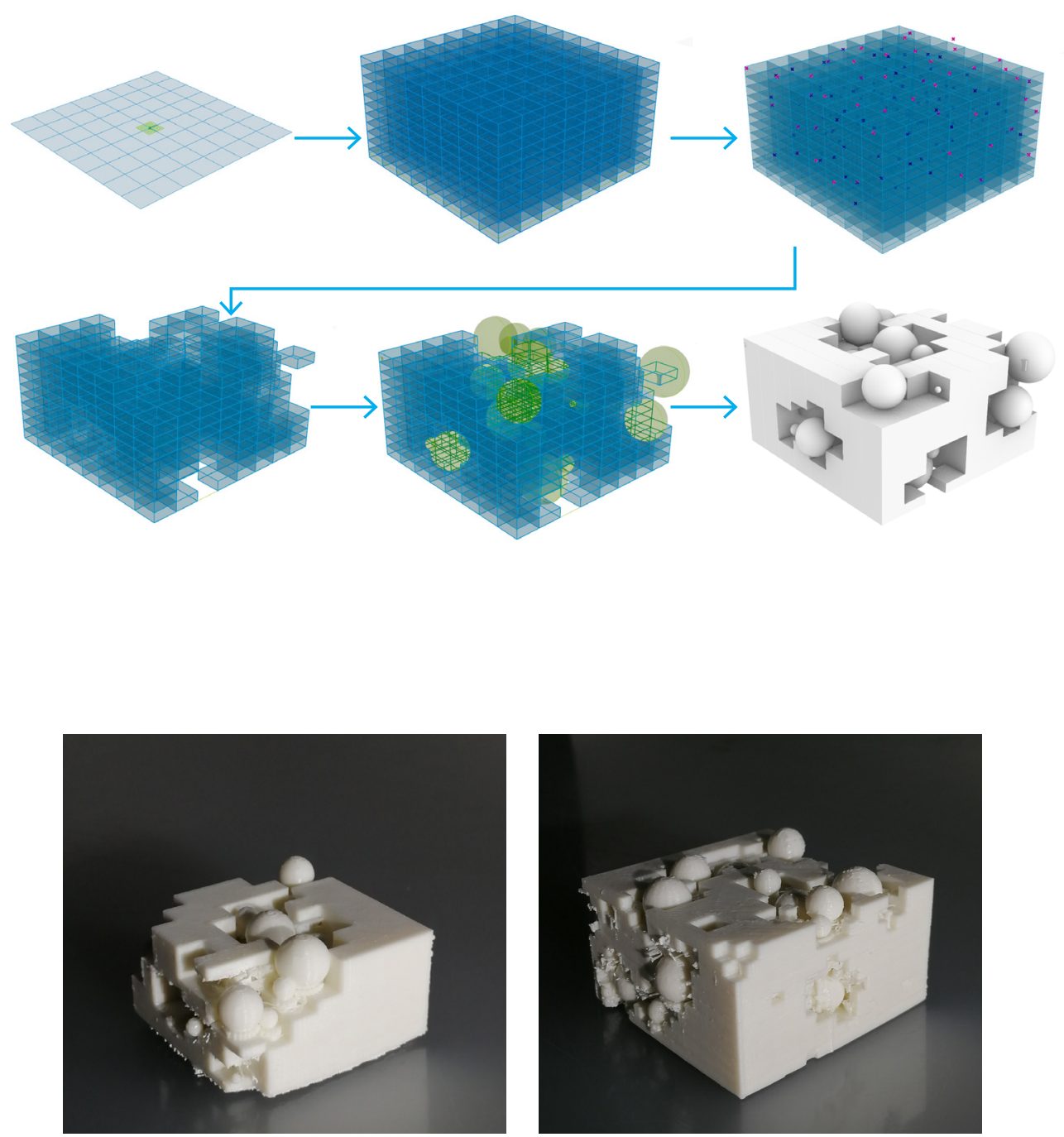

Fig. $42 \& 43$

FABRICATION

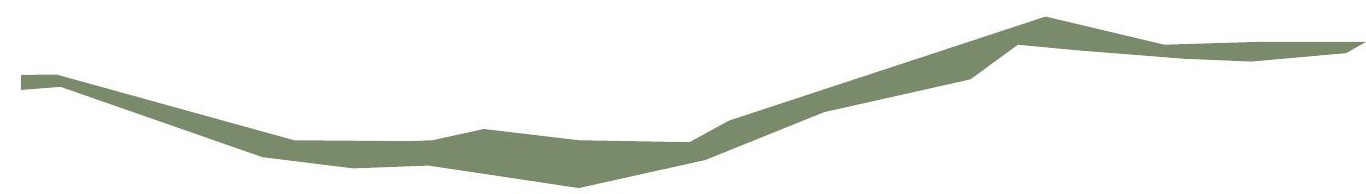

Random Reduce + Cube/Sphere Reduction

Rating of script/method: $6 / 10$

Ease of use: $7 / 10$

Level of customisation: $4 / 10$ 


\subsubsection{INITIAL PROTOTYPING}

\section{CORINTHIAN ORDER - LEAVES - GROWING DISK}

This design series followed a similar process to the 'growing sphere' script, except by using a different starting form. A similar process of expanding the surface area was used, except the base was a disk instead of a sphere. The inspiration was taking mainly from the story in the Corinthian order, and the ideas of weaving and the acanthus leaves that identified the key characteristics of the forms.

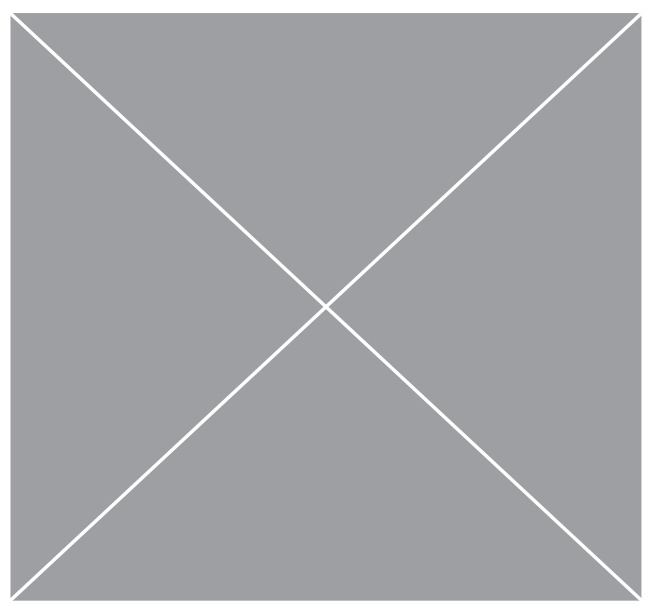

Fig. 44: Corinthian capital 

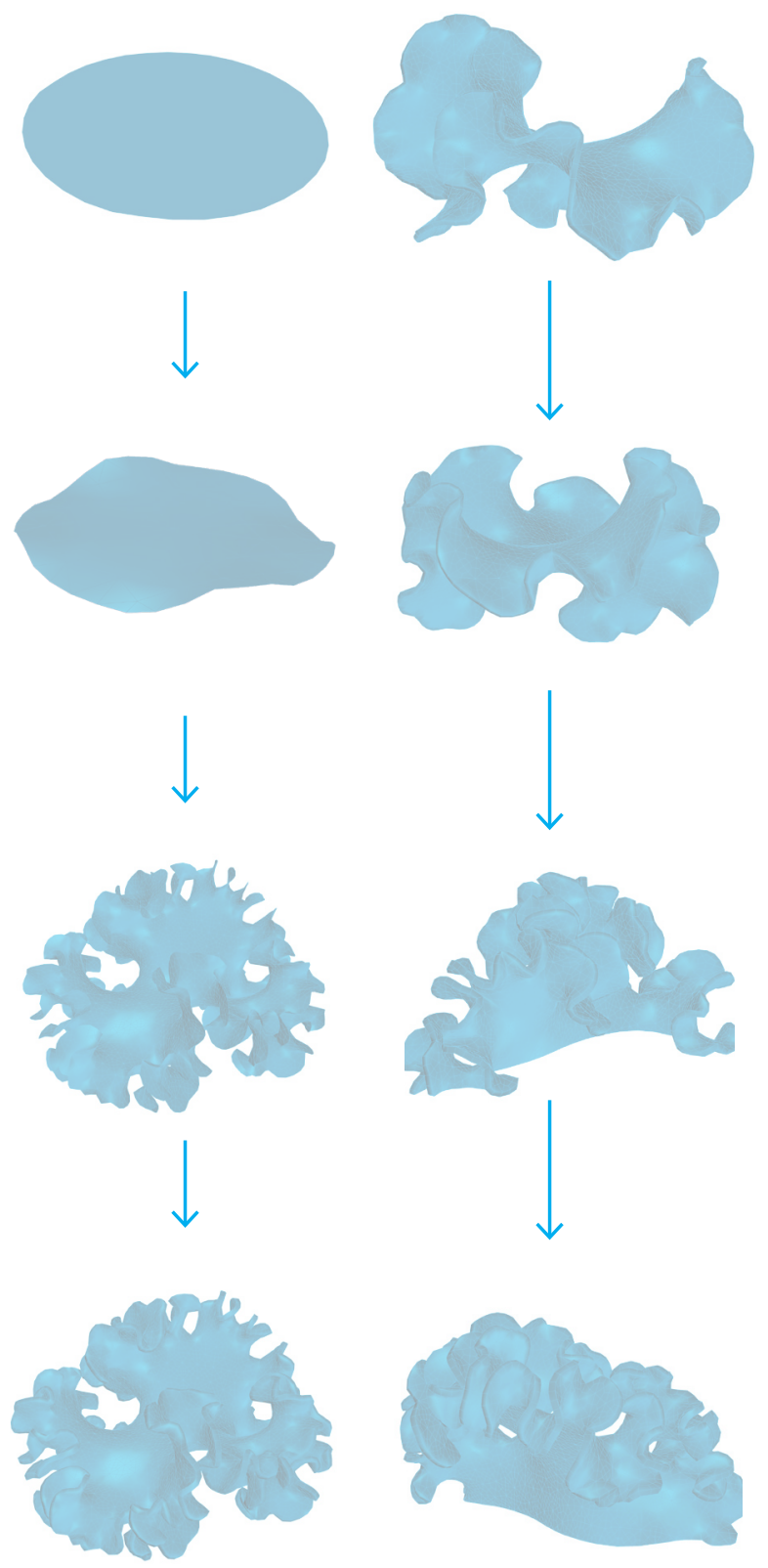

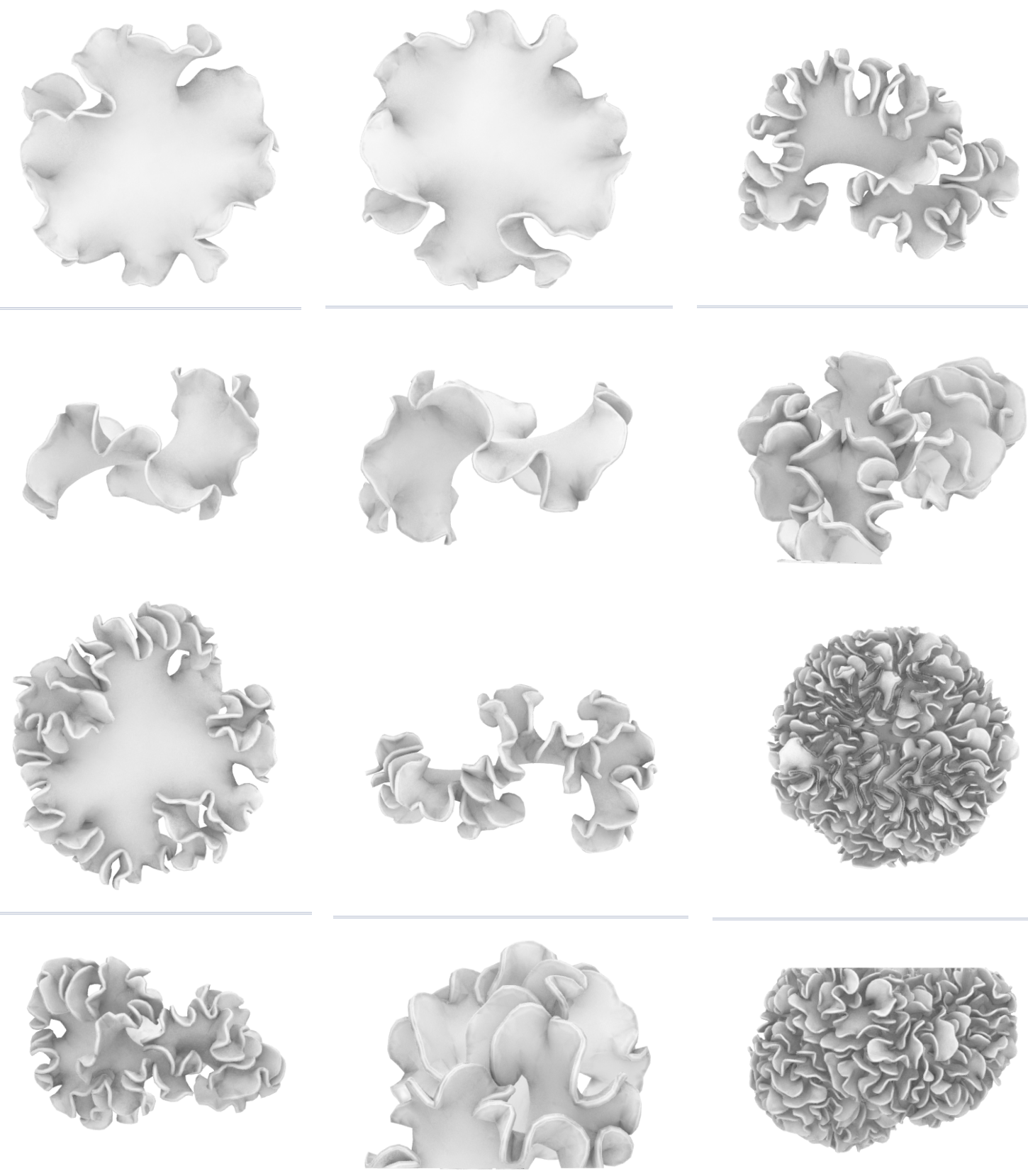

Fig. 46

\section{REFLECTION}

This script created some interesting curves and patterns. The increased level of complexity meant that there were some curved qualities that reflected on some inspiration from the Corinthian column. As it was a similar script to the 'growing sphere' pattern, there were similar limitations to the level of manipulation and customisation able to be made.
Rating of script/method: $6 / 10$

Ease of use: $7 / 10$

Level of customisation: 4/10 

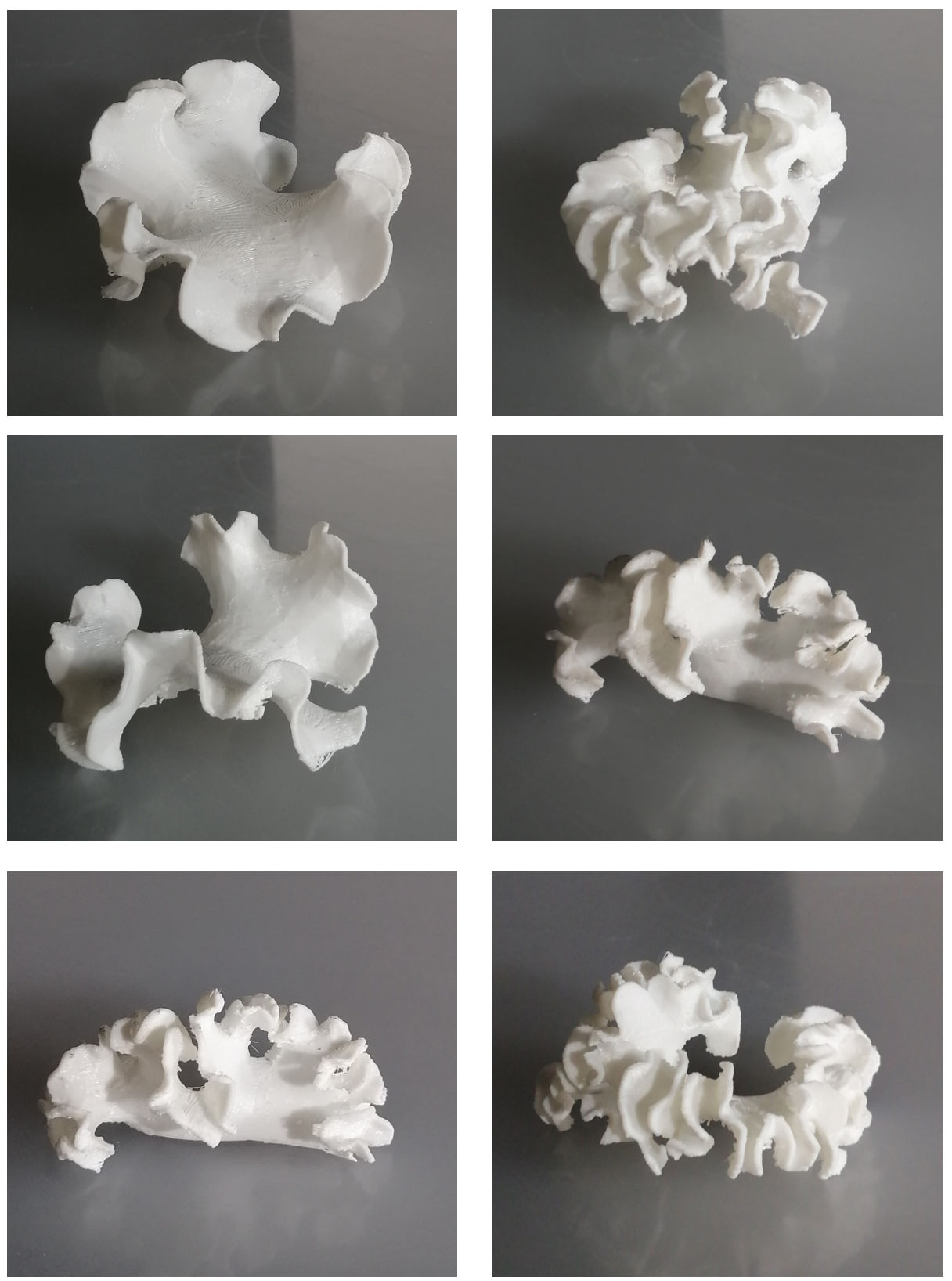

Fig. 47

\section{FABRICATION}

Because of the severe overhangs in these forms and the thin surfaces, these prototypes created by far the most scaffolding, and therefore the most waste. It was clear that although the curvature created some intricate forms, the practicality in the architectural and stability sense was going to be limited. 

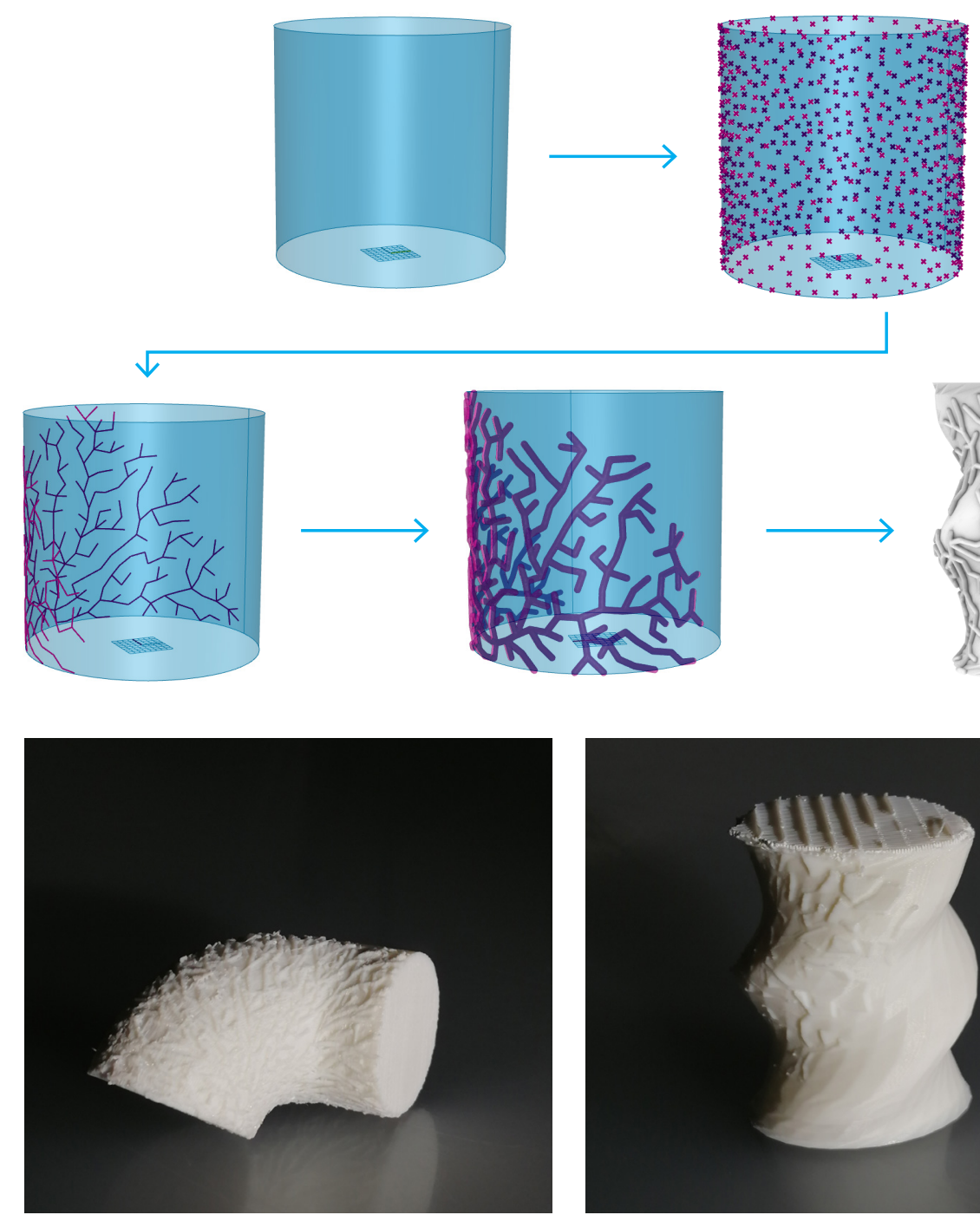

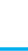
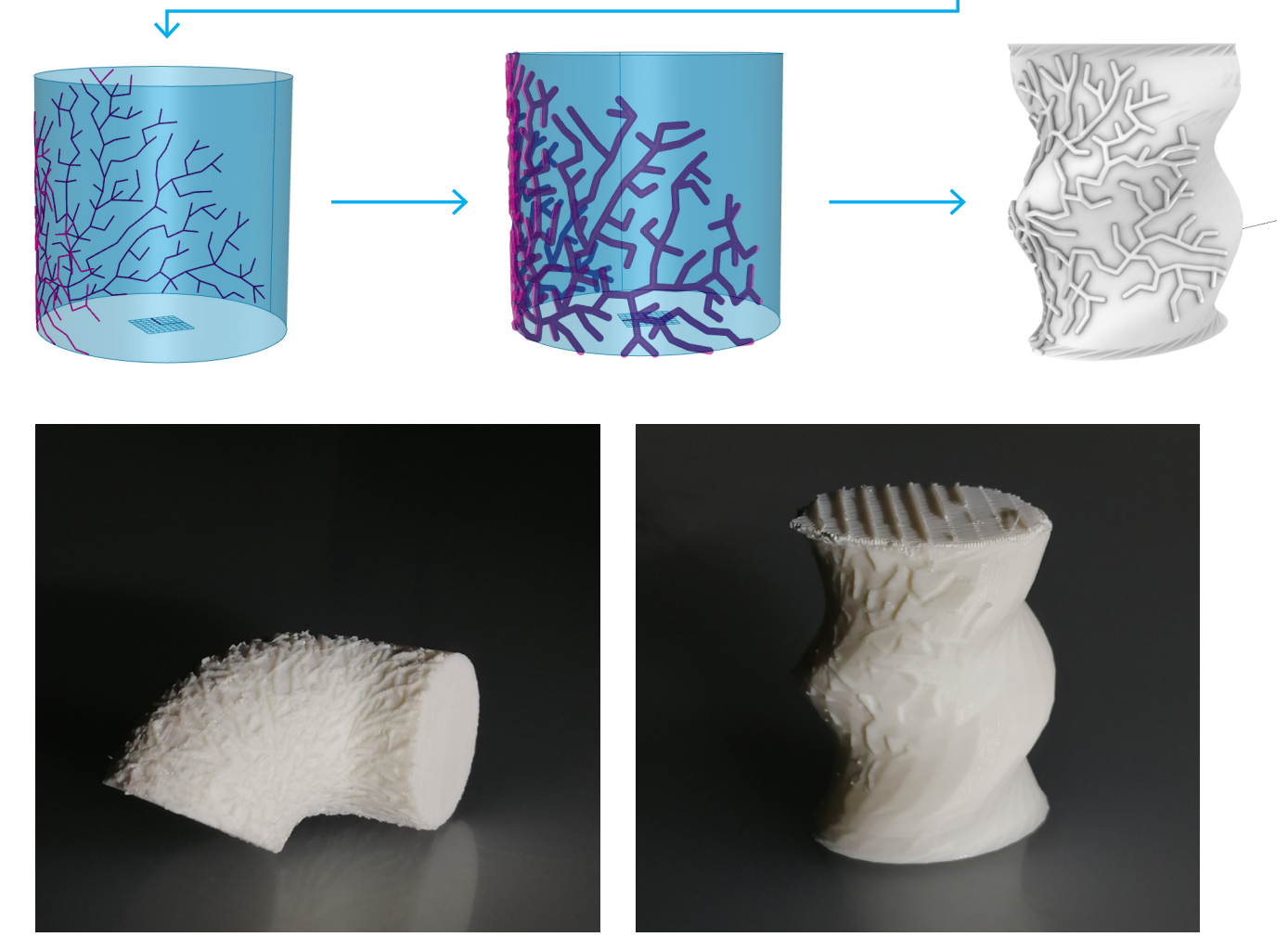

Fig. $48 \& 49$

FABRICATION

Twisting Forms/Venation Patterns - This design series was looking again at influence from the Corinthian column, particularly using a venation pattern applied to a surface, using the 'parakeet' plugin to grasshopper. This created some branch growth patterns that created intriguing surface qualities.

The script was easy to use and adjust, and the growth patterns worked well. Using twisting and rotating tools helped to add interest to the designs. When it came to fabrication however, the shapes were difficult to visualise easily on the
Rating of script/method: $7 / 10$

Ease of use: $8 / 10$

Level of customisation: $6 / 10$ 
3.4.1 FURTHER DIGITAL EXPLORATIONS

- MIXTURE OF FORMS
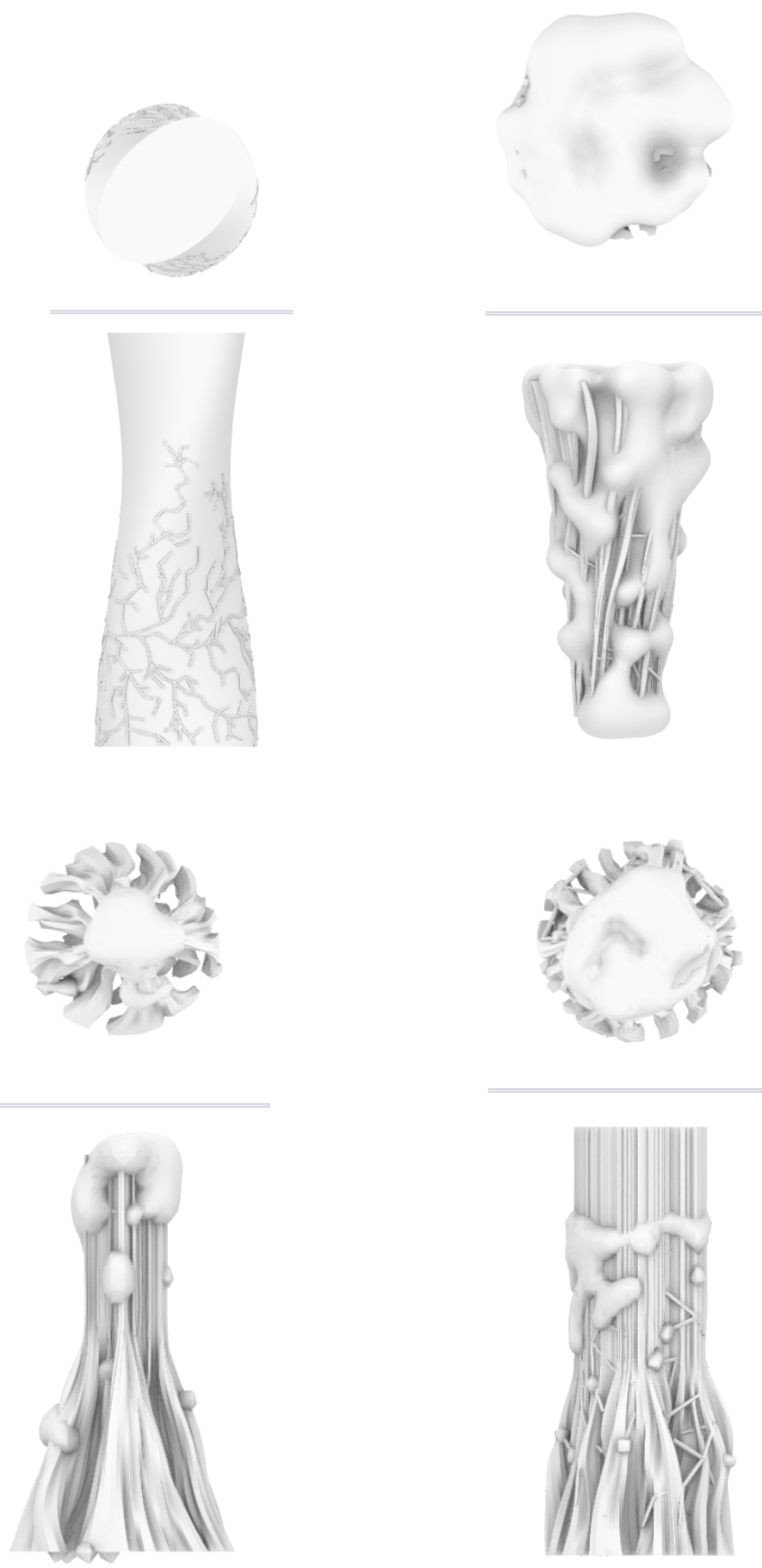


\subsubsection{FURTHER DIGITAL EXPLORATIONS - COCOON PLUGIN}

This series was intended to apply a similar quality to the 'growing sphere' iterations, but adapted with the use of a different extension. By using the 'Cocoon' plug-in, randomised points were used on a base volume to create organic forms. The intention was to create a similar quality, but with more manipulation. The addon was developed by David Stasiuk, and is a straightforward implementation of the Marching cubes algorithm for turning iso-surfaces into polygonal meshes (Stasiuk, 2016). It is focussed towards wrapping existing geometric elements with points, breps and curves, which allows the varying of parameters that enhance sculptural potentials (Stasiuk, 2016).

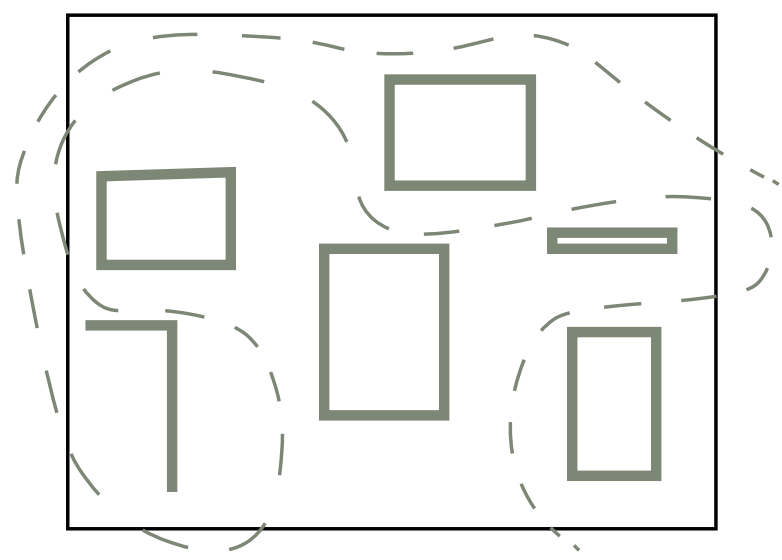

Fig. 51

REFLECTION

Although the script provided more manipulation than the previous spheres, there were a lot of limitations to the quality of the script. Because of the large meshes it created, it created a very slow process, and it was difficult to provide easy and fast iterations. The ideas behind the method definitely has potential, but some adjustments to optimize the usability of the script is needed for it to be successful.
Rating of script/method: $3 / 10$

Ease of use: $3 / 10$

Level of customisation: 4/10 

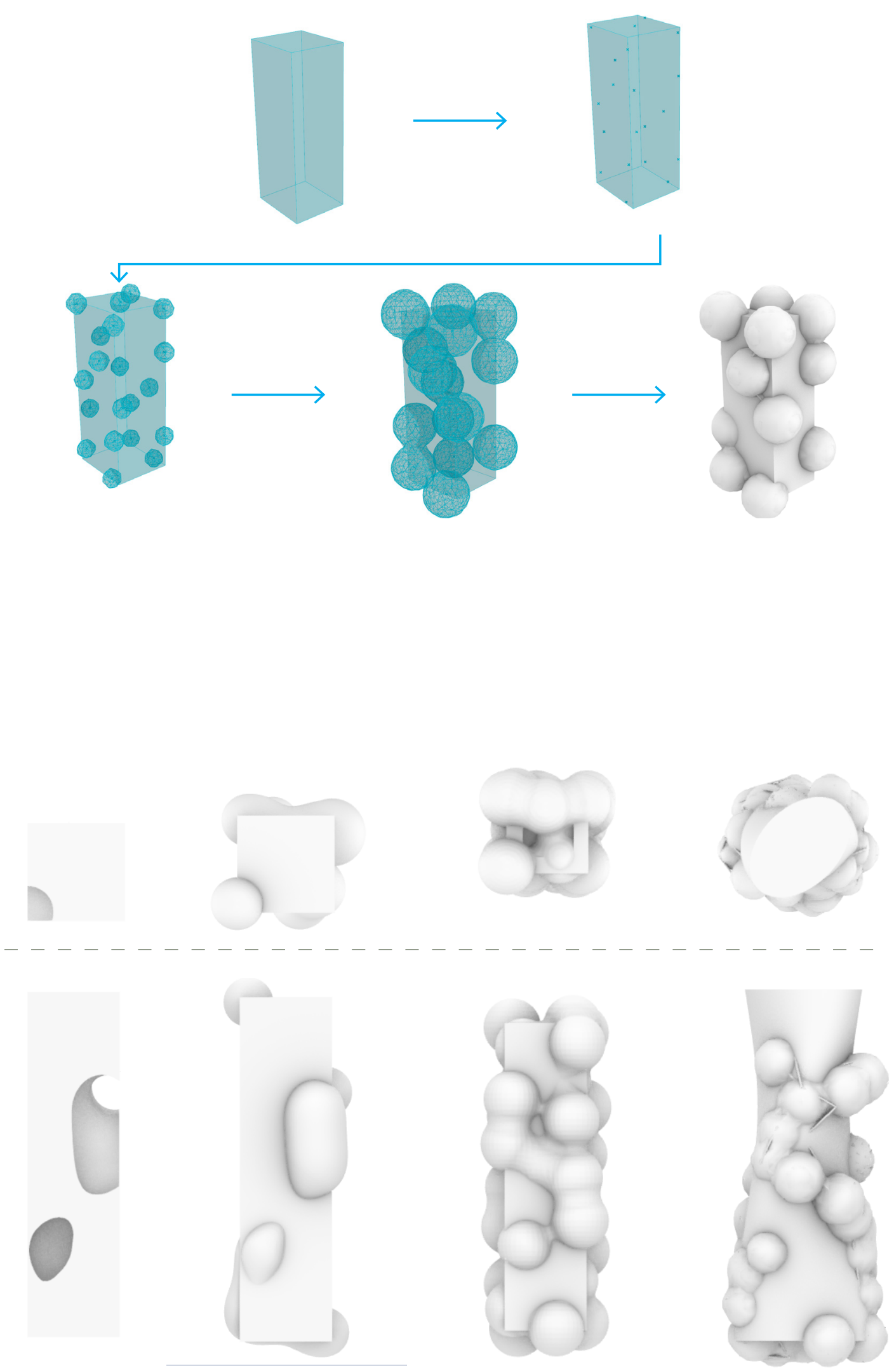

Fig. 52: Digital Process

Fig. 53: Rhino Digital Models 


\section{REFLECTION}

The initial conceptual stage in the research was crucial to understanding the workflow of Grasshopper, and the best methods to achieve different ornamental qualities that fit into a contemporary context. After exploring and testing the different scripts, it was clear that some were much more successful than others, and although some created exciting forms, they were however quite limited with how they were able to be adjusted and adapted, meaning they were lacking in achieving a good level of masscustomisation. Upon reflection, it was clear that it was important to find a balance between finding a script that was not too complicated, whilst still having enough components to be able to adjust and produce new forms from the first model. From each of the different design series, the 'coral' forms created the most successful iterations, with a good amount of variations, as well as level of adjustable components. Although the 'growing sphere' and 'growing disk' forms produced natural forms, they had a lot of limitations in adaptation, and therefore were less effective in achieving the desired research objectives.

The prototyping stage of the designing brought forward some crucial considerations.
A significant factor in the fabrication of these prototypes was the amount of time it took to complete a single print. Some models took 2-3 hours, but most were prints ranging from 1018 hours long, this was particularly true for the coral forms, as they had a lot of detail. Given that these models were small-scale, at about $5 \mathrm{~cm}$ wide, it is clear that using plastic and this process is not going to be suitable when moving to large-scale models - which reinforced some of the findings from the literature in the previous chapter. When moving to large-scale fabrication, it is clear that another material and additive manufacturing process will be more effective for an architectural scale. Another major issue was found in understanding the overhang levels, and the scaffolding requirements. Through this stage it became clear that limiting the wastage created in these models was going to be a key focus in future iterations, which meant that control of the sharp overhangs was needed in order to avoid the need for scaffolding and added supports. This will also become a more crucial consideration when moving into largescale fabrication, as well as when moving to other materials which may not have the ability to allow for scaffolding and supports. 
Fig. 54

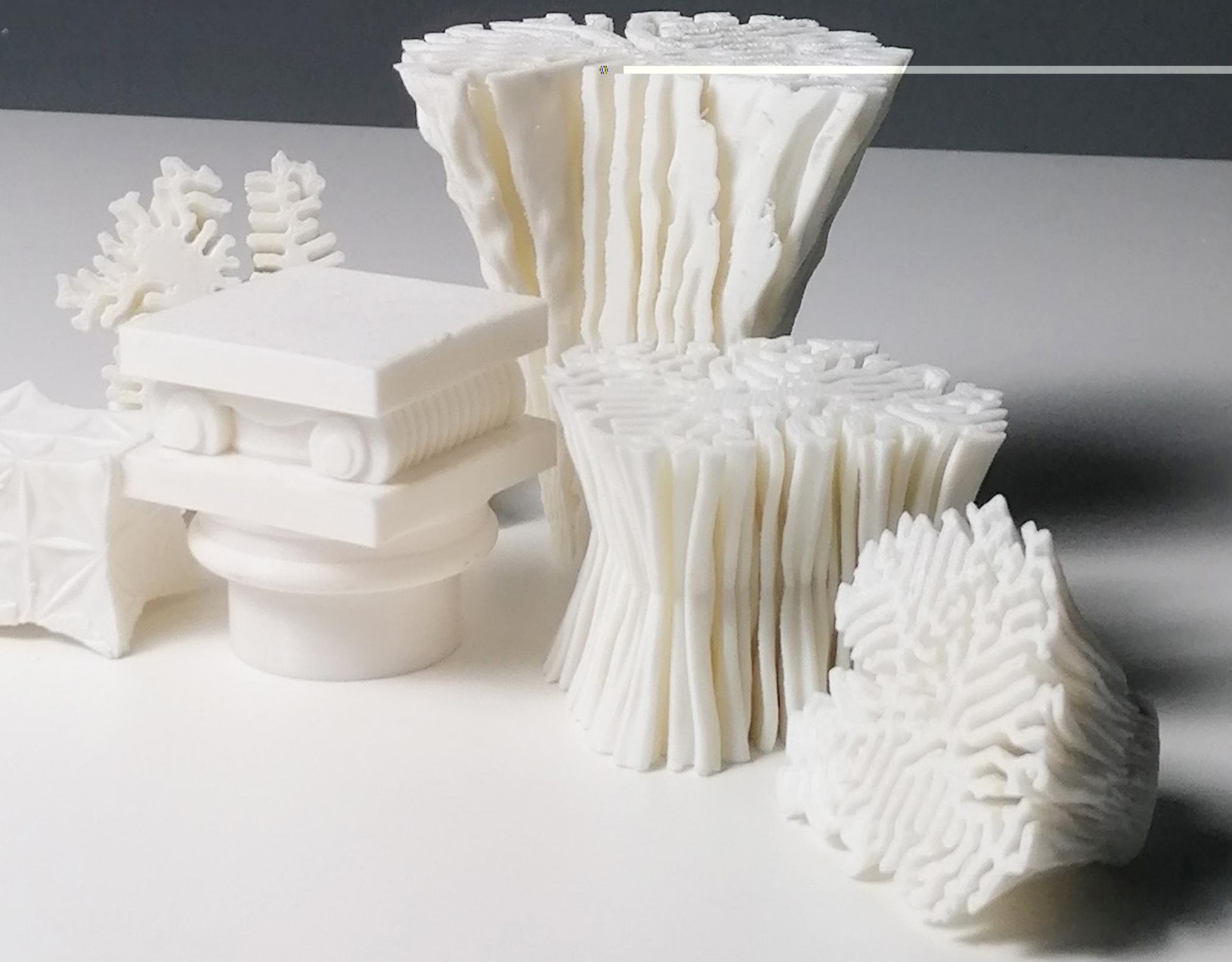




\subsection{INTRODUCTION}

The following chapter focuses on the developed testing phase of this research. By building upon the findings found in the conceptual stage, which included an initial understanding of visual scripting tools and the translation to the fabrication process, this stage works to understand how these ideas can be applied at an architectural scale, using architectural materials. This stage integrates these findings into a more unified design process, translating the small-scale prototypes into large-scale models using a robotic arm and clay extruder. The chapter begins with an analysis of clay printing as a digital fabrication tool, as well as an overview of the process of using robotics to fabricate these models. The various adjustments and design parameters were identified and tested, to develop an effective design workflow. Following a similar iterative process to the conceptual testing, design iterations were produced out of clay to produce larger scale models of columns, and these were again critically reflected on to further refine and develop the research. 


\subsection{CLAY PRINTING}

Clay is a material that has been used in architecture for centuries. It has predominately been used in traditional construction for building unfired walls (Rael \& San Fratello, 2017, p. 97), but has also been used in many other design areas, including ceramics and pottery, and it is now emerging in the digital fabrication industry. Clay has different advantages for being used as a construction material, including it having excellent thermal mass characteristics, fire resistance, and it being relatively inexpensive, widely available, and earth-friendly (Rael \& San Fratello, 2017, p. 97). Recently, the use of clay in the realm of AM has become more and more popular, with larger companies now taking a focus towards providing equipment and software specifically for this, in turn bringing a revitalisation to this traditional material, by combining the environmental benefits, and the extended capabilities that fabrication technology brings.

Although additive manufacturing and 3D-printing have been continually progressing since the 1980s (Hull, 2015, p. 25), it is only in the most recent decade that clay $3 \mathrm{D}$-printing has properly begun to evolve in the architecture and design industry. This is largely regarding the insufficient material properties of the currently used build materials (Gurr et al., 2017, p. 10214). To effectively print a model, considerations regarding the consistency of the material are critical, as it greatly affects the quality of the extrusion process, and therefore the quality of the final product. With clay, the viscosity, colour, and texture; as well as the tools, settings and tool paths are all important variables that have a significant effect on the outcome of the model (Gursoy, 2018, p. 22). The drying time of clay is also greater than materials such as plastic (a matter of days rather than minutes), which creates a risk of fall and collapse problems (3DWASP, n.d.).

"when, layer by layer, we set down fluid dense materials like clay through LDM (Liquid Deposition Modelling) processes, there are some limits due to the geometrics, to the collapses, and to the requirements. In all these cases, the extruded material has a fundamental role in order to get final acceptable results" (3DWASP, n.d.).

Currently, clay 3D-printing is still mainly limited to pottery and ceramics, and there are limited examples of clay printing at an architectural scale. International companies such as Potterbot and World's Advanced Saving Project (WASP) however, are developing their extruders and printers to now become commercially available (Gursoy, 2018, p. 23). These have created not only more accessible tools at a small-scale, but have also resulted in some 3D printed houses, such as the TECLA house (3DWASP, 2019). WASP uses clay extruders to print columns and walls up to twelve feet high, using their BigDeltaWasp printer (Rael \& Fratello, 2018, p. 142). Projects like this bring more sustainable alternatives to construction.

\section{CASE STUDY 3DWASP - Eco-sustainable 3D printed house - TECLA}

The TECLA project consisted of the development and construction of "the first unique fully $3 D$ printed construction based on natural materials and made with multiple 3D printers operating at the same time" (WASP, 2021). The habitat was engineered by WASP and designed by Mario Cucinella Architects (WASP, 2021). This is a clear example of the potential that clay additive manufacturing has at a large scale, showing how the material issues can be overcome to produce successful architecture. 


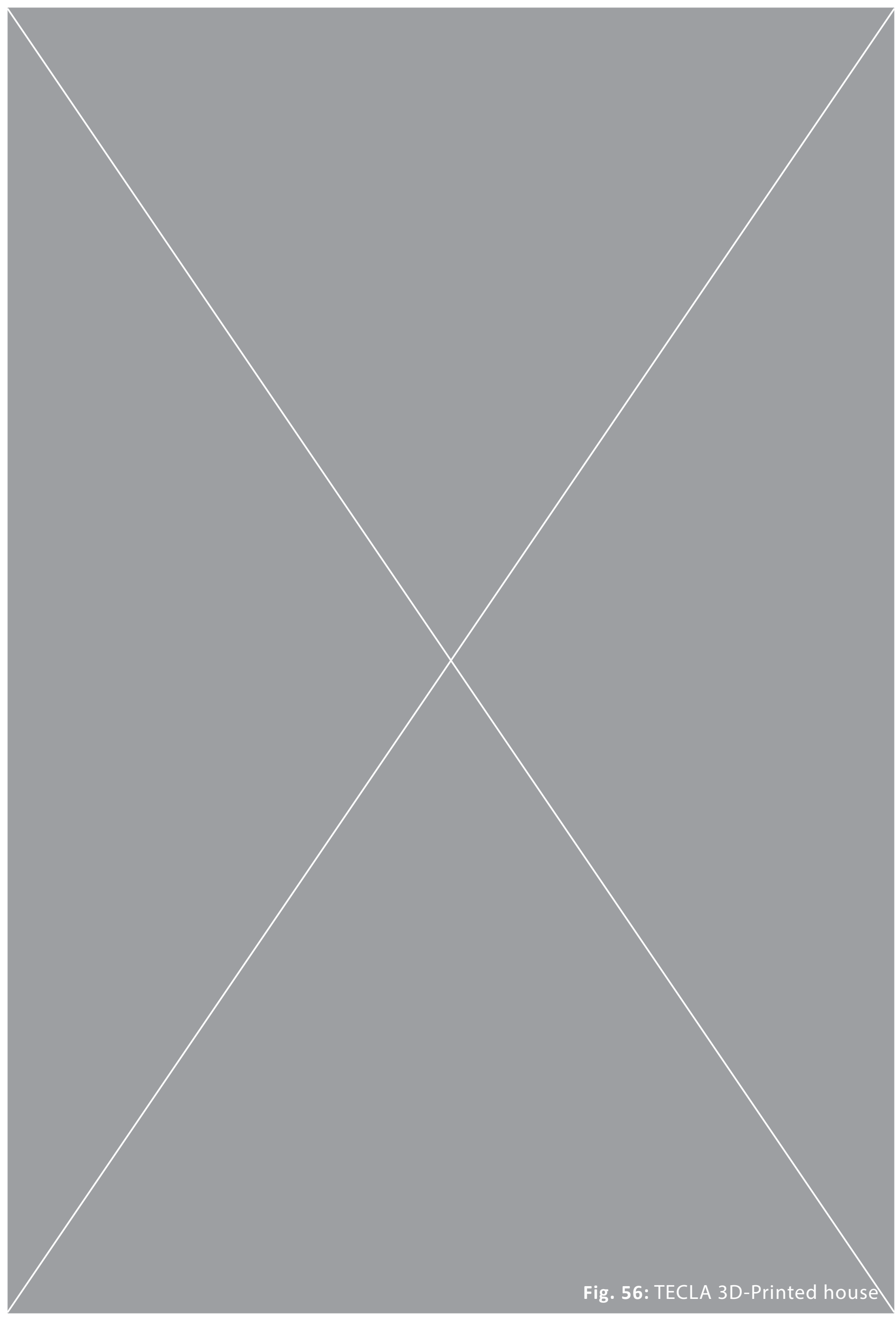




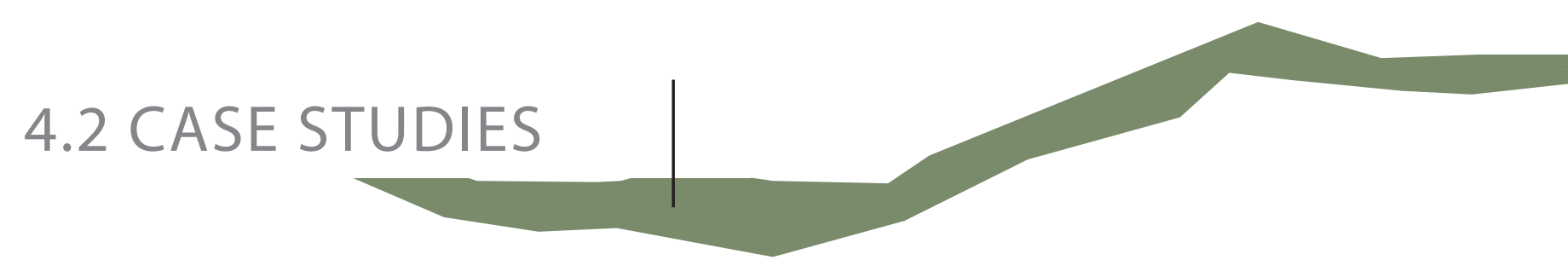

BRIAN PETERS: BUILDING BYTES

"Combining a traditional building material (ceramics) with a new fabrication technique (3D-printing) to rethink an ancient building component (bricks), the Building Bytes project demonstrates how 3D printers can become portable, inexpensive brick factories for largescale construction" (Peters, 2014, p. 113).

This is an ongoing research project of the development of 3D-printed ceramic bricks, using a standard desktop 3D-printer (Peters, 2014 , p. 113). The research project includes the investigation of different material characteristics and fabrication techniques, as well as the development of the use of Grasshopper during the fabrication process (Peters, 2014, p. 114). 


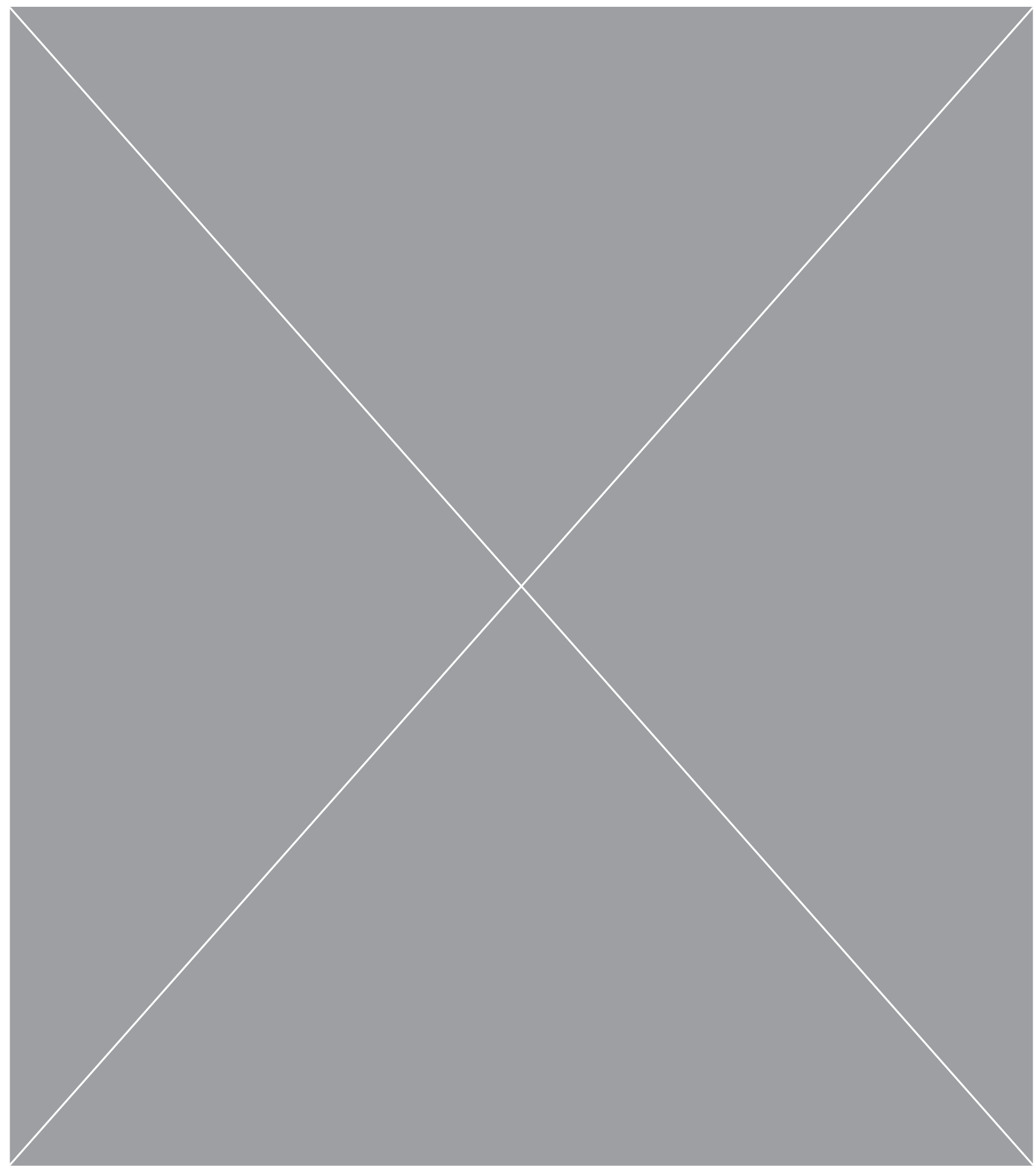

Fig. 57: Building Bytes ceramic bricks 


\subsection{ROBOTIC FABRICATION}

The post-graduate workshop and robotic studio at Victoria University of Wellington contains an ABB IRB 6700 Robotic Arm. With the variety of tool attachments available, it is capable of completing a large quantity of different additive and subtractive methods. Whilst its usage has primarily been focused on the use of research regarding subtractive methods, such as milling and sawing; recently in 2019 the attachment of a PotterBot extruder, and associated hybrid closed loop stepper motor meant that it could be used for additive manufacturing processes as well. The attachment of this has meant that the robotic arm can effectively work as a largescale clay 3D-printer, with the ability to print in a much larger area than with a standard desktop 3D-printer - with the benefits of added control and precision. 


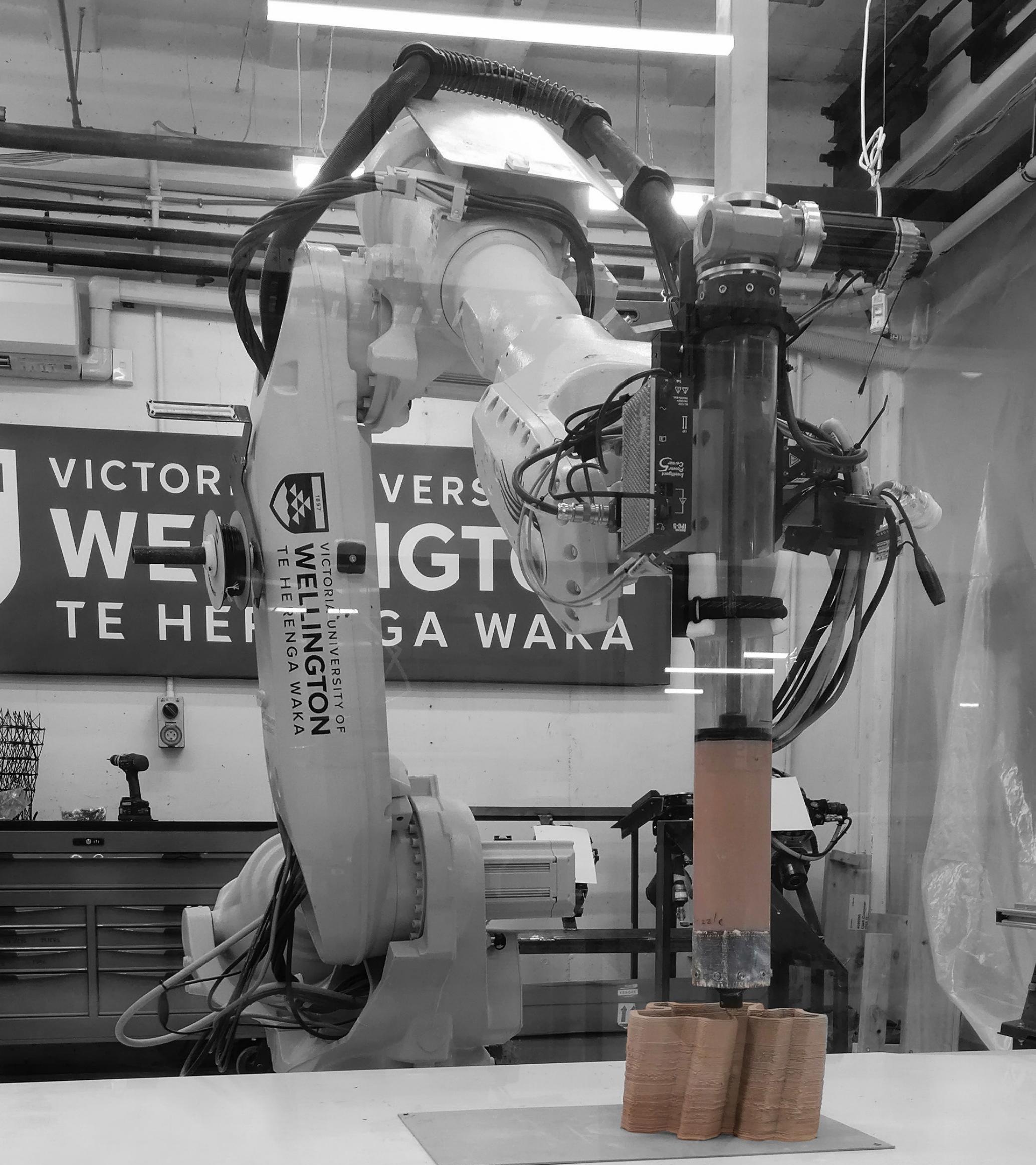

Fig. 58: ABB Robotic Arm \& Clay Extruder at Victoria University 


\subsection{FABRICATION PROCESS}

In order to begin the printing process, there is a number of steps required in order to prepare the material and tools for fabrication. This includes:

\section{PREPARING THE CLAY}

This preparation includes mixing the clay with a small amount of water, in order to get the material to an effective consistency that will flow smoothly through the extruder and nozzle. Although the PotterBot is designed for the use of real clay, some small modifications are still required. The mixing of this requires a process of adding water, and then using a drill to blend the material together to the correct consistency.

\section{LOADING THE CLAY INTO THE EXTRUDER}

This requires a process of manually packing the clay into the poly-carbonate tube, ensuring the clay is packed in tightly with as minimal air bubbles as possible, to ensure smooth extrusion during printing.

\section{SCREWING THE COMPONENTS TOGETHER}

This requires the attachment of the nozzle, as well as the motor and syringe. The syringe needs to be drilled down to ensure there is suitable pressure in the tube for printing.

\section{CONNECTING THE MOTOR \& EXTRUDER TO THE ROBOTIC ARM}

For the extruder to work with the robot, the motor needs to be attached and plugged in to the robotic arm, by completing a tool-change. The extruder itself is then attached to the motor, strapped in and then the correct wires are connected to allow for the two components to work together. 

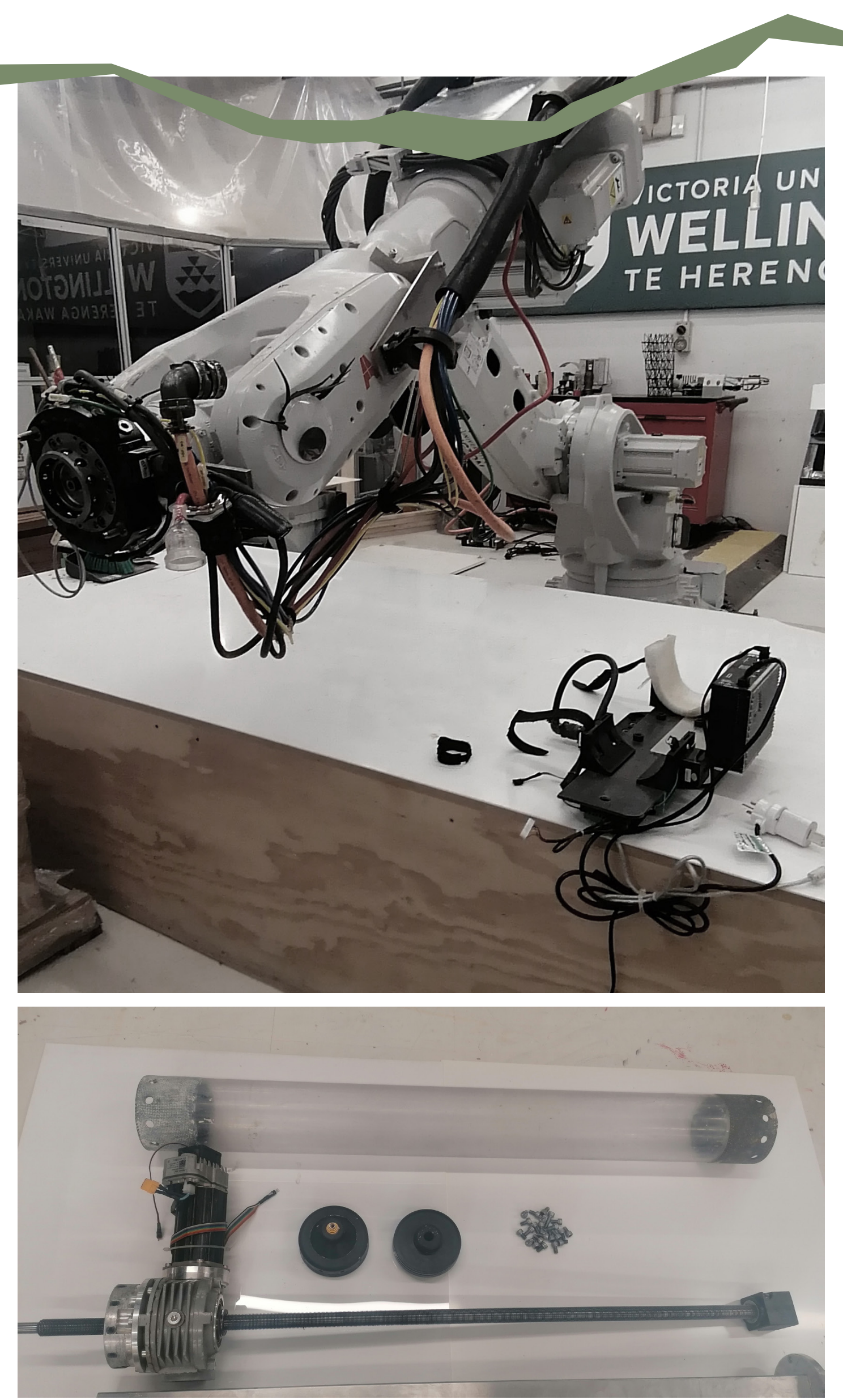

Fig. 59: Robotic Arm \& Clay extruder attachment Fig. 60: Clay extruder parts 


\subsection{SCRIPT ORGANISATION}

For the Robotic arm to be able to successfully print the model, RAPID code needs to be generated for the robot to understand the correct toolpath to follow and the extrusion. This is achieved by using Grasshopper, alongside the HAL Robotics plugin. This Grasshopper script takes the desired digital model and then follows a process of slicing it into a series of contours, which are then divided into a number of vertices that determine the path that the robot will follow. Parameters such as the height of the table and the rate and speed of extrusion are also defined in this script. The results are then exported to RAPID code and then loaded onto the controller for the robotic arm to be ready for printing. 


\subsection{PRINTING DESIGN ITERATIONS}

This stage of the research was focussed on becoming familiar with the fabrication process of robotics and clay extrusion, as well as the material qualities and parameters associated with them. Because this stage not only involves increasing the scale of the model but also changing the material, various new limitations and parameters needed to be identified and adjusted accordingly.

As with the conceptual stage, each model was given a description and rating, as well as a listing of any adjustments that needed to be made to improve the printing quality and process. These tests included the consistency of the clay, the printing speed, the extrusion rate, and the nozzle sizing.

Because the use of clay in the printing process meant that scaffolding and support were unable to be printed, this eliminated some of the previous tests that were unable to be produced during this stage, such as the 'growing disk' series, which was too impractical to be reproduced in clay. Some other models and their associated scripts had to be adjusted to accommodate for the much larger nozzle size and therefore some simplifications in the overall form in some cases were needed. 


\subsubsection{PRINTING DESIGN ITERATIONS}

This series was based on the 'coral growth' script from the previous chapter. By adjusting the scripts, the models were scaled up, and adjustments including the spacing between the curves were made in order for the model to be suitable to be printed.

Fig. 61-62
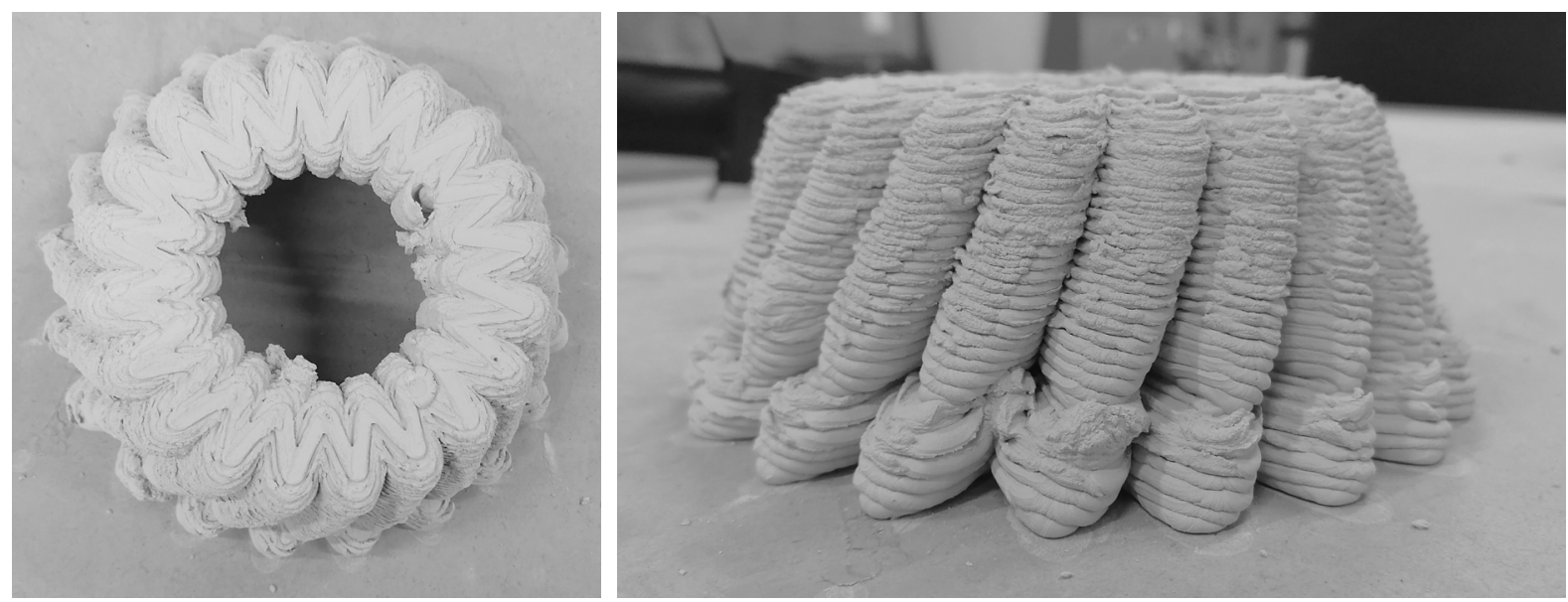

ITERATION ONE

Design Description: Rotating zig-zag pattern

Qualities being tested: Distance required between each curve, failure angle for overhangs.

Fabrication Issues: There were gaps in the clay extrusion, the overhang angle meant there was slumping because of the weight of the clay. The speed meant there was lumping of clay in parts.

Adjustments Needed: The speed of the robot needed to be increased and the extrusion rate of the clay needed to be reduced to allow for a smoother flow. The rotation angle needed to be reduced to prevent the slumping.

Effectiveness of Print: $3 / 10$ 
Fig. 63-64
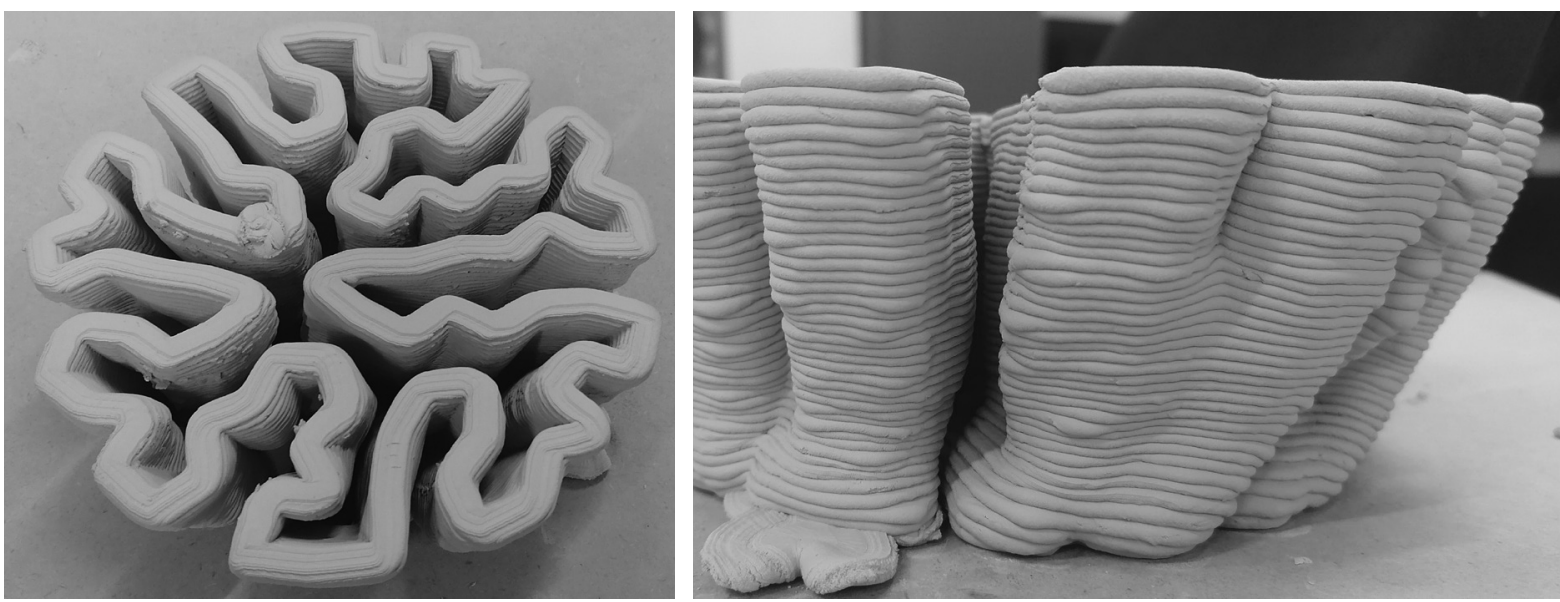

ITERATION TWO

Design Description: Coral form

Qualities being tested: Level of detail able to be produced, spacing needed between curves.

Strengths: Printed reasonably accurately, there were no errors in the extrusion and speed.

Fabrication Issues: A small amount of slumping occurred in the areas of large overhangs. The large amount of lines meant that only a limited height was able to be produced.

Adjustments Needed: Be cautious with the overhang angle, and adjust the way the model is divided in the script - divide by distance within the grasshopper script so more prints are able to be created.

Effectiveness of Print: $6 / 10$

Comments: Limitations recognised in how much code the robot can take per print, need to simplify the script down further in order for the model to print higher. 

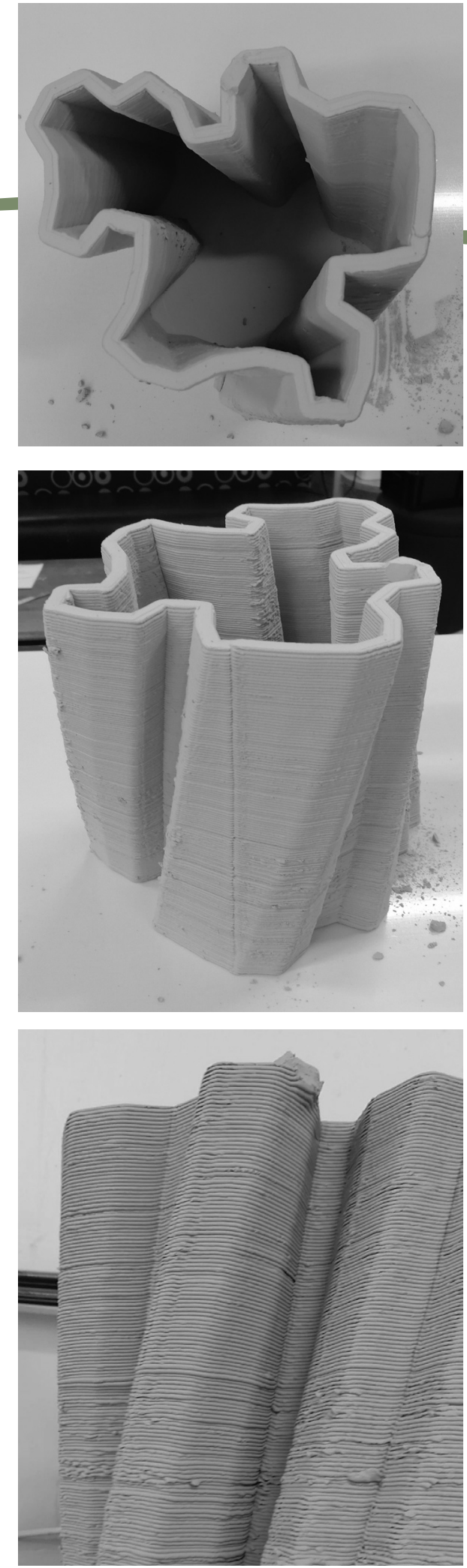

\section{Design Description:}

Geometric twisting form

Qualities being tested:

Stability when scale is increased, effectiveness of detail when printing at a larger scale.

\section{Strengths:}

The file exported and printed well with few issues. The model held together with the added weight of the layers of clay, and the overhang was not too much to cause any slumping.

\section{Fabrication Issues:}

Because of the added weight of the clay, the layers were squashed down thinner, so any errors or faults in the clay prints were more noticeable.

\section{Adjustments needed:}

A faster extrusion rate of the clay in order for the layers to be thicker.

Effectiveness of print: 7/10

\section{Comments:}

The print itself was successful, it was more the aesthetic qualities that were causing issues. Thinking about the visual properties of the individual layers would be important for the design of future prints. 

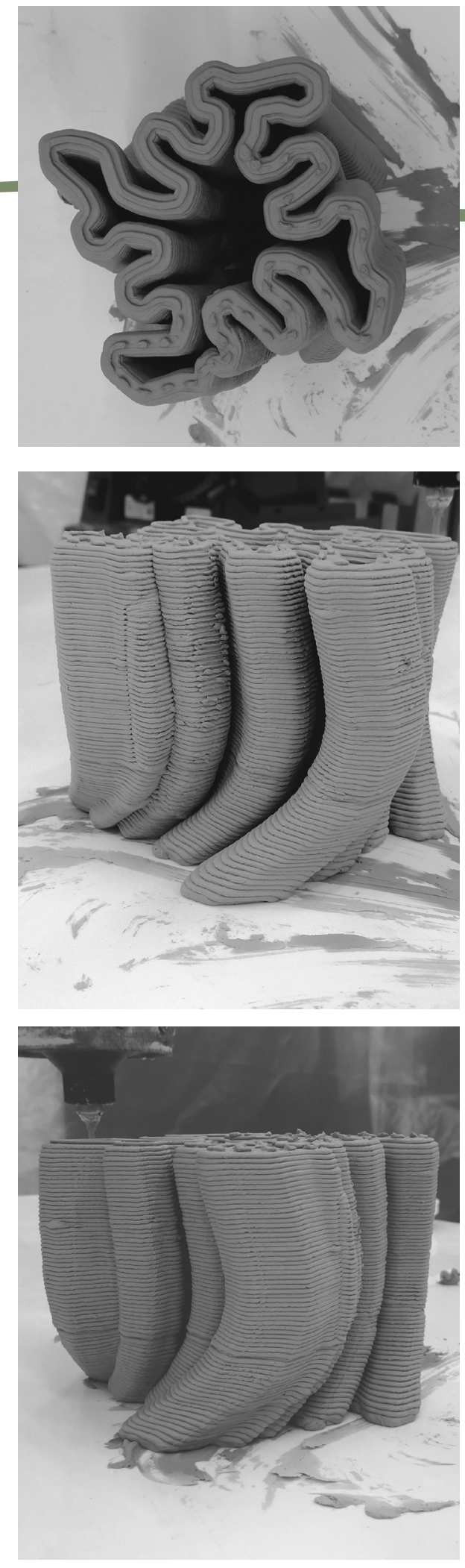

Design Description:

Organic twisting form

Qualities being tested:

How well the curves work with overhangs

\section{Strengths:}

Visually, the design was effective, the curves added interest to the form and worked well with the lines of the horizontal layers.

\section{Fabrication Issues:}

No huge errors in the fabrication of the model, there was some slumping, but that worked well from a design point of view overall

\section{Adjustments needed:}

Slightly less of an overhang angle to ensure structure will hold itself together.

Effectiveness of print: 8/10

Fig. 68-70 

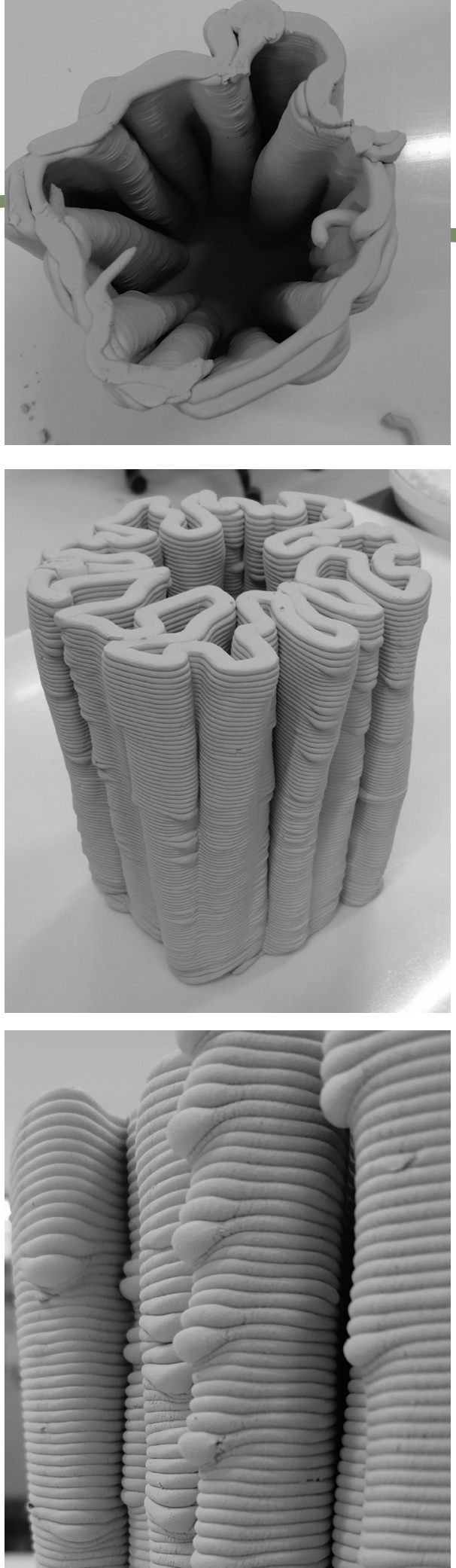

Design Description:

Organic twisting form II

Qualities being tested:

Increased level of curves in form.

\section{Strengths:}

The print overall worked well, however the detail and interest was still focused on the top which would be hidden if it were in a building context.

\section{Fabrication Issues:}

There were some issues in a bit of lumping in some of the clay

\section{Adjustments needed:}

The speed of the clay printing reduced to reduce clumping issues.

Effectiveness of print: $6 / 10$

Fig. 71-73 


\section{FABRICATION ERRORS}

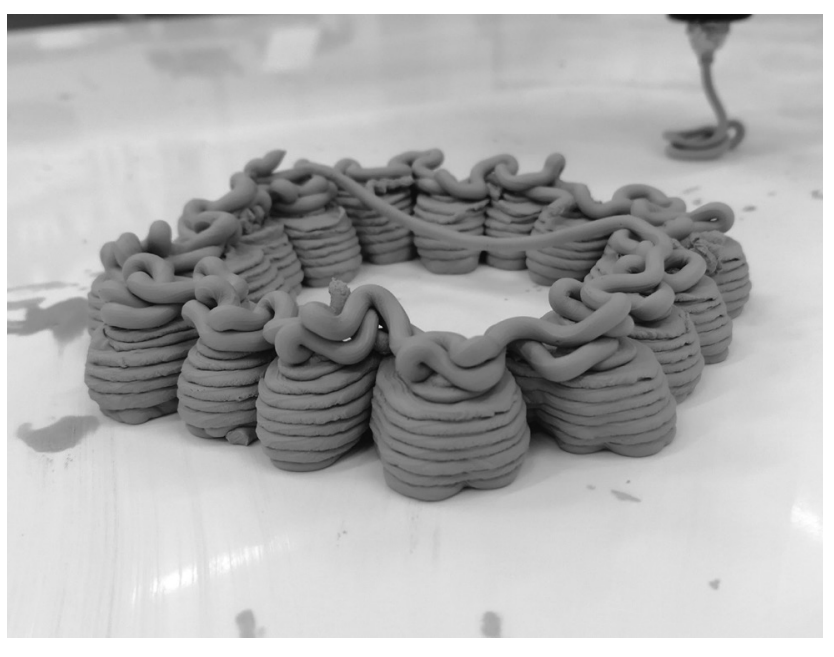

\section{Error Description:}

Nozzle size too large for the resolution of the print - needed a smaller diameter, or to print at a larger scale.

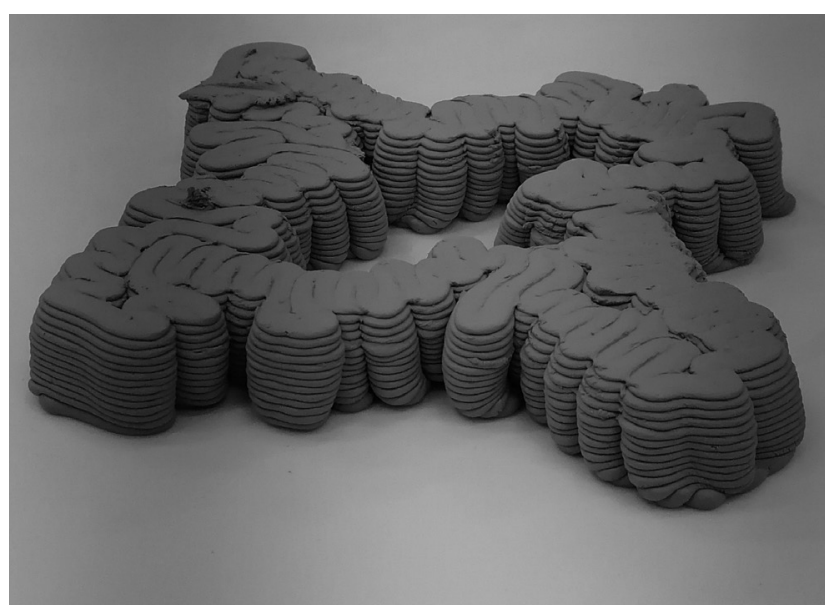

ERROR TWO

\section{Error Description:}

Layer height too small - needed to be adjusted in script, and speed needed to be decreased.

Fig. $74 \& 75$ 


\subsubsection{PRINTING DESIGN ITERATIONS}

This design series used a 'noise mapping' script to create a bumpy surface texture. For this series, the emphasis was focused towards enhancing the horizontal extrusion lines found through the clay. By using this surface texture, a slumping effect was able to be created on the models.

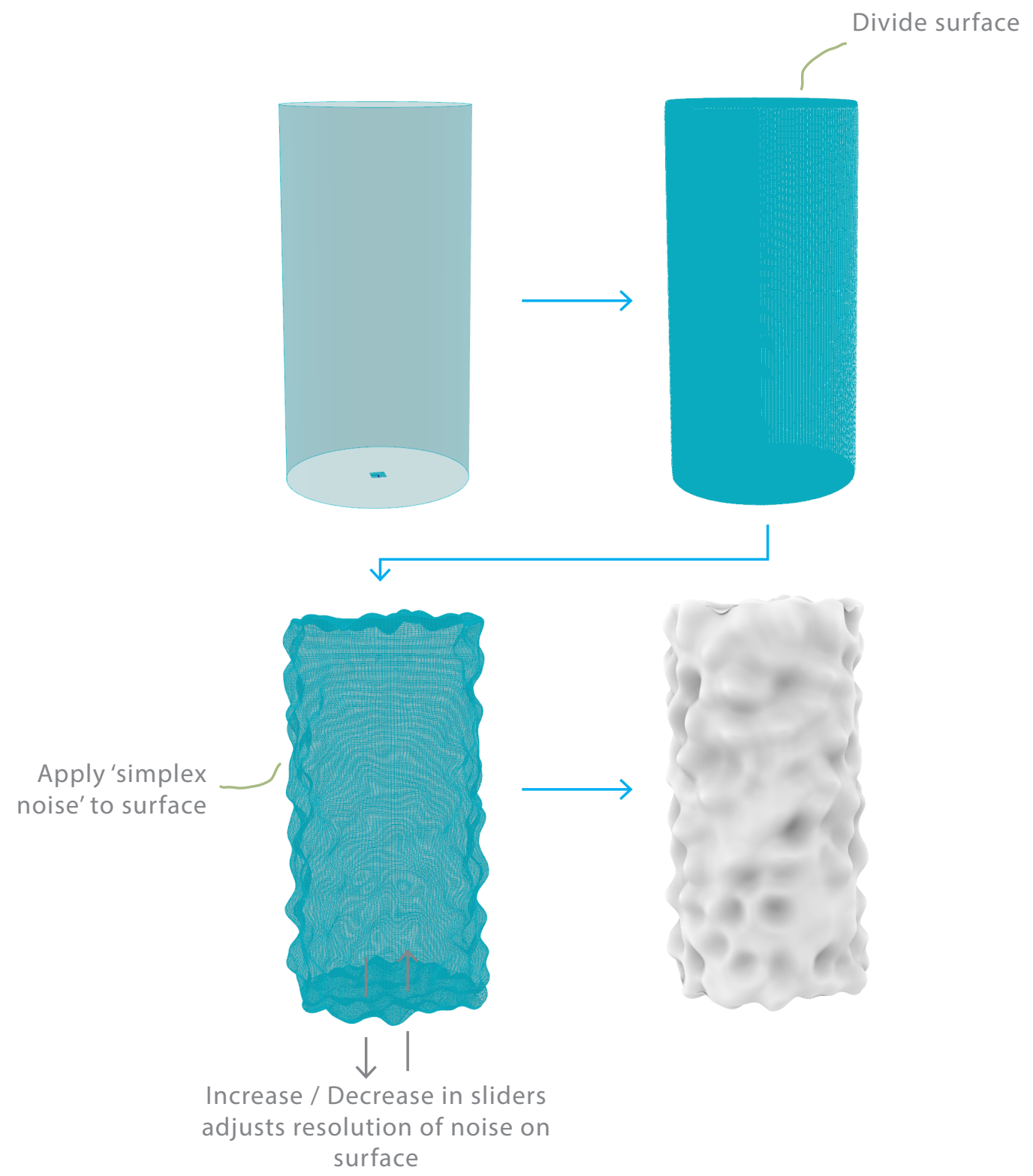

Fig. 76: Digital Process 


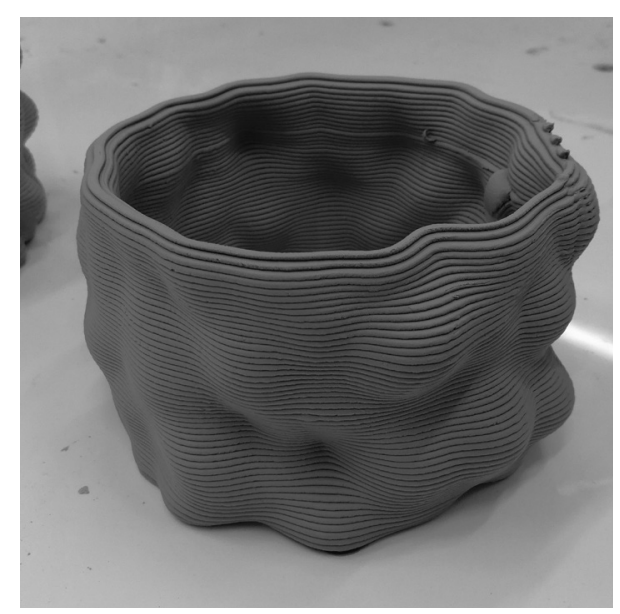

Design Description:

Noise mapping I

Qualities being tested:

Design effectiveness

\section{Strengths:}

Using this design style created an effective design result. The shadows and curves created through the script had interesting design aesthetics, and the model held together well.

\section{Fabrication Issues:}

No major errors

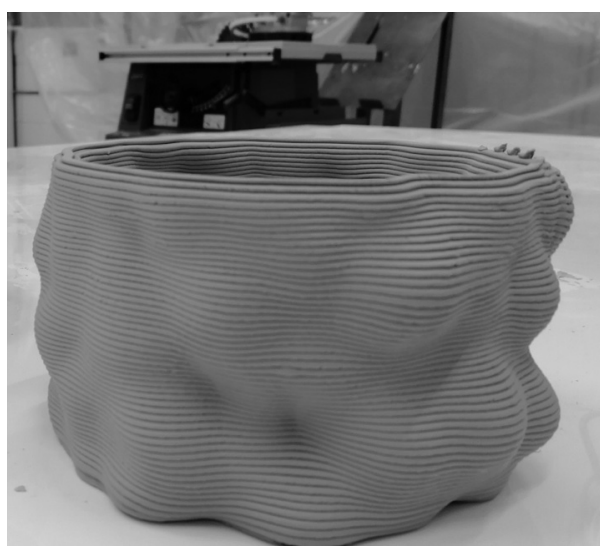

Adjustments needed:

Adjustment to the design to reduce the harsh seam line in the model could be useful.

Effectiveness of print: 8/10

Fig. 77-78 

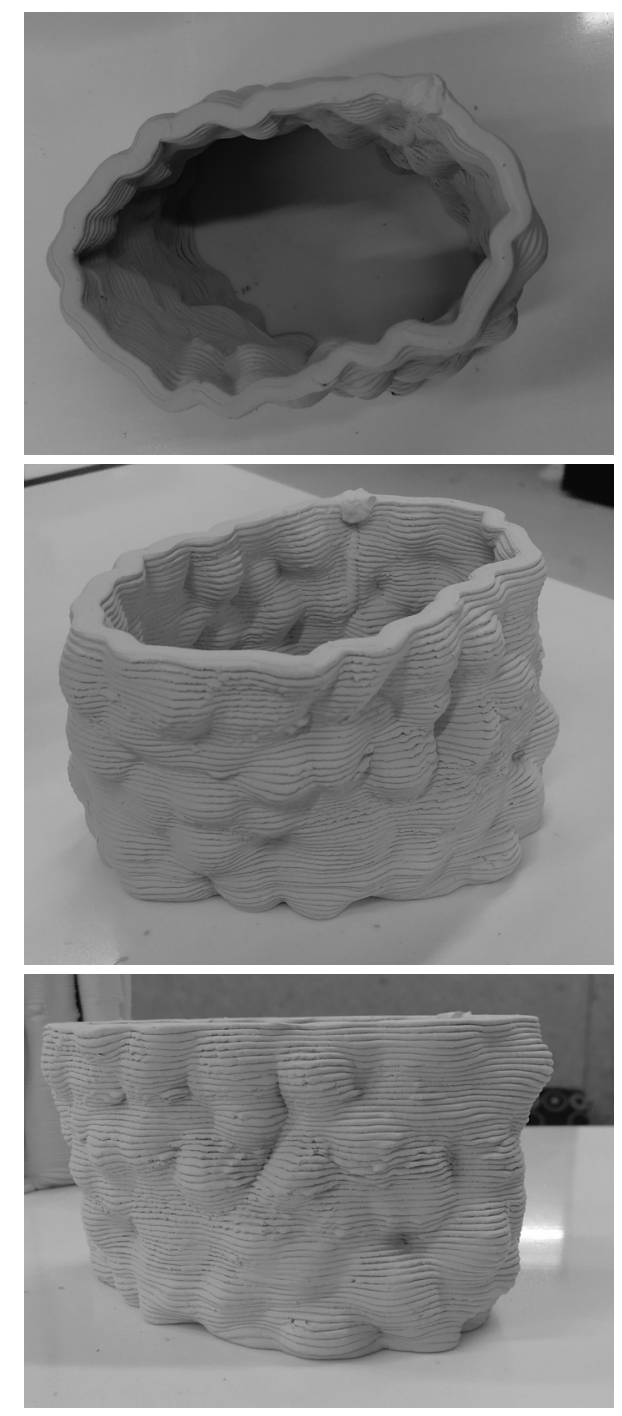

Design Description:

Noise mapping III

Qualities being tested:

Twisting the form

\section{Strengths:}

Worked successfully

Fabrication Issues:

No major errors

Effectiveness of print: $8 / 10$

Fig. 82-84 


\subsubsection{PRINTING DESIGN ITERATIONS}

To further explore the concepts of weaving from the Corinthian column, as well as the qualities of the clay, this design series used a sine/cosine curve script, alternating with each layer to create a weaving pattern on the column.
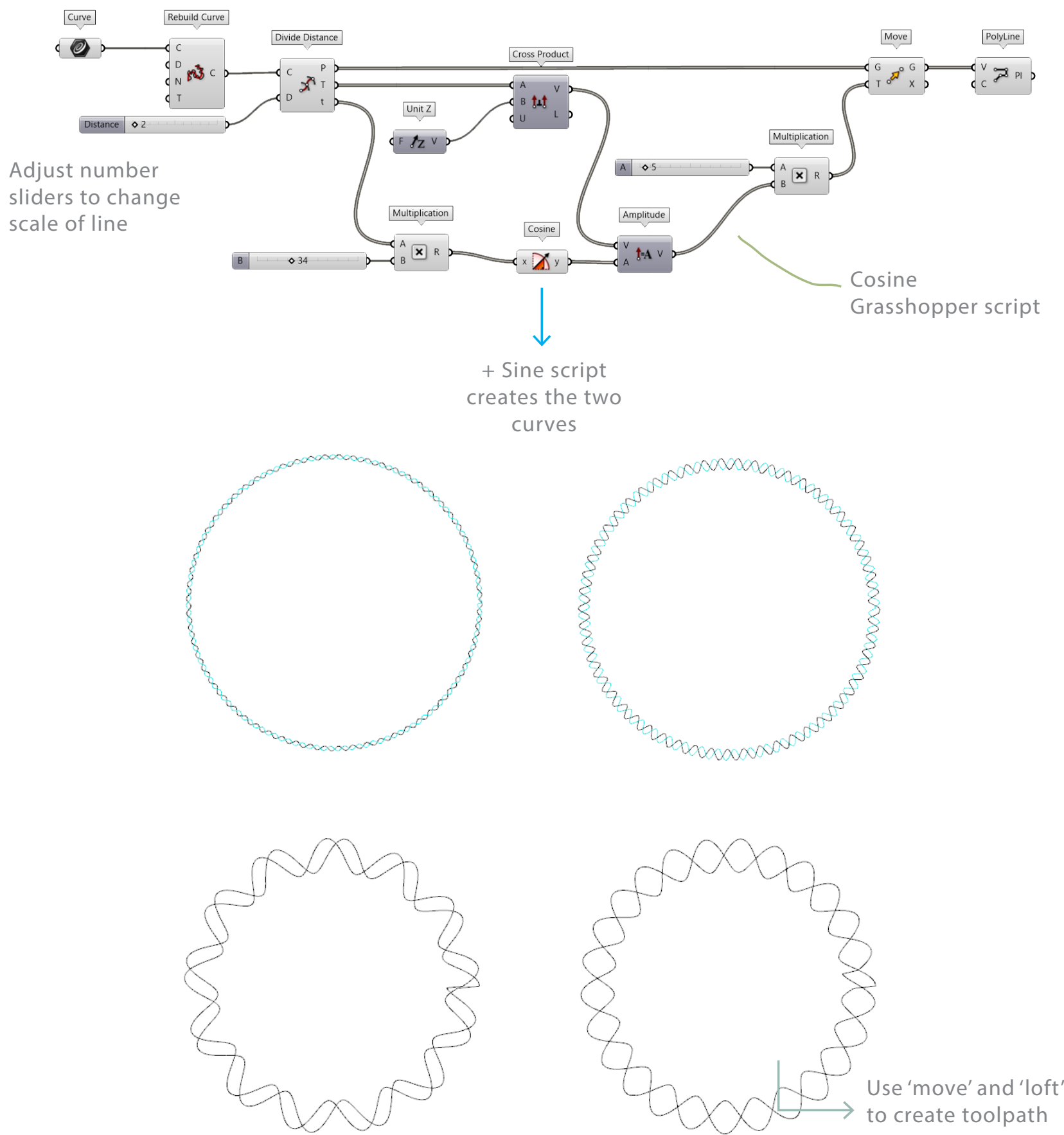

Fig. 85: Portion of Grasshopper script \& Digital Process 


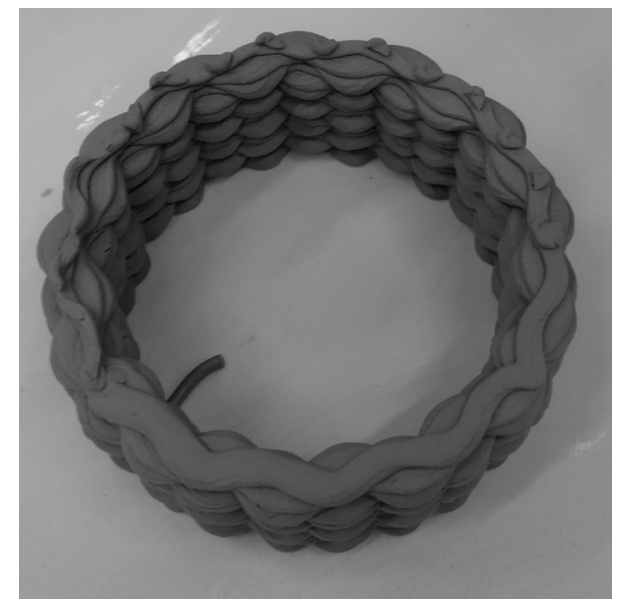

\section{Design Description:}

Sine /Cosine Weaving I

Qualities being tested:

Testing effectiveness of the layering/weaving quality

\section{Fabrication Issues:}

Too much of a distance between the two curves, so too much slumping

\section{Adjustments needed:}

Making the spacing between the curves smaller.

Effectiveness of print: $4 / 10$

\section{ITERATION ONE}
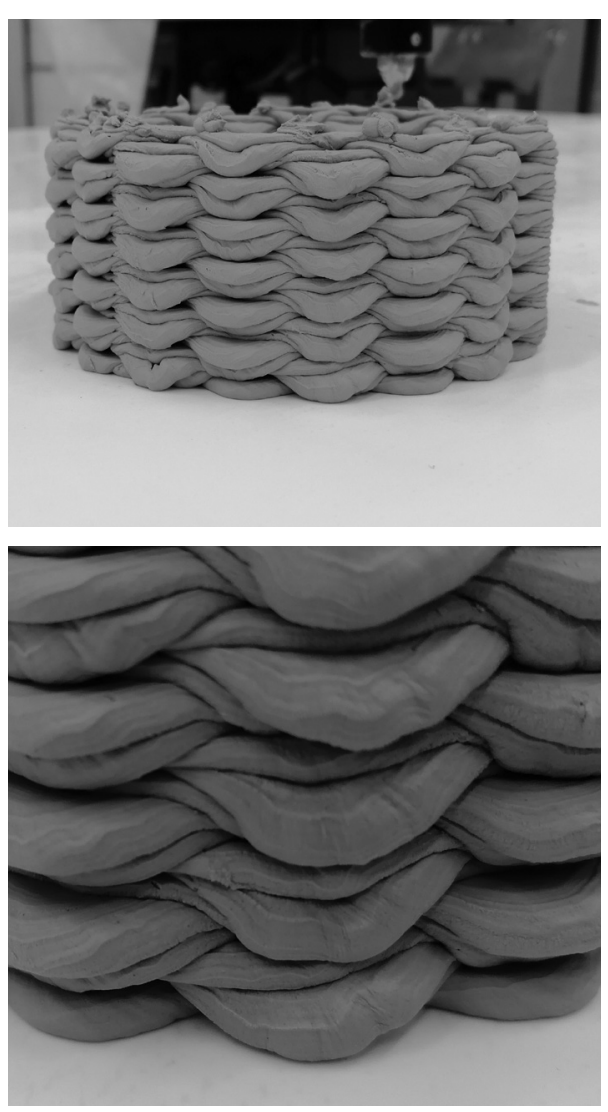

Design Description:

Sine /Cosine Weaving II

Qualities being tested:

Testing effectiveness of the layering/weaving quality

\section{Fabrication Issues:}

Too much of a distance between the two curves, so too much slumping

\section{Adjustments needed:}

Making the spacing between the curves smaller.

Effectiveness of print: $3 / 10$

Fig. 86-88 

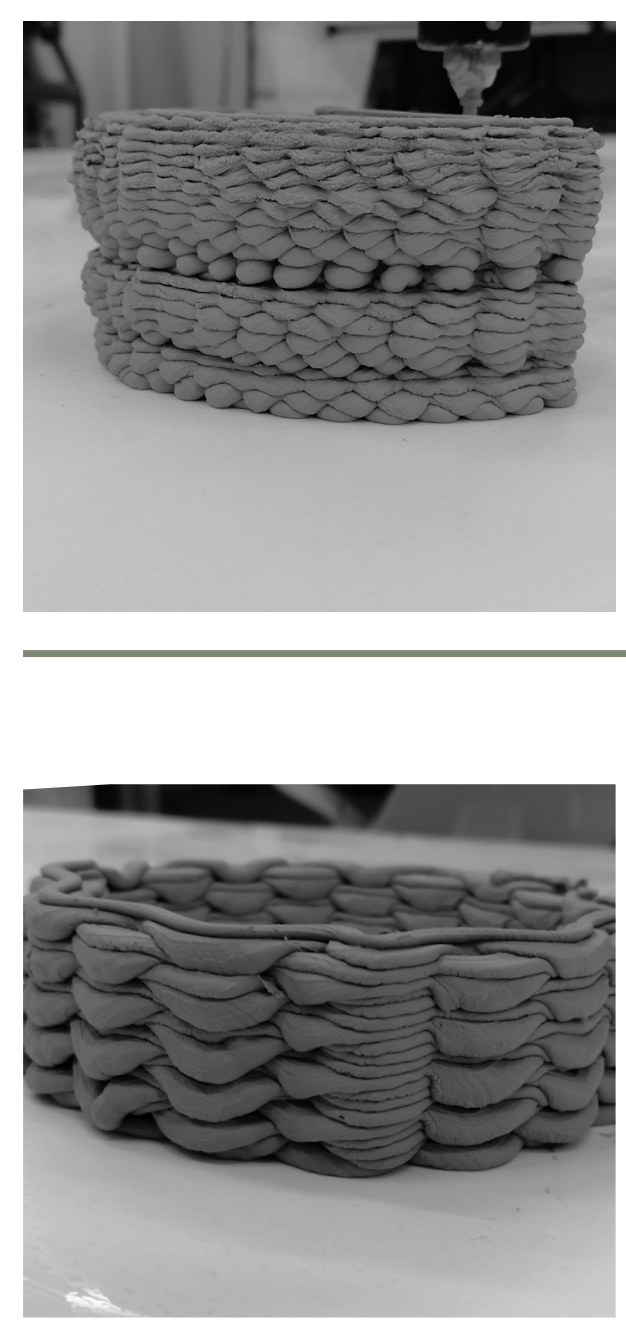

Design Description:

Sine /Cosine Weaving III

Qualities being tested:

Testing effectiveness of the layering/weaving quality

\section{Fabrication Issues:}

The scale of the pattern was too small so the print did not print evenly

\section{Adjustments needed:}

Increasing the width of the spacing to allow for smoother extrusion.

Effectiveness of print: $2 / 10$

\section{ITERATION THREE}

\section{Design Description:}

Sine /Cosine Weaving IV

\section{Qualities being tested:}

Testing effectiveness of the layering/weaving quality

\section{Fabrication Issues:}

The width between the sine + cosine curves was too high, therefore weaving effect was not as successful

Adjustments needed:

Reduce the width between curves in script

Effectiveness of print: $3 / 10$

Fig. $89-90$ 


\section{FABRICATION ERRORS}

\section{ERROR ONE}

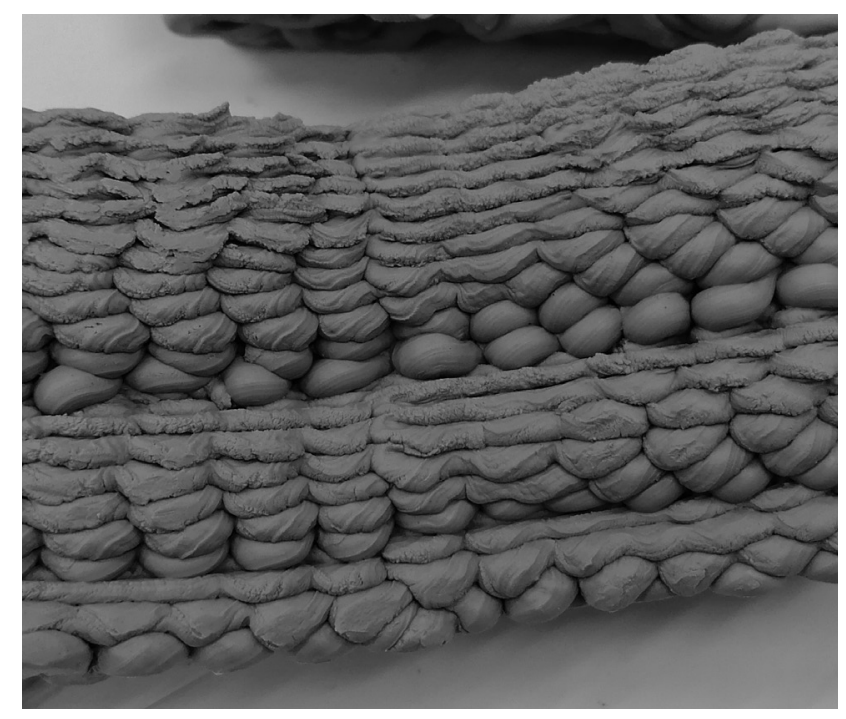

Error Description:

Nozzle too large for small scale of pattern.

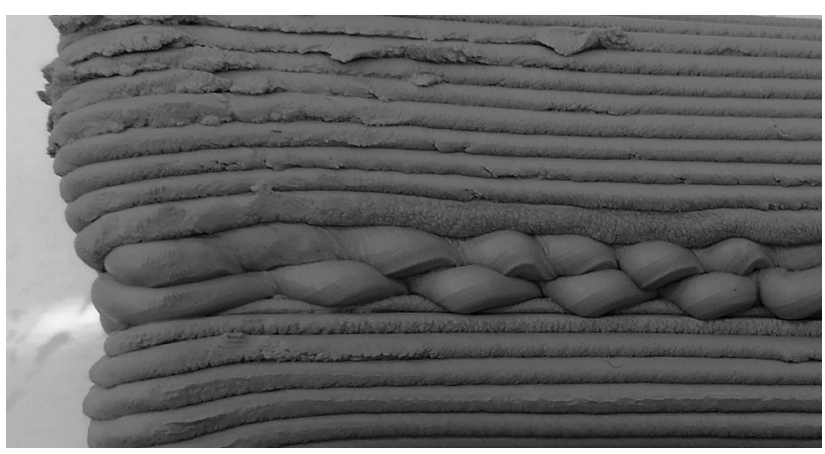

ERROR TWO

Fig. 91-92

\section{Error Description:}

Curves too small to show cleanly in print. 


\subsubsection{PRINTING DESIGN ITERATIONS}

Continuing from ideas from the Corinthian column, and the ideas of the wicker basket from the Corinthian story, this script was a way of replicating that idea onto a surface. A cylinder acted as the base surface, and a line pattern was applied to the curved surface and used to morph the surface. This also used the 'kangaroo 2 physics' plugin in the process.

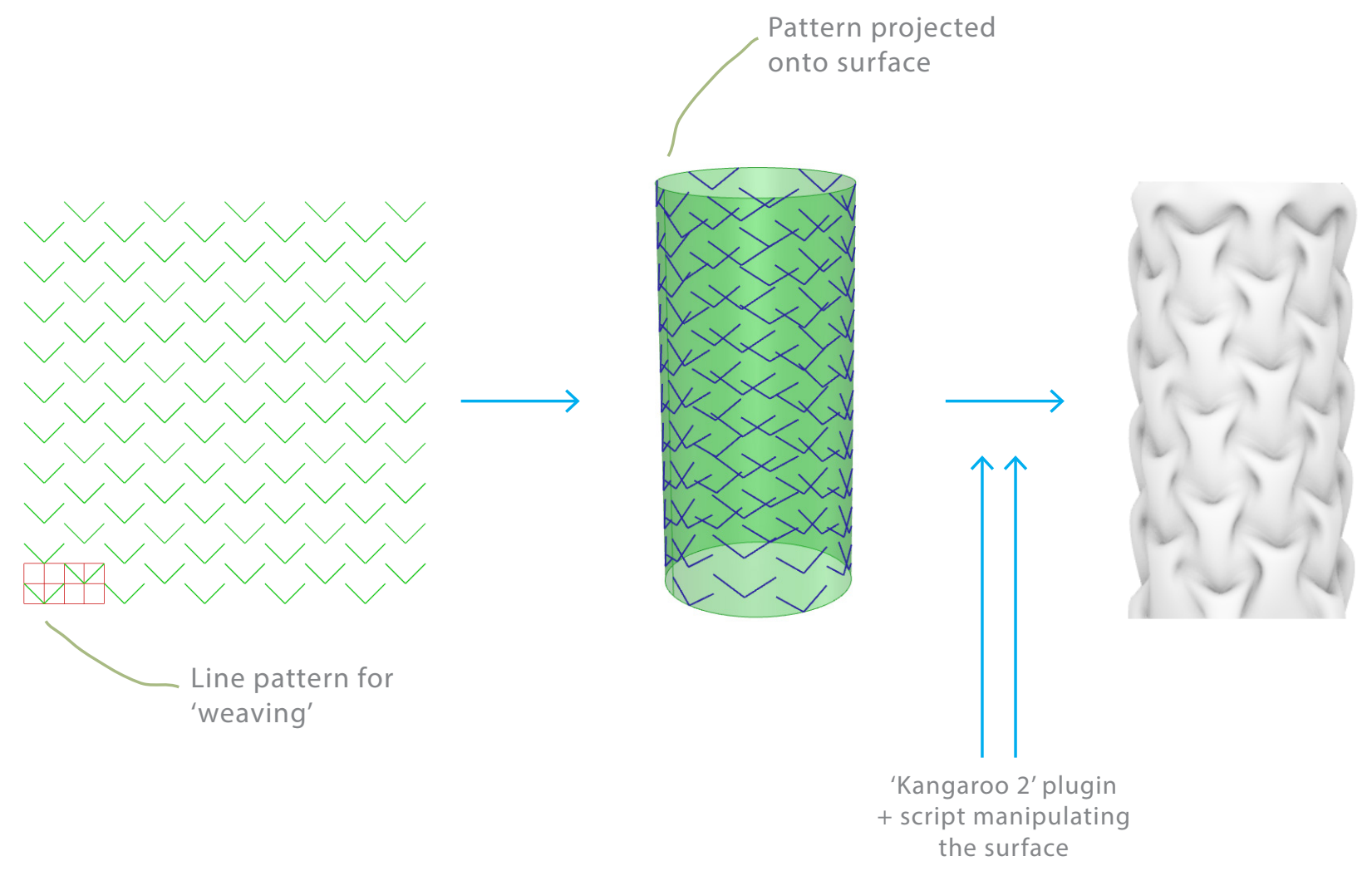

This script had a lot of complicated elements to it, which made it difficult to adjust easily without the model failing. When the adjustments worked correctly however, the weaving patterns on the surfaces worked successfully. 

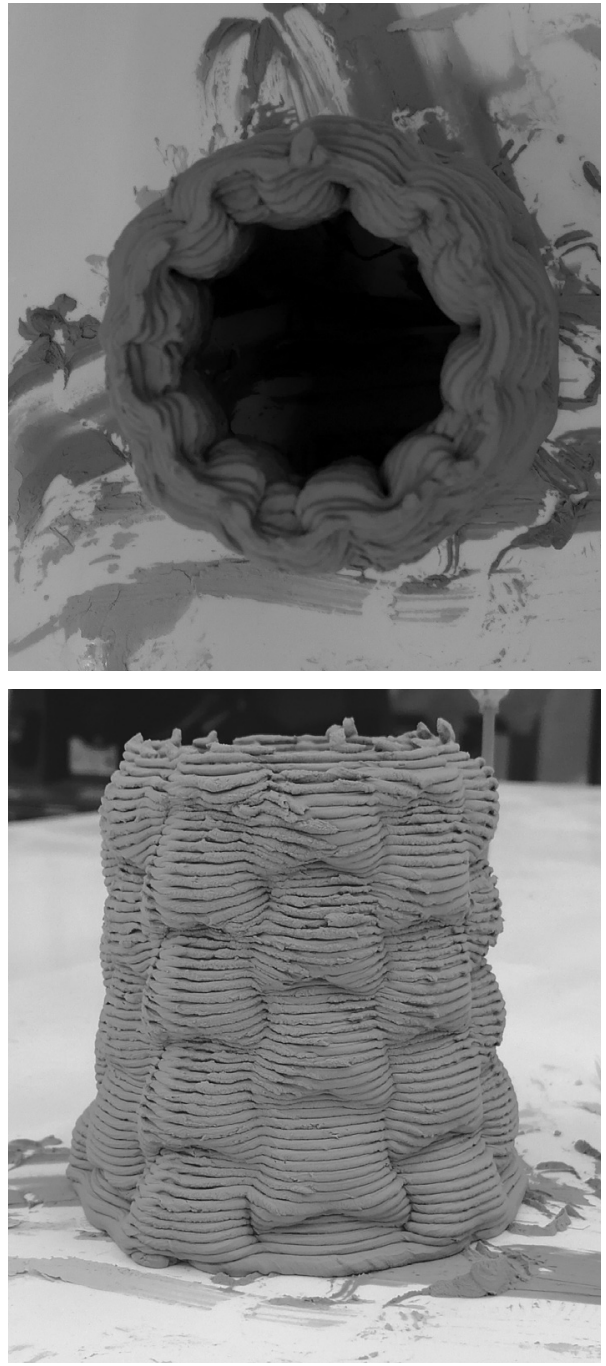

\section{Strengths:}

Printed successfully, created interesting weaving quality that looked nice on the surface.

\section{Fabrication Issues:}

Because it was printed at a smaller scale there was a little bit of lumping.

\section{Adjustments needed:}

Increasing the scale of the print or decreasing the nozzle size.

Effectiveness of print: $7 / 10$

Fig. 94-95 

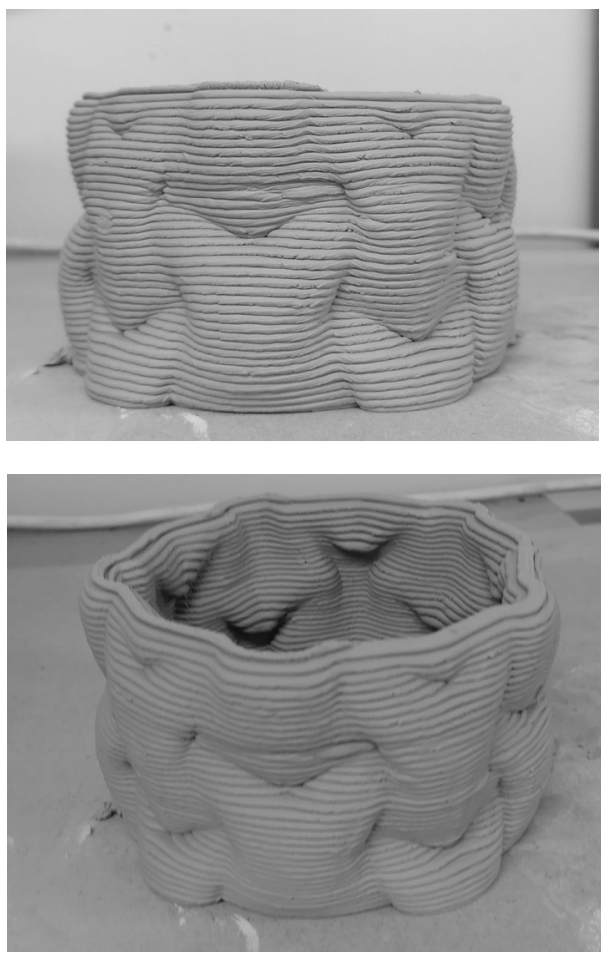

\section{Strengths:}

Printed successfully, the lines came out really clean and there were no errors in any of the extrusions.

\section{Fabrication Issues:}

The level of curves in the surface meant the RAPID code became too large, so the size had to be limited

\section{Adjustments needed:}

Reduce the resolution to the points to produce a larger model.

Effectiveness of print: 7/10

Fig. 96-97 


\section{FABRICATION ERRORS}

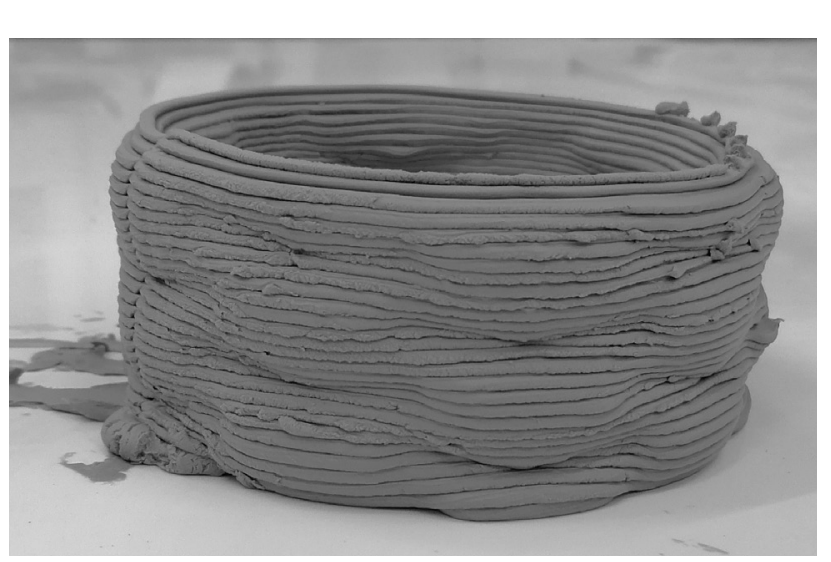

\section{Error Description:}

Clay too watery, slumping occurred

ERROR ONE

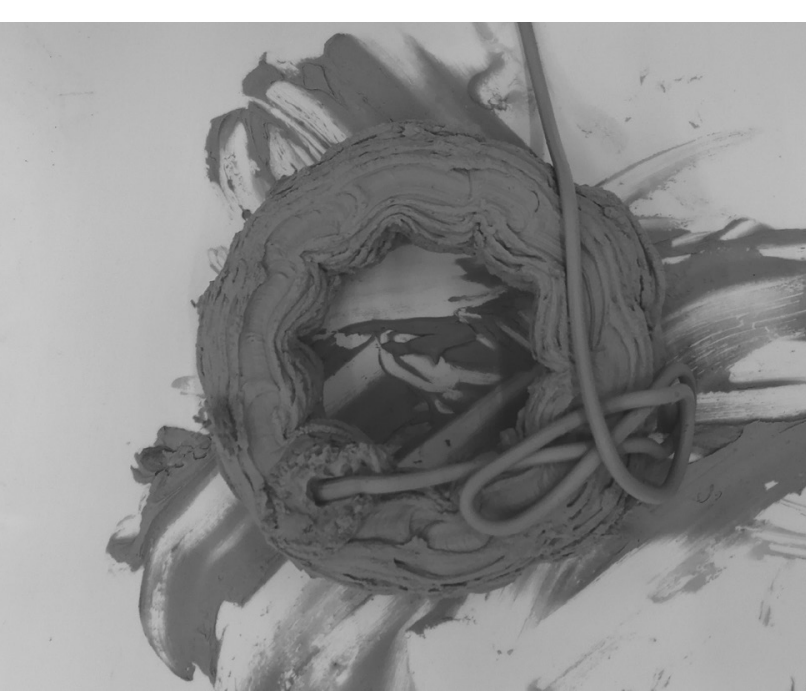

\section{Error Description:}

Nozzle too large, dragging occurred in printing

Fig. 98-99

\section{ERROR TWO}




\subsubsection{PRINTING DESIGN ITERATIONS}

This series was looking to achieve similar surface qualities to the designing in comparison to noise mapping design iterations, however with more control over the texture qualities. To do this, a script using an image sampler was used, which extruded out various points on a cylindrical surface according to the levels of black and white in the sampled image mapped to it.

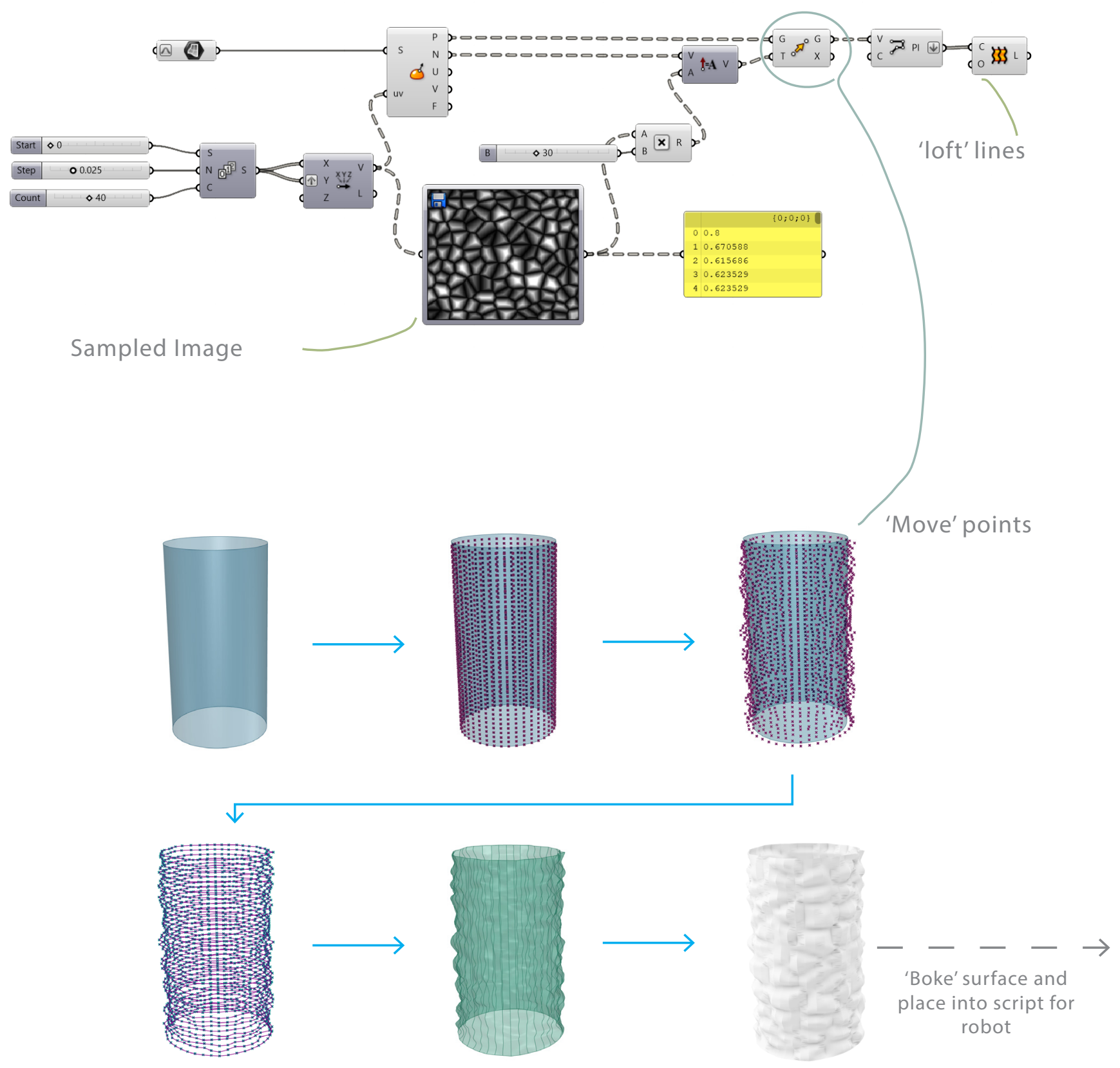

Fig. 100: Portion of Grasshopper script \& Digital Process 

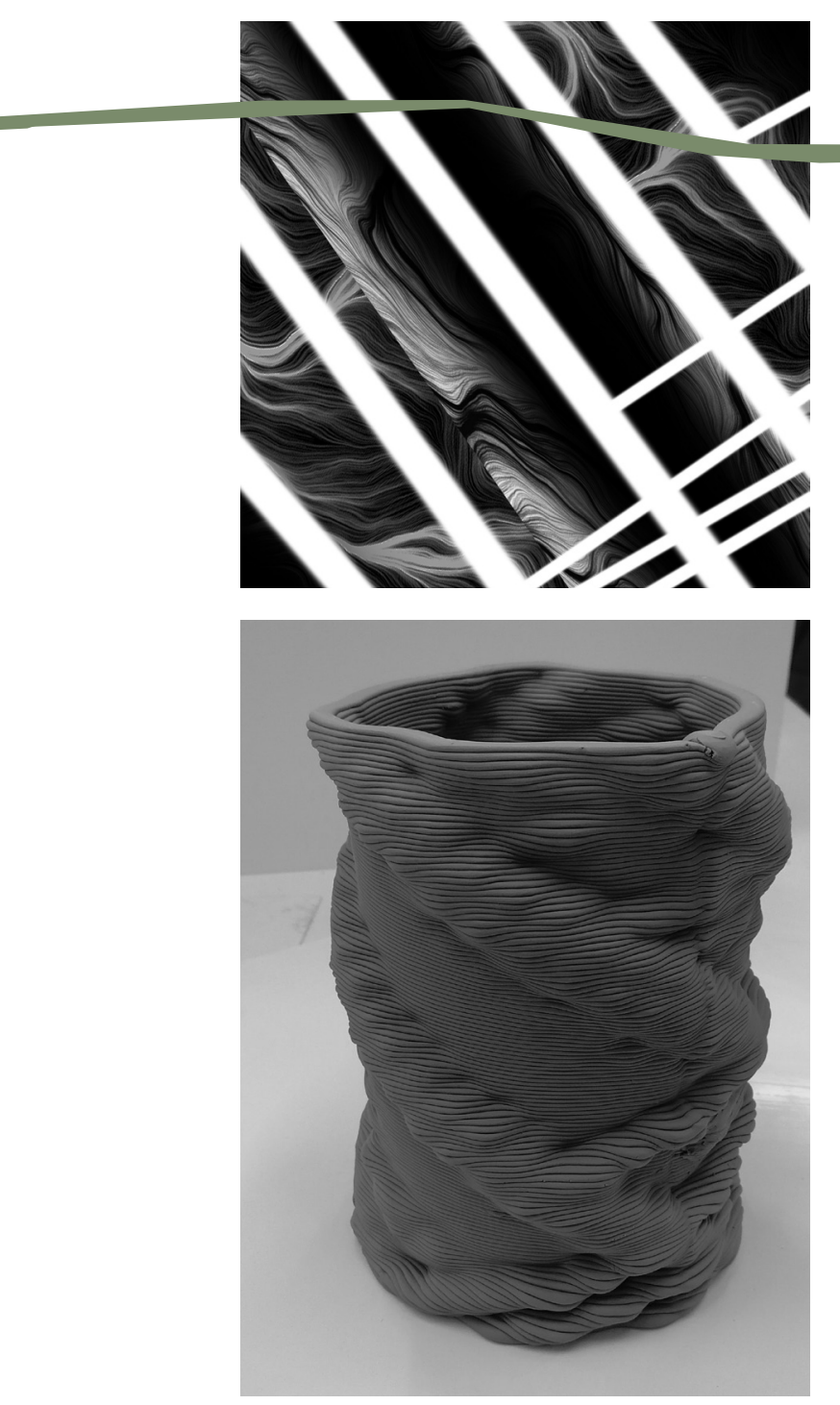

Design Description:

Image mapping III

Qualities being tested:

Addition of more lines in sampled image

\section{Fabrication Issues:}

Small areas of collapse in some places, there was an air bubble in the extrusion mid-print which caused an error in the surface.

\section{Adjustments needed:}

Slight reduction in overhangs and ensure clay is packed tightly enough.

Effectiveness of print: $6.5 / 10$

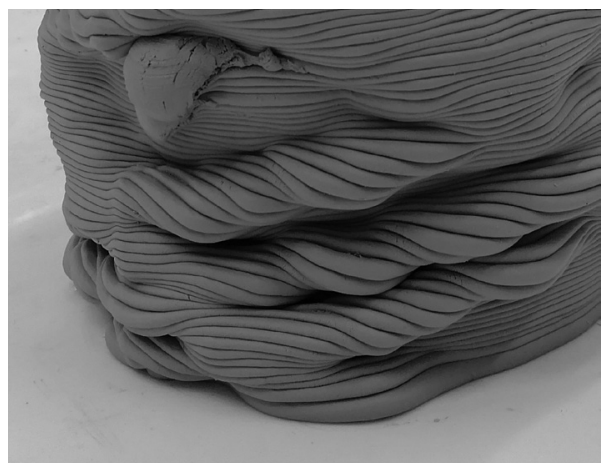

Fig. 107

Fig. 108-109 


\section{FABRICATION ERRORS}

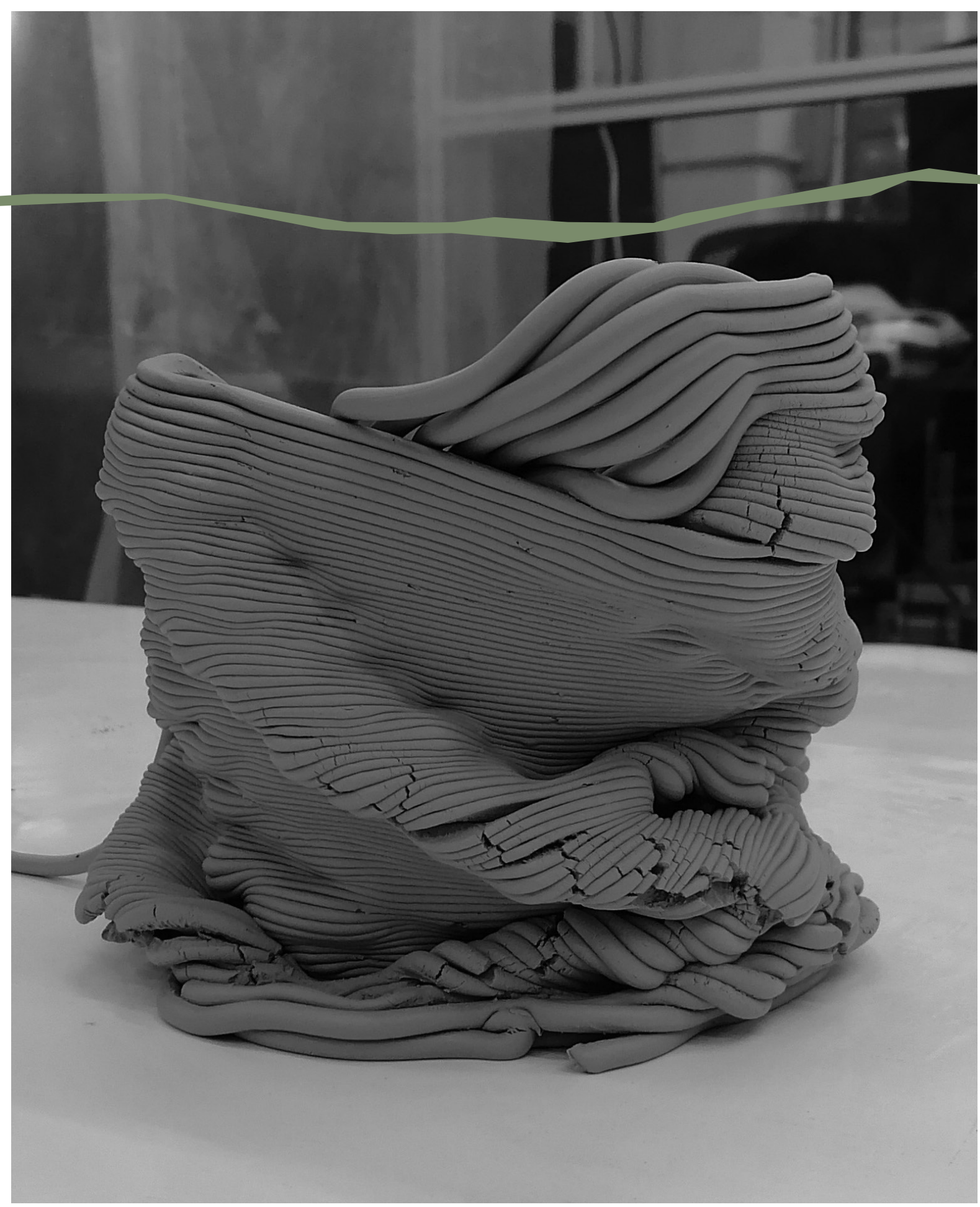

Error Description:

Fig. 110

Too much of an overhang on the structure, therefore the model collapsed over the weight of the column. 
FABRICATION ERRORS

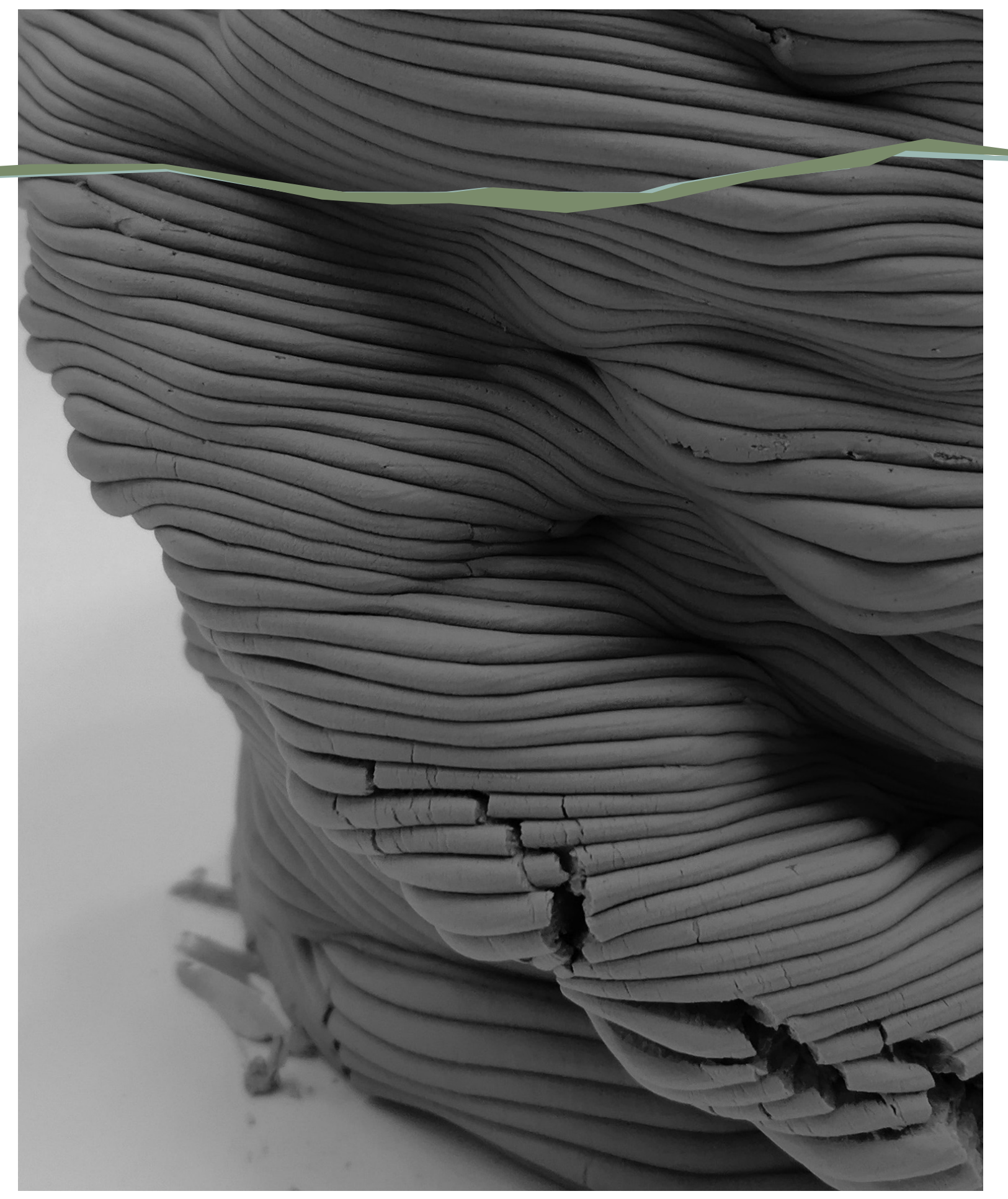

Fig. 111 


\subsection{REFLECTION}

The developing testing stage of this research was an important phase to test a variety of different aspects. Introducing a new material, as well as using additional tools and needing to export additional code meant that there were many new considerations and adjustments needed. It became clear from the beginning that the consistency of the clay, the rate of the extrusion, and the speed of the printer were all critical components that needed to be modified correctly to get the best printing results. A main modification in regards to the actual designs of the columns meant that there needed to be a simplification to the model itself. Because the nozzle sizes were much larger than the ABS 3D-printer, the level of detail in some of the models was reduced through the fabrication process. This reinforced the information found from the earlier literature research. To ensure the path flowed effectively, a parameter was added to the script to ensure that the spacing between the lines, and therefore the tool path, was kept at a minimum of $6 \mathrm{~mm}$.

Because of the thicker nozzle, the horizontal lines were much more visible to the model, when compared to printing using plastic at a smaller scale, this added a unique quality to the designs and it was decided that this was a characteristic that was to be incorporated into the further designs. The overhang was also a major component that had a large effect on the stability of the models. The use of slight overhangs created an effective slumping and stringy quality to some of the models, however when it was too big of a distance, the weight of the clay meant that failures and collapses occurred in some cases. The consistency of the clay, including the need for it to hold its form during the long drying process meant that the angles in the designs needed to be limited to ensure the designs would not fail. Because of the added water content of the clay, there was shrinkage in the drying process of the models, and so careful attention to the ratio of added water was needed to ensure the models reduced in size at the same rate.

In some prints, the height of the nozzle became an issue and caused problems in the dragging and squashing of the already extruded layers of the columns. This meant that the nozzle offset and the speed were needed to be monitored to ensure there was not a significant effect on the outcome of the models. It was also found that in more complex models with more organic and fluid designs, the speed of the printer was needed to be reduced to $85 \%$ from $100 \%$ to allow the timing of the clay extrusion and the toolpath were kept in alignment.

\section{GRASSHOPPER \& CODE}

Early adjustments to the models during this testing was required, as it was found at an early stage that the complexity of the surfaces on the designs created a file size that was far too large - due to the large amount of curvature in the designs, there required a large number of vertices, and therefore a large amount of code generated to follow these large toolpaths. Because the robot has a limit of 65,000 lines of RAPID code that it can read per file, in some cases the digital models needed to be simplified by either reducing the mesh, or the number of divisions. This also meant that in some cases the models were needed to be scaled down in size, or printed in segments in order for them to work effectively. 


\subsection{DESIGN REFLECTION}

Incorporating a new architectural material to the design development meant that different design aspects were able to be developed alongside the models. The material surface qualities were important in exploring as they added a lot more depth to the designs, as well as some limitations. Upon reflections of the designs themselves, the designs each had individual surface qualities that proved to be successful, however the overall cohesiveness to them were limiting. To develop these further, exploring further behind the meaning and the purpose of the ornamentation, as well as referring back to some of the ideas presented in the literature from classical architecture will be important. Thinking further about the ideas of hierarchy and order, and thinking about the cohesiveness as a whole will be important in the final stages of the designs. This phase was effective in developing a strong workflow and understand of the tools and equipment, and now it is clear that the focus needs to be brought back to the initial literature and research, to give meaning and cohesiveness to the designs. 


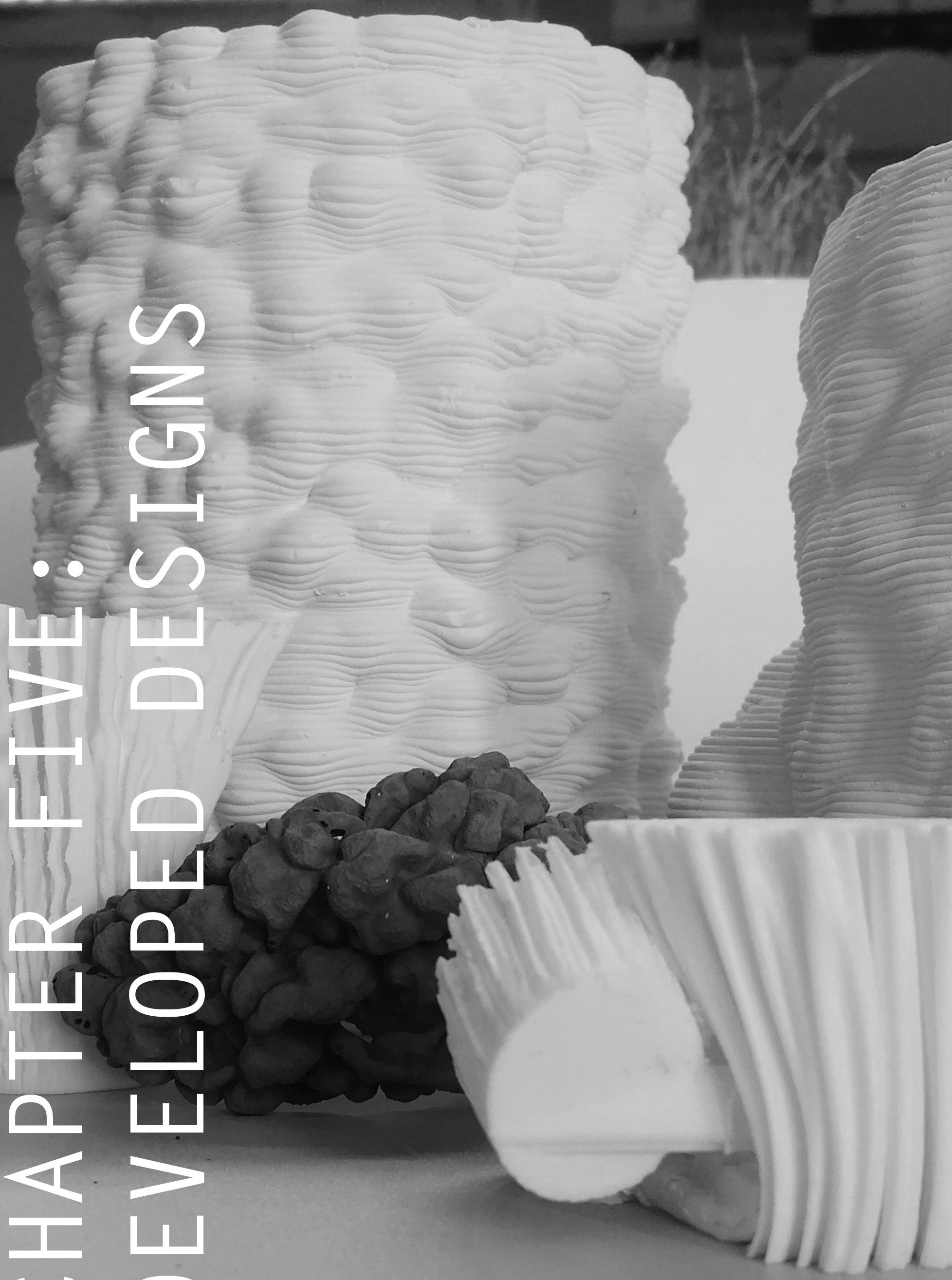

$\circlearrowleft 0$

Fig. 112: 3D-Printed Models 


\subsection{INTRODUCTION}

This chapter covers the final design stages of this thesis, by applying the research findings into an architectural context. After reflection on the design processes in the previous chapters, this stage further refines the use of visual scripting to create architectural scale designs and applies them to a design intervention on the Wellington waterfront. This showcases how these ornamental designs could work in a realworld contemporary context, to fully represent the quality of the design and fabrication tools and the potential that customisation has in creating variation. The previous chapters provided a literature basis for this research, and then the conceptual stage developed a digital workflow. The development stage worked to refine the material processes with robotics and working with clay and the extruder. The developed design stage takes these workflows and further refines them, as well as applies meaningful context to the design of these columns, to give a representation of how ornament could successfully be reimplemented into contemporary practice.

The chapter begins with a reflection of the previous design outcomes, and then an understanding of how nature could be used as a design driver in creating full-scale columns. An overview of the brief and site is shown, and then an overview and explanation of the design outcomes. The chapter then continues with the application of these designs to systems of mass-customisation, as well as an application to industry in New Zealand, including the use of concrete 3D printing. 


\subsection{RETURNING TO NATURE AS DESIGN INFLUENCE}

Building upon the reflections outlined in the previous chapter, it was clear that the design iterations each had their particular strengths in them, whether it be textures, intricacy, or curvature and fluidity. What they are generally lacking however is an overall sense of cohesiveness as full column designs. A level of hierarchy and order would be an effective way of achieving this. These kinds of rules were a key characteristic in classical Greek design and ornamentation, and therefore the use of these ideas in this context will be effective in providing a cohesive design scheme.

The focus of the fabrication stages of this research has primarily been towards defining a clear methodology and effective workflow. In the earlier literature however, the importance of cultural and historical aspects was shown, and therefore this developed design stage will reintroduce these aspects to the designs and scripts. In ornament, a level of symbolism or meaning behind the architectural components have been seen as effective ways of creating successful ornamentation. Because the intention from the beginning was never to replicate, but rather to redefine, the use of nature and organic form in this design scheme will be used as a method of incorporating hierarchy and layering into the columns.
Some examples of growth and layering in nature have been used to influence this:

1. Leaves/crumpling

Key design interest: The folding and twisting patterns.

2. Coral growths

Key design interest: The growth patterns and layering

3. Lichen growing on bark

Key design interest: The layering of texture, and transition of different scales.

By using a similar workflow to the conceptual and developed design phase, ideas from these precedents have been taken and translated into a digital script, in order to create the final design iterations. 

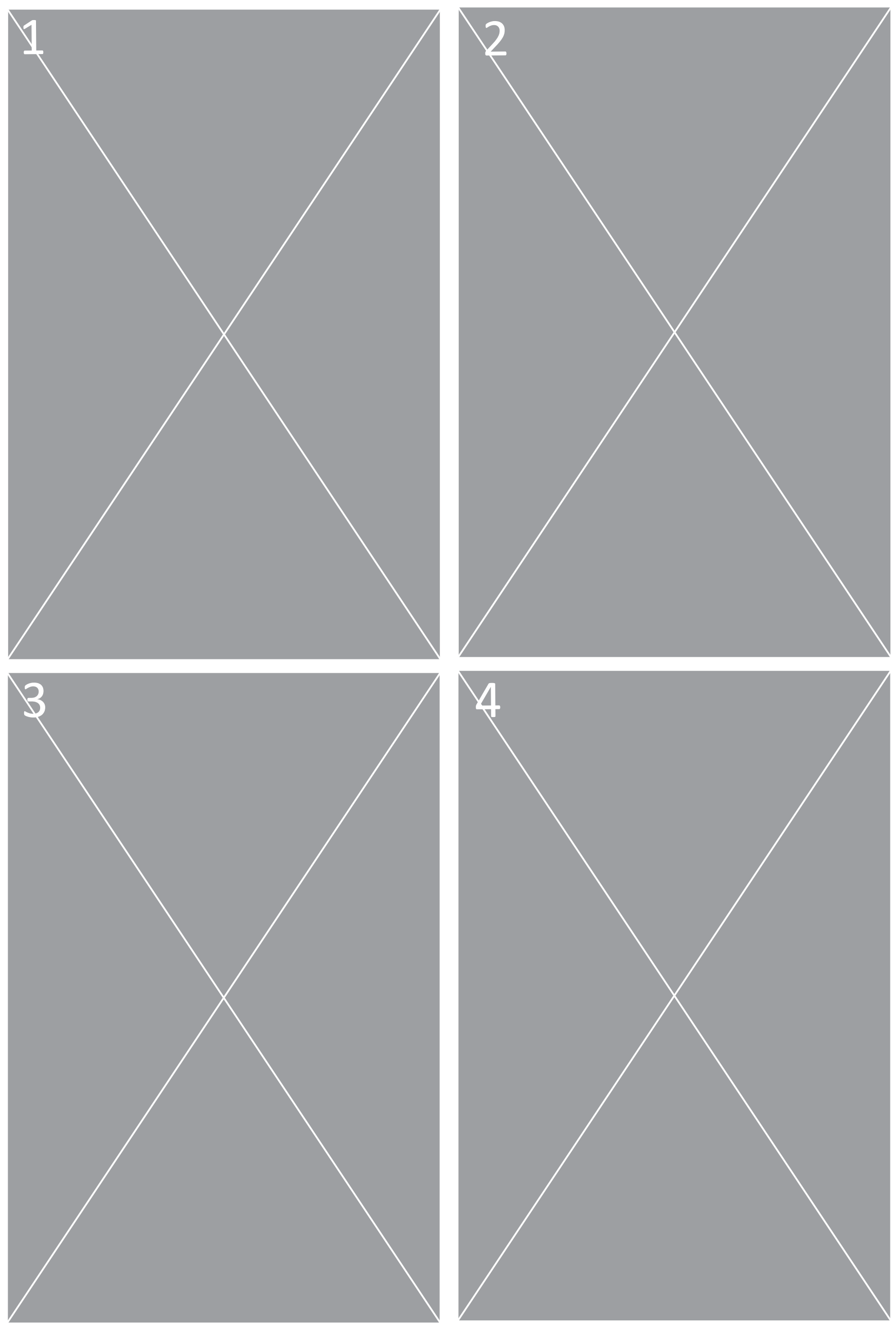


\subsection{APPLICATION TO ARCHITECTURAL CONTEXT: BRIEF}

\section{THE BRIEF}

Site Location: Wellington Waterfront [near Te Papa/Odins Plaza]

Design: A public design intervention, consisting of a series of columns, each with their own unique characteristics which relate to their position on the site.

Purpose/Design Intent: To show how this research can be applied to a full-scale architectural context, with meaning and detail. 



\subsection{THE SITE: WELLINGTON WATERFRONT}

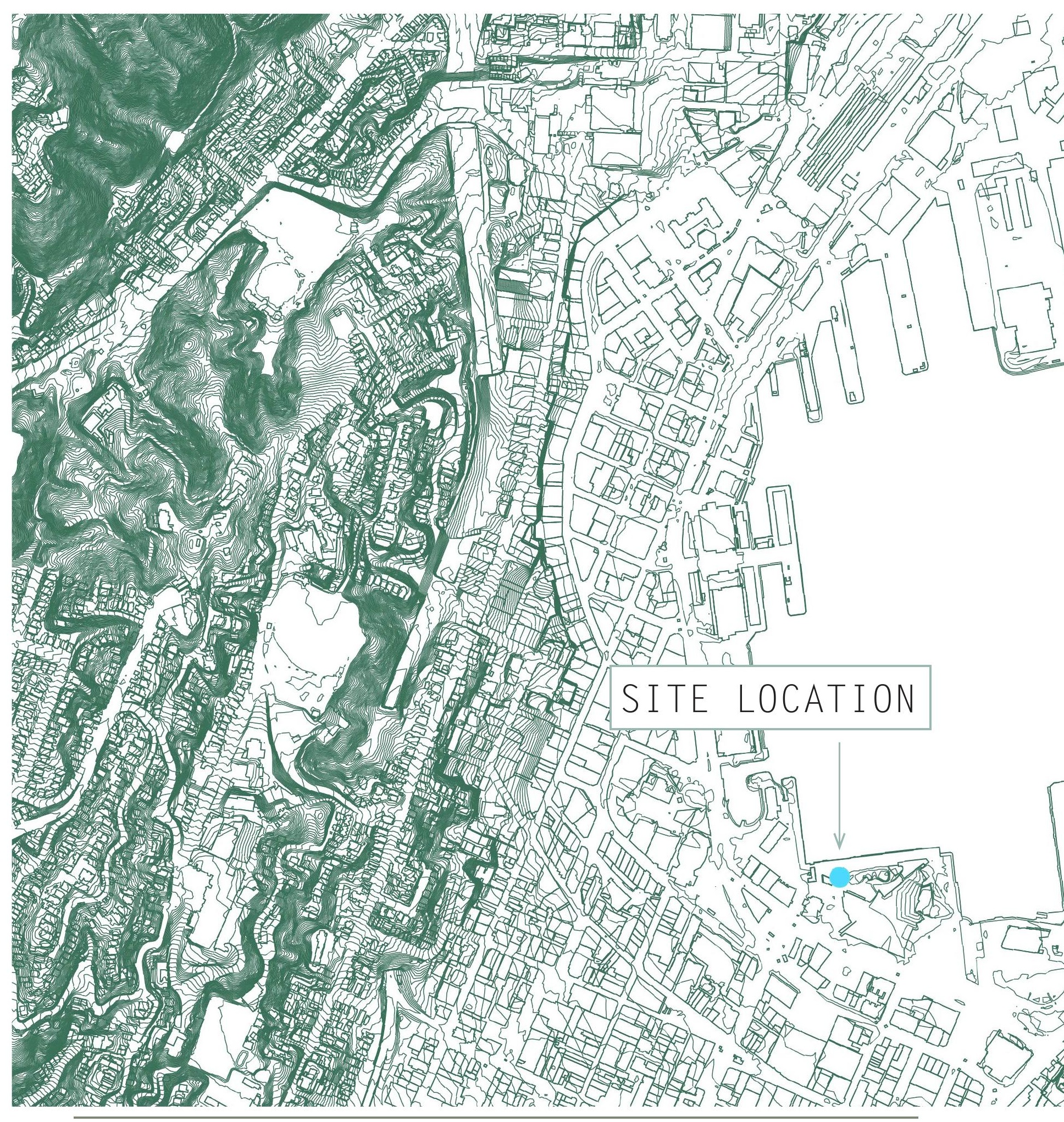

Fig. 118: Site context 
This design series of columns is taking aspects of the historical research, the findings from the previous design explorations in both the digital scripting and fabrication processes, as well as inspiration from nature in order to create ornamentally designed, mass customisable columns. To give the columns a grounding and an inspiration for the design, different script components have been combined to create varied columns that are inspired by different natural elements of the wider Wellington region. Depending on the column's location on the site, will determine the design effect and different levels of textures they each will have.
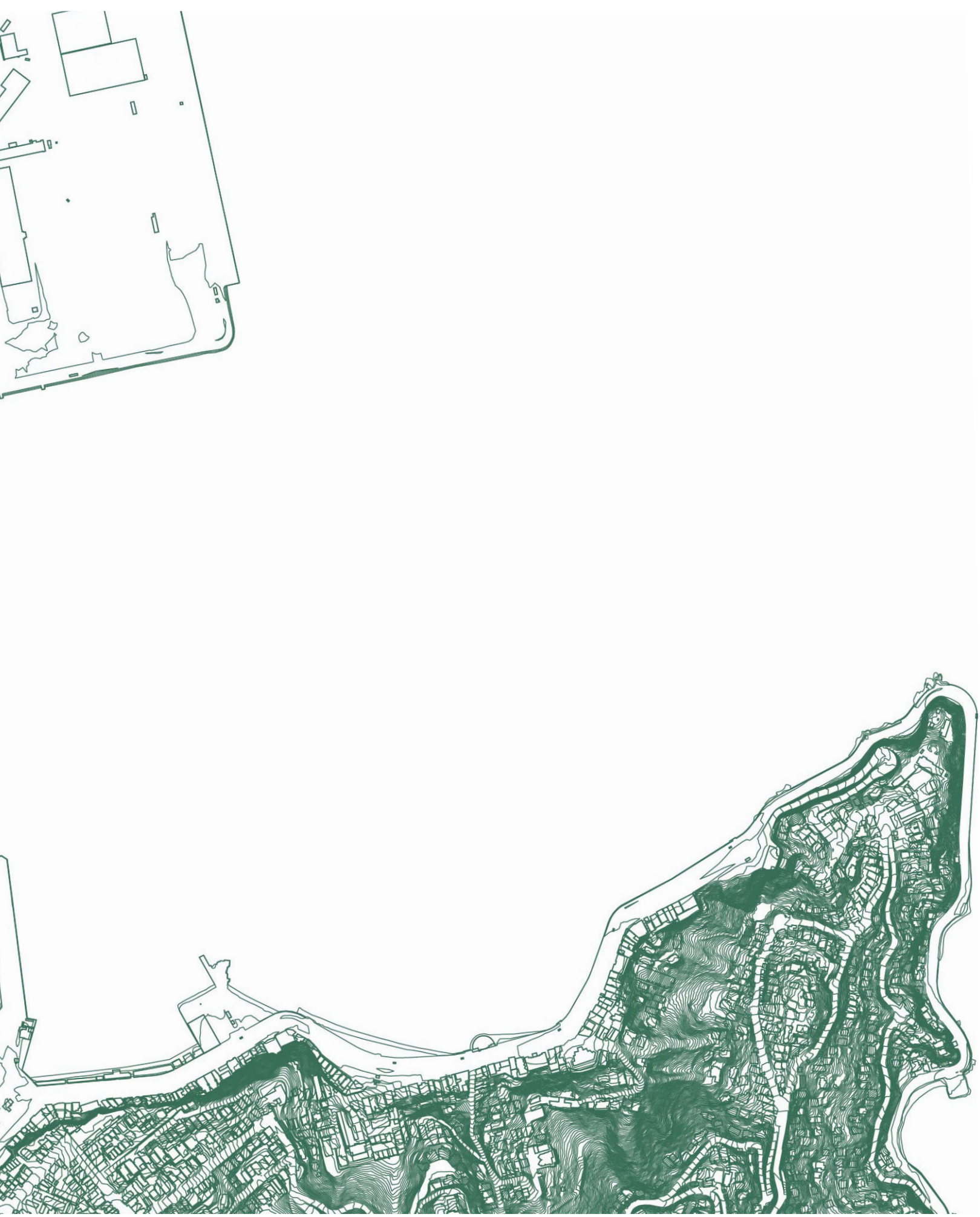


\subsection{EXPLANATION OF FINAL DESIGNS}

The different aspects have been built upon the surrounding context of the site: the sea, the wind, the buildings and the nature in the wider Wellington region have all acted as an influence for particular elements of these columns, which, by using the designed Grasshopper script, will all flow together in different levels and layers, showing the mass-customisation potential that this technology has for architecture and the significant potential it has to allow for ornamentation and detail in the design.

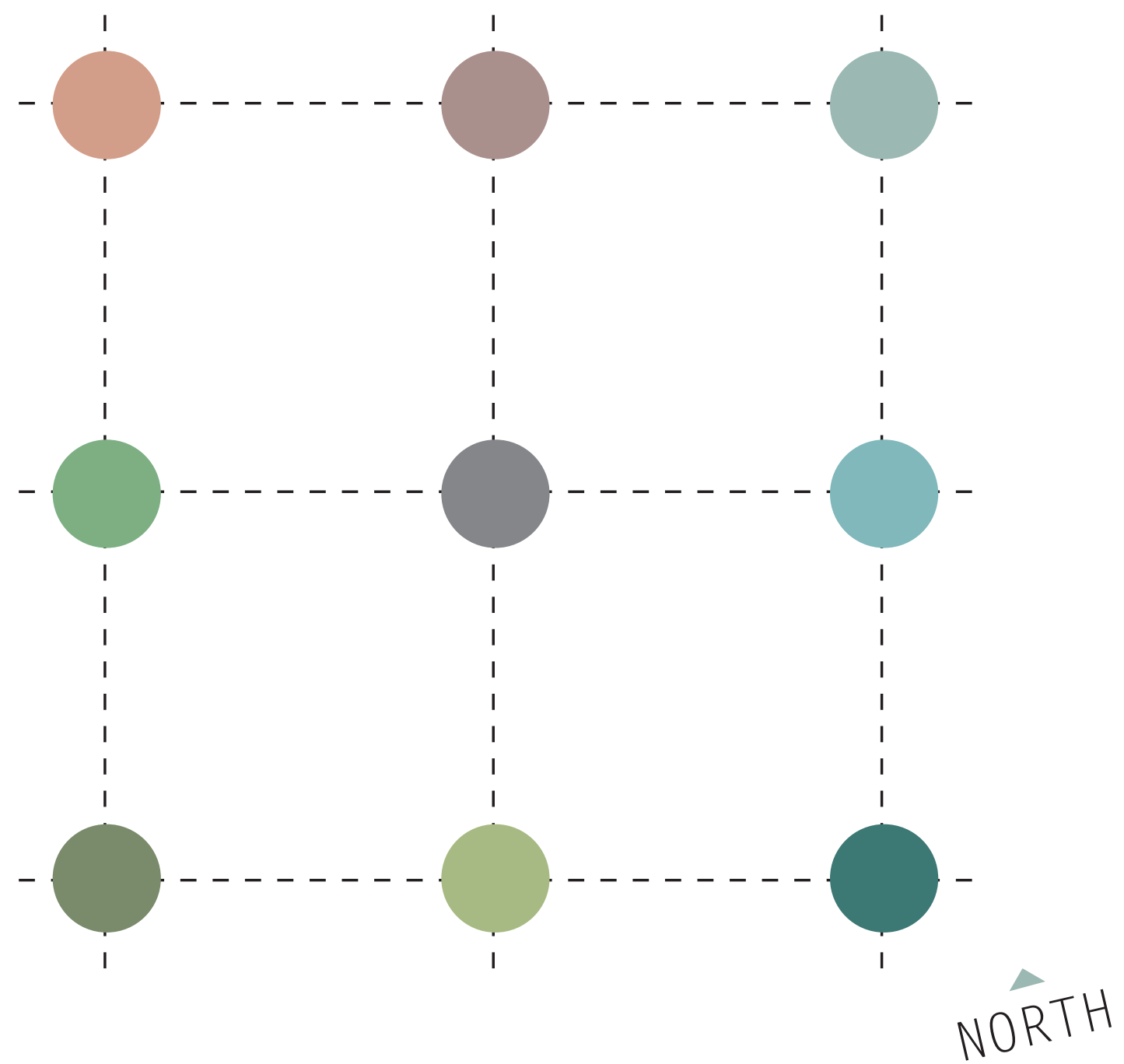

Fig. 119: Column layout 
THE SEA \& THE HARBOUR - DIGITAL TRANSLATION: THE CORAL/GROWTH EFFECT

Building upon the previous explorations in the previous chapters and design stages, the effects this curve expansion brings will work to be a representation of the Wellington harbour and the surrounding sea.

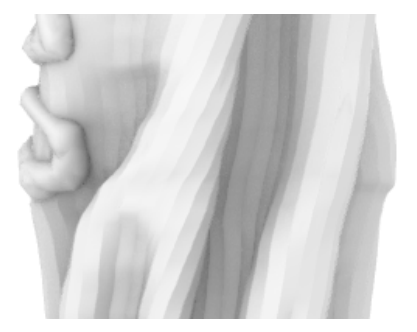

\section{THE WIND - DIGITAL TRANSLATION: CREASING / NOISE MAPPING}

This script best created interesting surface patterns, that will be a representation of the wind in the site context. These scripts work with adjustments in two ways, the creasing pattern is adjusted through a graph mapper, which adjusts the intensity and location of the pattern; and the noise mapping is used through the use of an image sampler, changing the gradient pattern in the image to affect the level of surface texture.
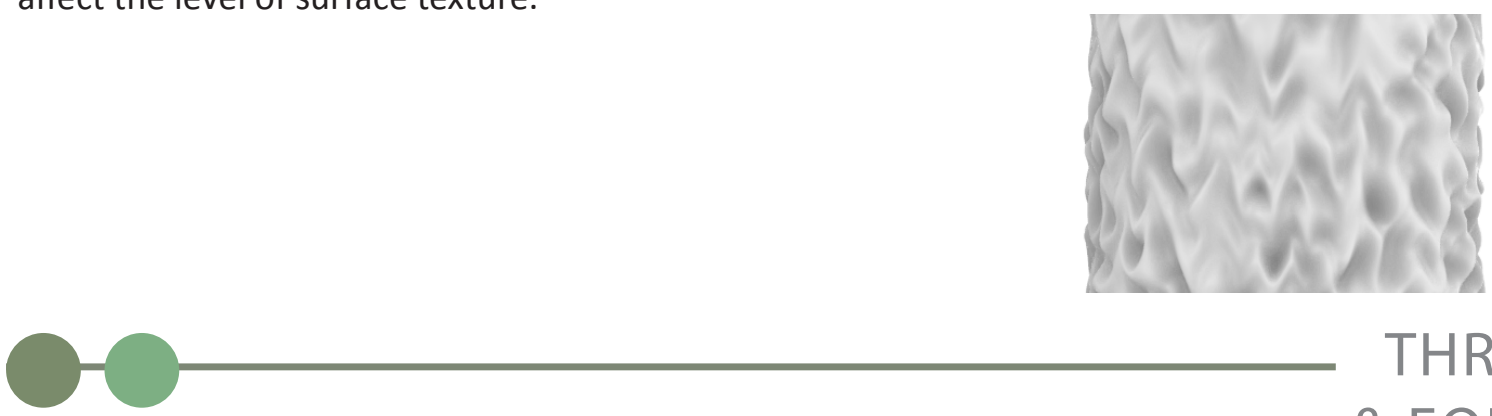

\section{THREE \& FOUR}

THE SURROUNDING LANDSCAPE + TREES IN WIDER WELLINGTON REGION - DIGITAL TRANSLATION: THE "COCOON" GROWTH \& FOLDING PATTERN

This part of the script will be used to represent the nature around the wider region, including the natural way that growths such as lichen grow on trees, and the way that seaweed grows on the structures on the wharf. These are adjusted through curves and points, and the marching cubes are used to create a wider surface, able to be applied to the design.

Fig. 120-123: Rhino Digital models of the different Grasshopper scripts
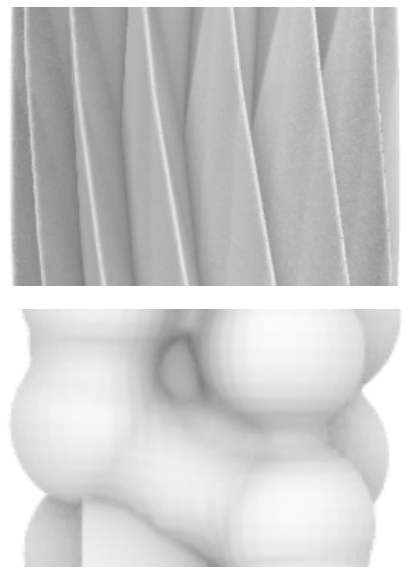


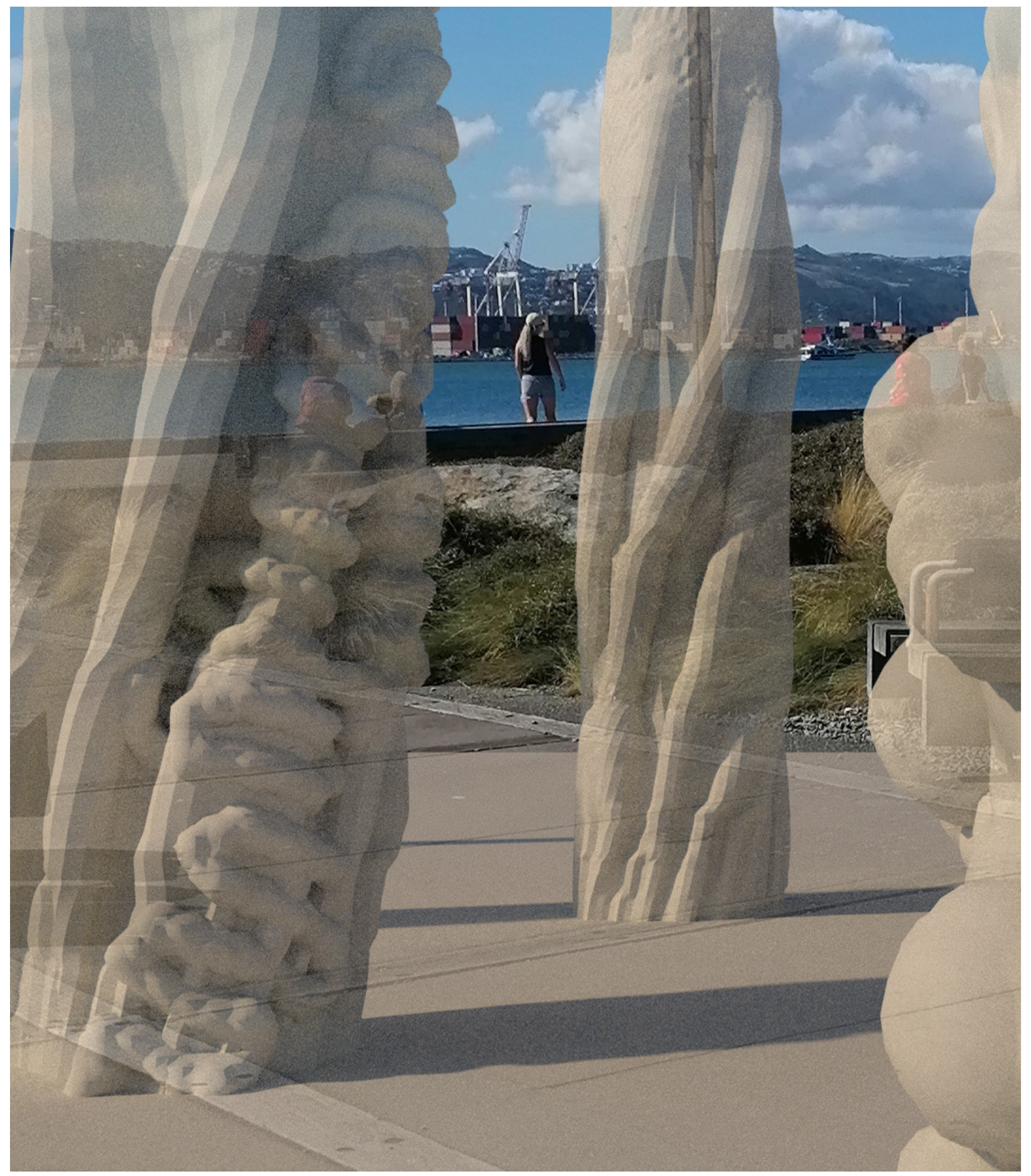




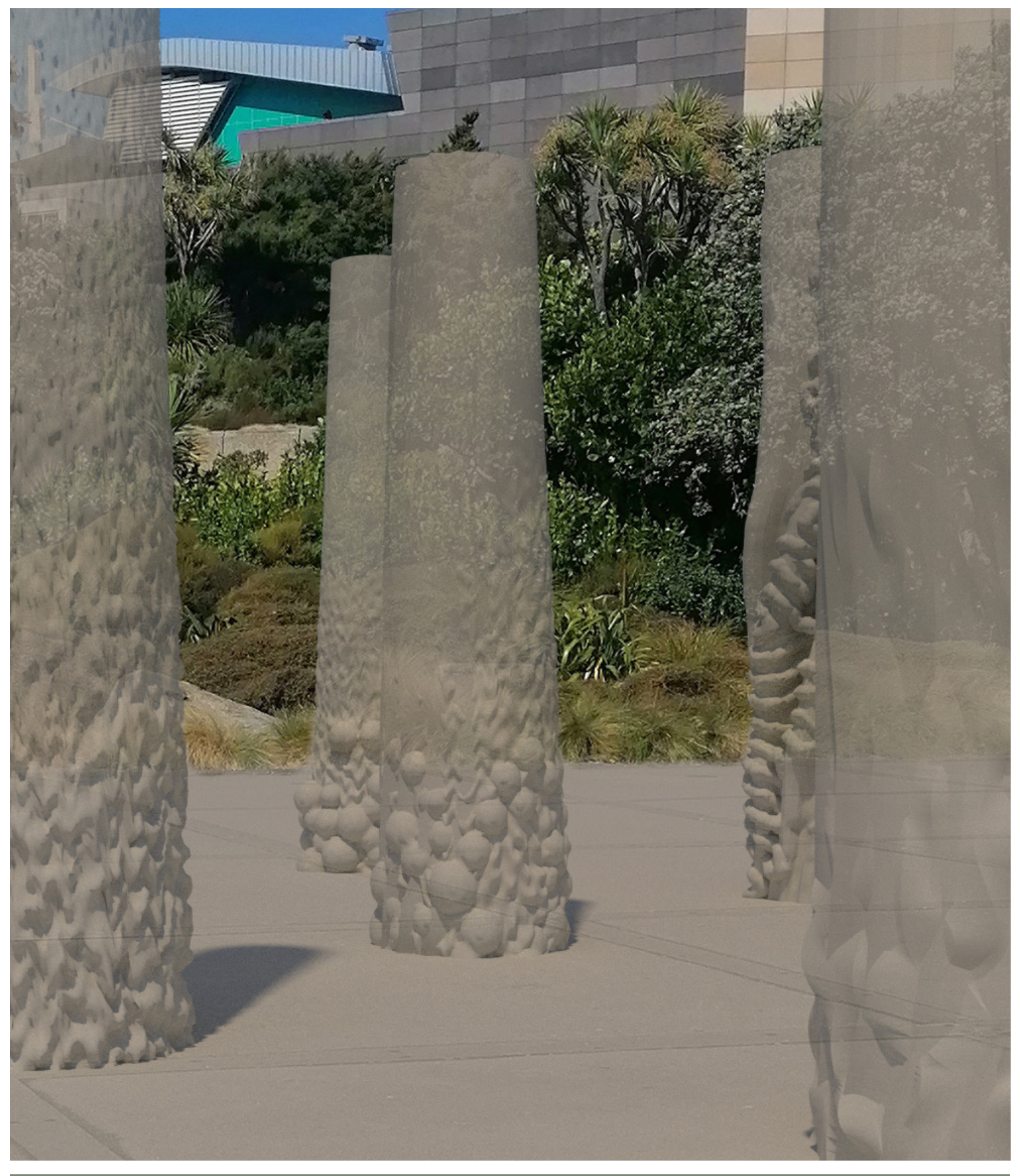

Fig. 124 


\subsection{FABRICATED COLUMN}

To provide a physical representation of the entire process, from the initial script and digital model design through to the final fabricated form, a printed column was produced and then fired using a kiln. The centre column of the design series has been chosen to be robotically fabricated. This design includes a combination of the different ornamental styles, layered together on the surface to create the overall ornamentation and design. The qualities of the column incorporate the creasing, folding, and coral-like growths together to one unified design.

\section{ADJUSTMENTS TO THE SCRIPT}

Because these final designs were created using multiple surfaces, an adjustment to the script was necessary for a correct tool path to be found. This included a process of using the 'union' component in Grasshopper to create boundary contour lines, and avoid any errors. To avoid errors with overlapping lines occurring, the 'clean tree' component was also used to refine the surface. These were inputted within the Grasshopper script that defined the tool path and parameters for the robot.

\section{PRINTING}

The available tools for this research meant that there were some restrictions to the size that was able to be printed. The size of the tube for the clay extruder meant that the height that was able to be printed before needing to remix and refill the extruder was limited. The complexity of the curves on the surface and the associated limitations with the size of the RAPID code able to be loaded onto the robot for one print also added restrictions to the printing scale. The kiln used to fire the final models also restricted the available height. With these in mind, to accommodate these implications, the final column was printed at 1:2 scale, and it was printed in 6 segments, in heights ranging from $200 \mathrm{~mm}$ high to $250 \mathrm{~mm}$ high each. To achieve this, a mesh-split command was used in Rhinoceros and then inputted into the Grasshopper printing code separately. They were then printed and left to dry separately, before being fired off-site in a kiln. 


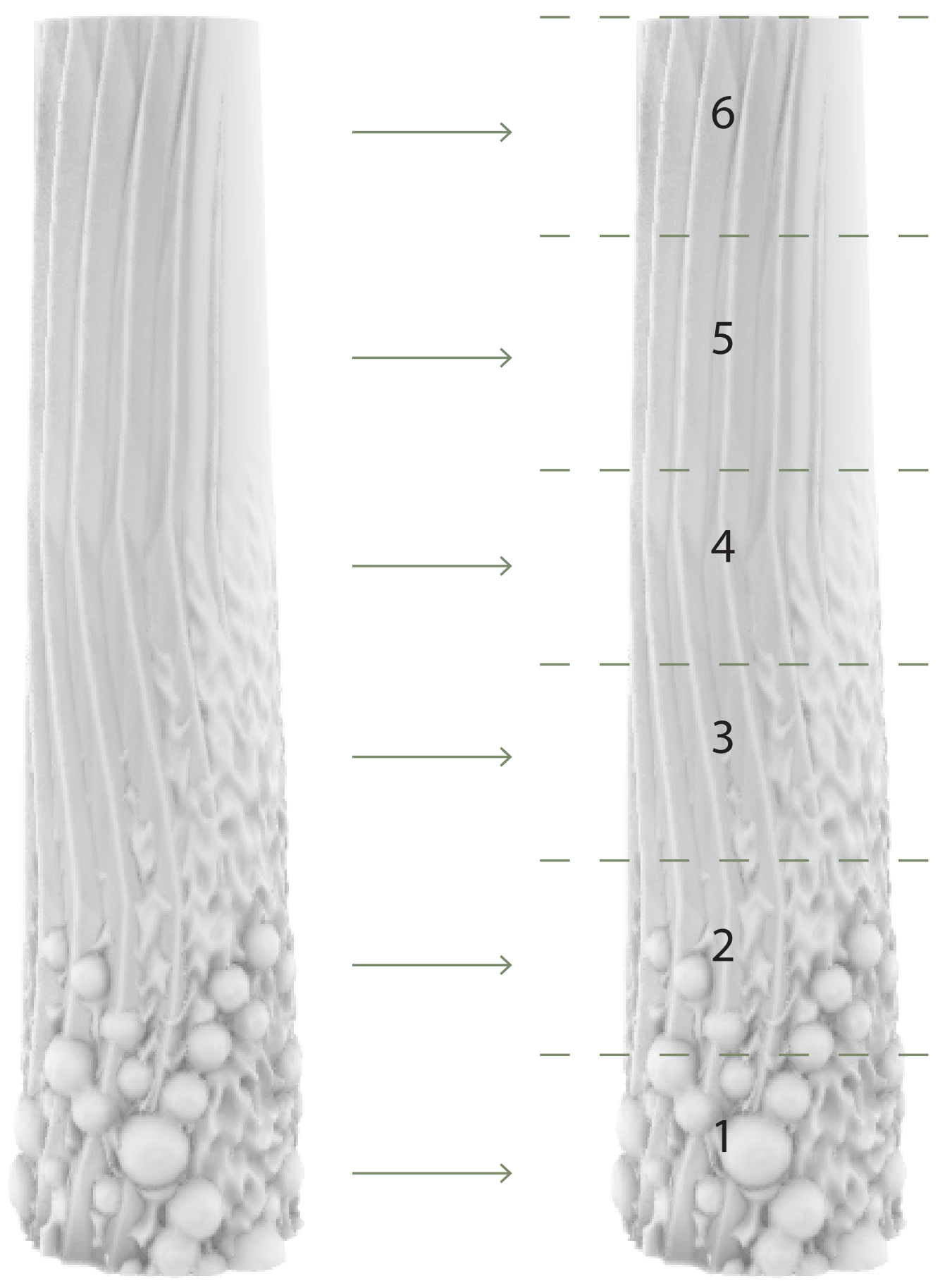




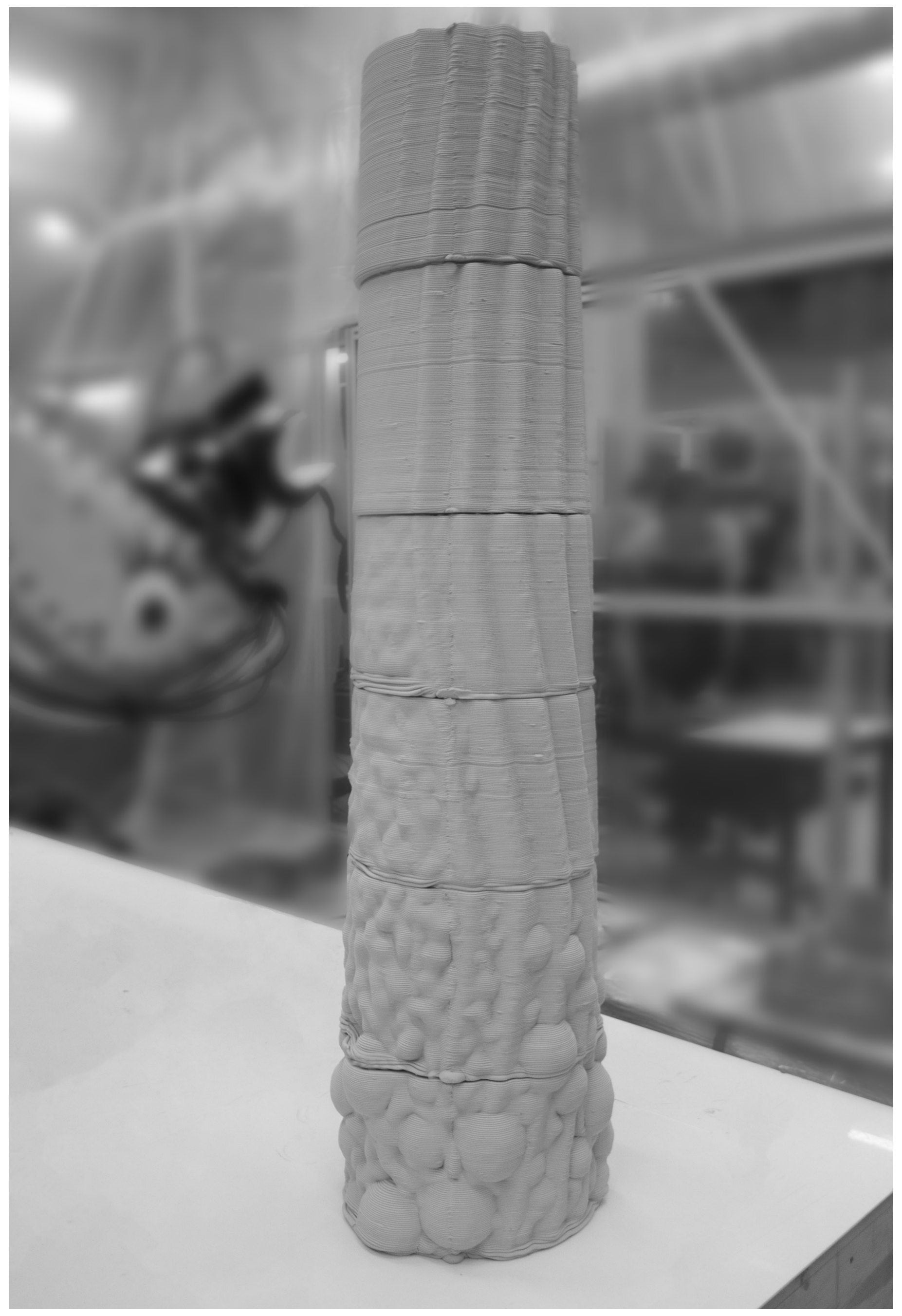



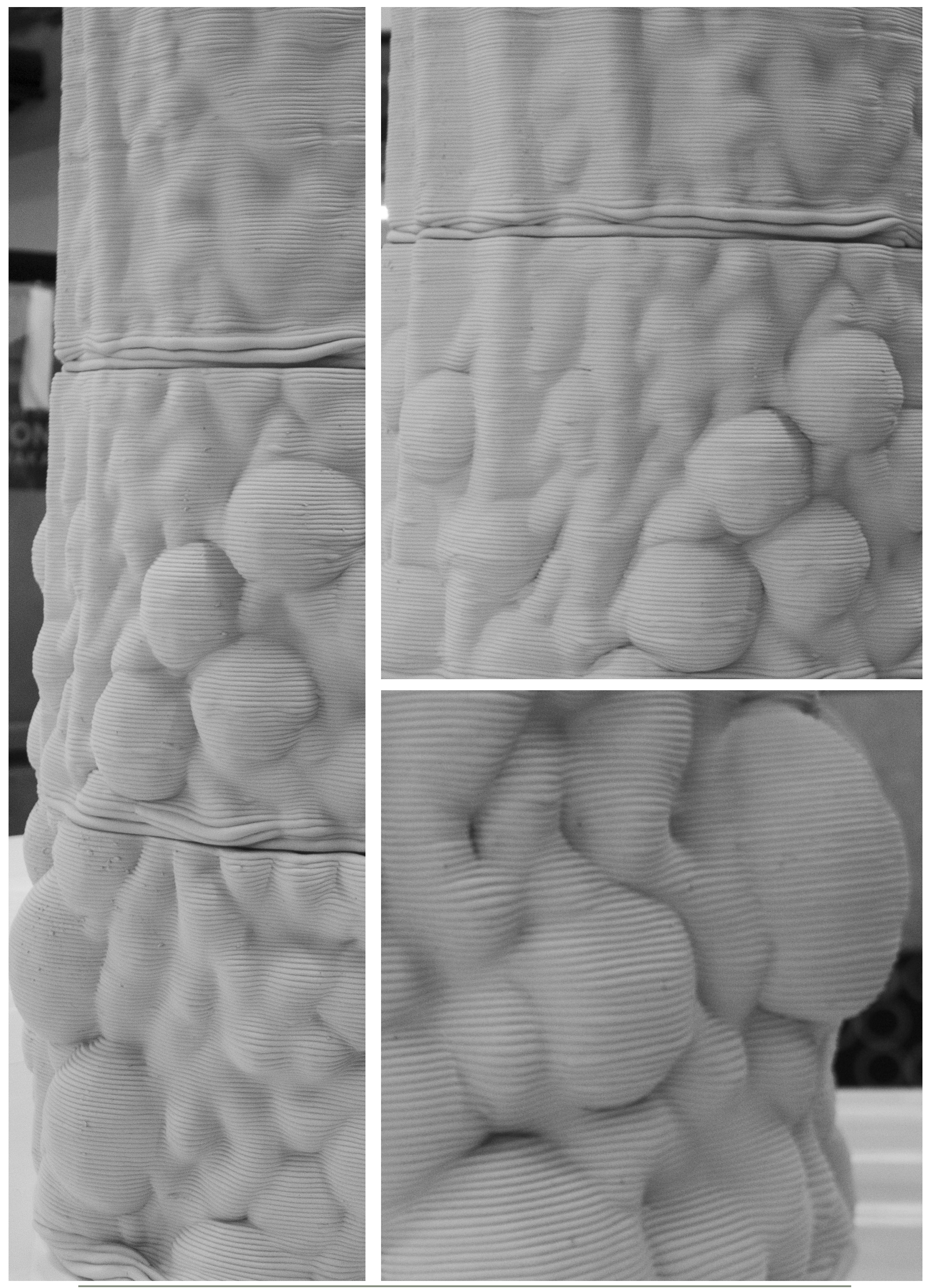

Fig. 126-129: Compiled final column (unfired) 


\subsection{MASS CUSTOMISATION}

As identified throughout this research, the ability of mass-customisation in these designs has been an important consideration to reflect on the effectiveness of these ornamental designs. By using methods of $A M$, as well as visual scripting through the use of Grasshopper, it has been made clear that through simple adjustments an abundance of variation can be created, and using these methods have the ability to open up wide possibilities for mass-customisation in architecture. With the manipulation of number sliders, components, and the addition of plugins, designs that would have been unable to be produced through the use of traditional methods can now be achieved.

Although this research has used architectural columns as the design mechanism and output, the versatility of software such as Grasshopper means that these ideas can be applied to a variety of different architectural components, such as walls, or applied at full-building scale, as shown in the TECLA case study in the previous chapter (3DWASP, 2019). By adjusting the scripts, the surface qualities created can be applied to a variety of different geometries and contexts, further expanding the potential that these tools can have. 


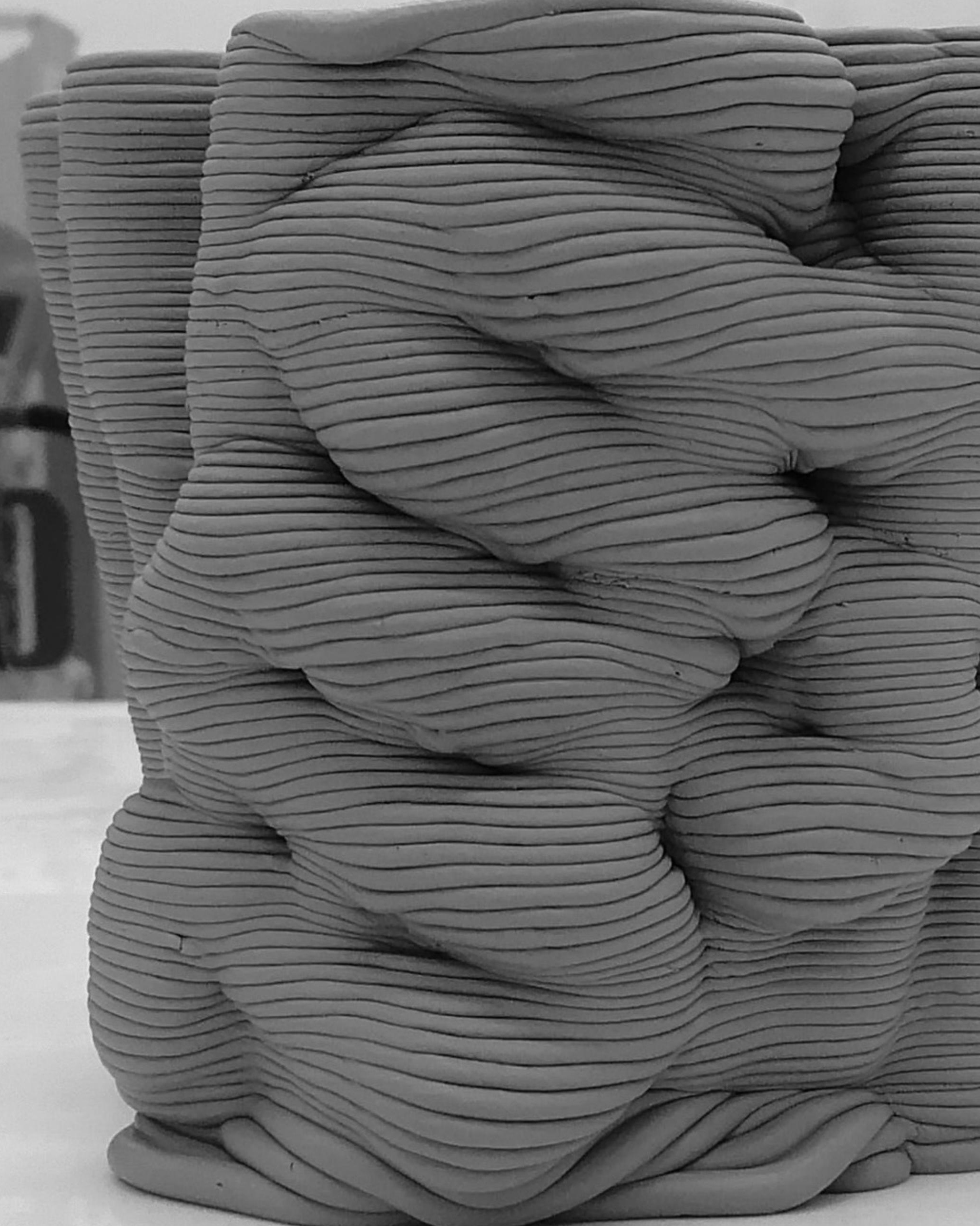

Fig. 130: Clay Printed model 


\subsection{APPLICATION TO CONCRETE 3D-PRINTING}

The scope of this research has been focused within the bounds of clay 3D printing, however the fabrication of these digital models could be achieved using a variety of different materials and compounds. One of the major benefits of these digital fabrication additive manufacturing techniques is their ability to be produced through different materials, and concrete is no exception. Internationally, concrete 3D printing has been developing significantly, with ETH Zurich's 'Concrete Choreography' being an example of this (Anton et al., 2020). Very recently this technology has been emerging in New Zealand as well. In November 2020, the country's first industrial-scale concrete 3D-printer was imported into New Zealand from the Netherlands, as part of the Waikatobased start-up QUROX, becoming the first in the Southern hemisphere to undertake commercial concrete 3D-printing (Callaghan Innovation, 2020). Their collaboration with Hamilton City Council in 2020 meant that in November they were able to provide New Zealand's first public demonstration of a robot 3D-printing a commercial scale concrete object (Callaghan Innovation, 2020), a $2.8 \mathrm{~m}$ long bench of a bespoke waka design, by Boffa Miskell landscape architects, being able to be printed in just under 45 minutes (Rowland, 2020). These new innovative projects show the potential that robotics and printing have to the construction industry. The technology has benefits such as reduced manpower; greater geometric freedom; reduced material consumption and wastage; improved accuracy and safety on-site (Loporcaro \& Zhao, 2019, p. 1). With more research projects and innovations, the development of these processes will get better, and in turn become cheaper and more democratized, widening the opportunity for use in the industry. 

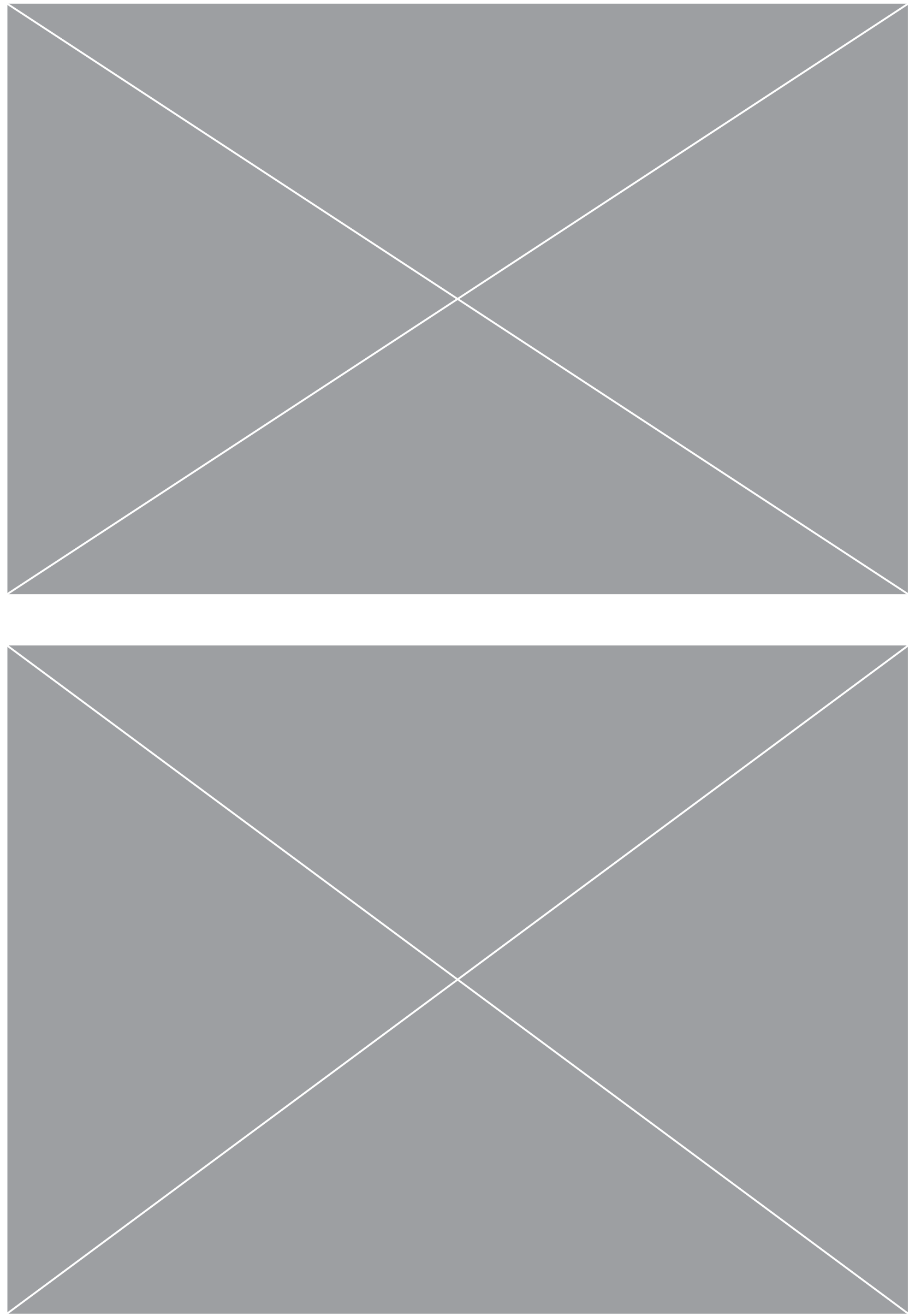

Fig. 129: 3D-Printing of concrete bench

Fig. 130: Concrete bench designs 


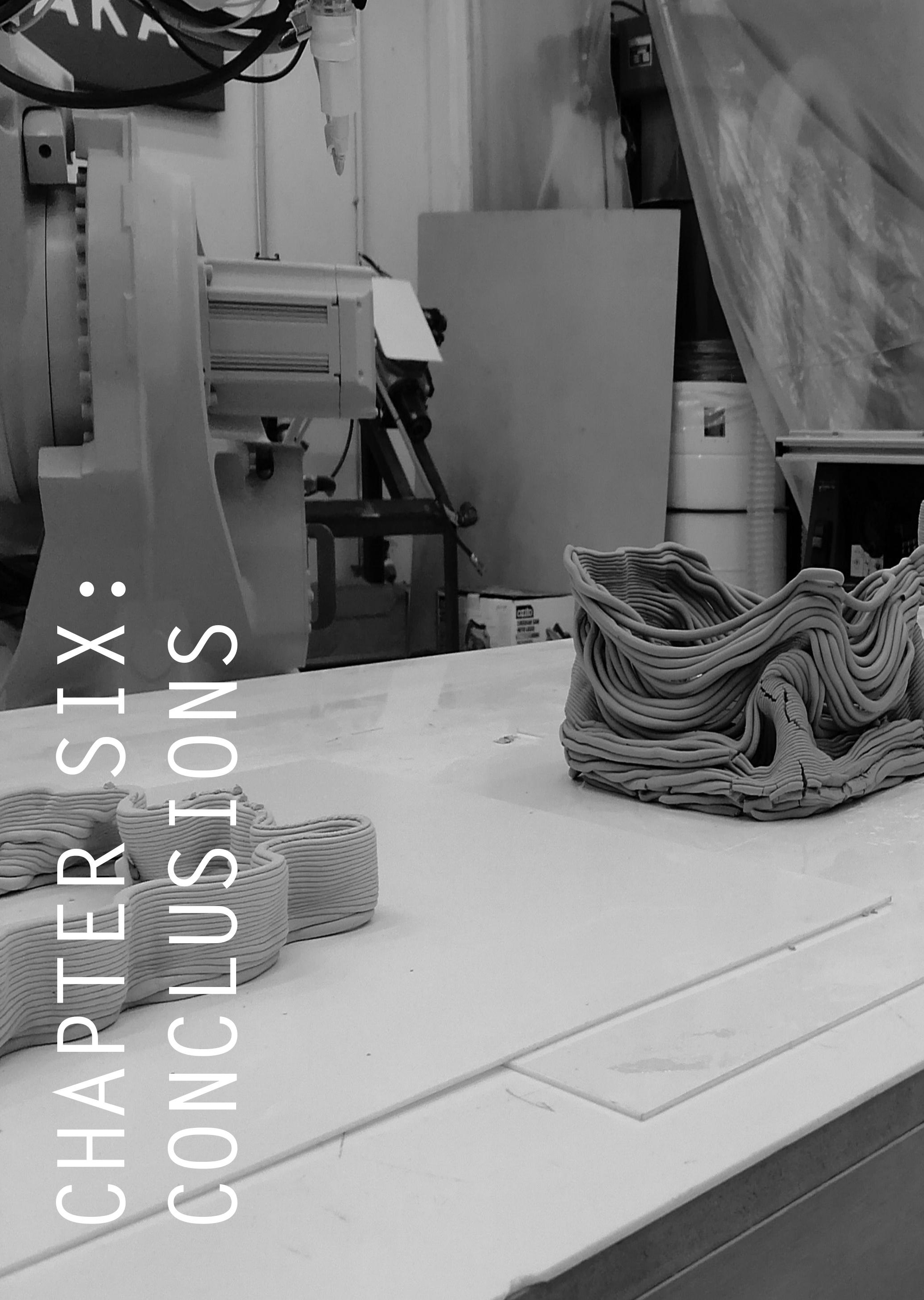




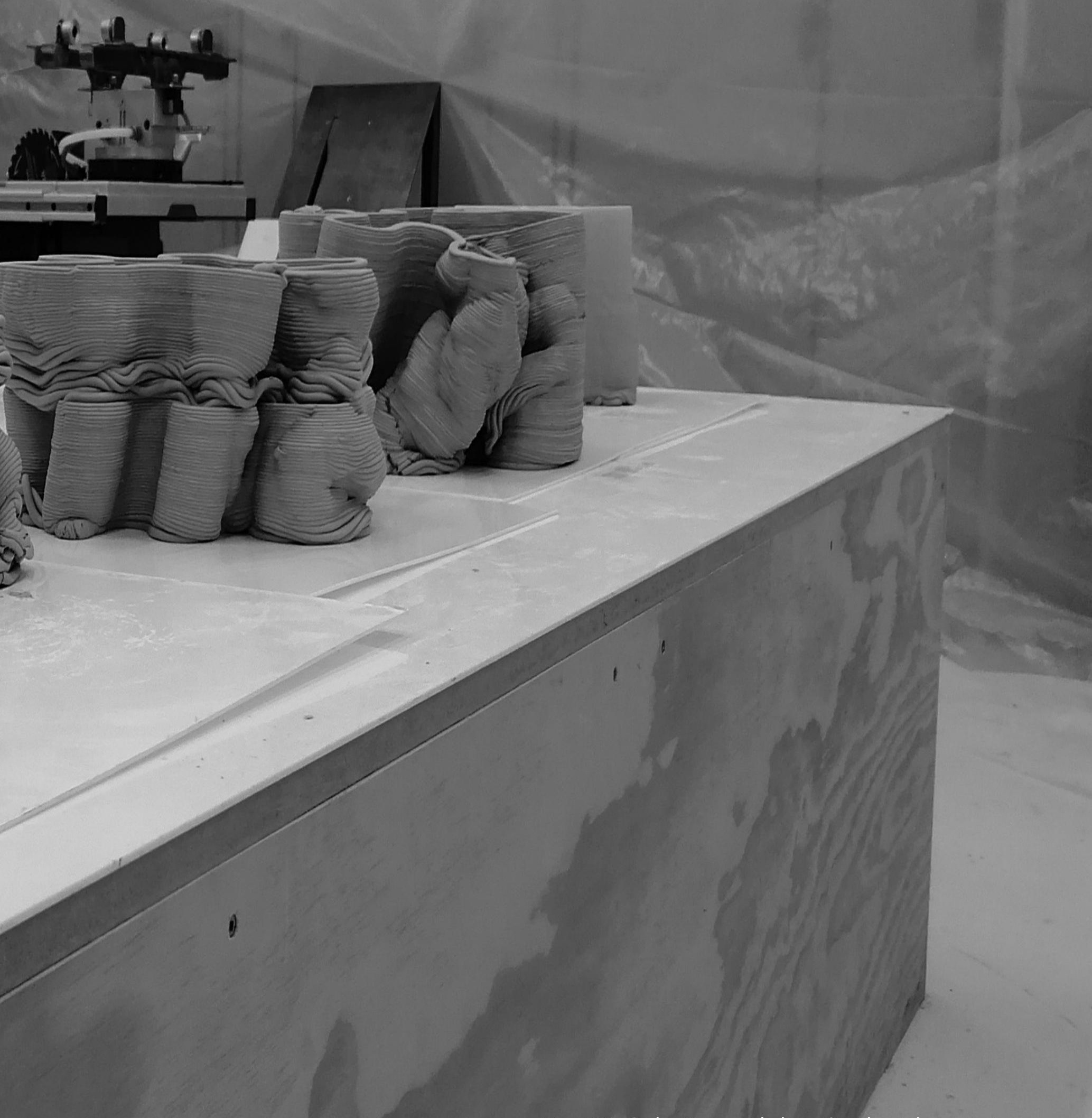

Fig. 131: Robotics workshop \& other clay prints 


\subsection{LIMITATIONS}

As this research project involved the use of advanced digital technologies and robotics for prototyping architectural columns, it was expected that there were to be some limitations to the work. With limited knowledge in using Grasshopper, the iterative design process from the first stages was a huge learning curve throughout this thesis. Understanding the tools, the parameters and the best workflows for designing was a time-consuming process, which required a lot of trials and adjustments to modify the scripts successfully.

3D-printing was an unfamiliar process, and therefore this research required the learning of the use of these tools. Similarly, with programming the robotic arm and clay extruder there were a significant number of components that required precision, including the tool set up, speed, consistency of the clay, as well as the quality of the script itself. Although this process was time-consuming, once the workflows were established effectively the process ran smoothly, with only minor adjustments needed. There were continued issues with getting the pressure of the initial layers of the models correct, which did cause inconsistencies in the final columns when they were compiled together. In future prints, to limit the impact of this on the outcomes, extruding clay out to the side of the print space before beginning the code would help to reduce this.

Due to the limitations in the size of the extruder itself, and the available kiln for final explorations, the height of the fabricated columns was limited, and so they needed to be completed in parts. Because of these restrictions, it meant that the final column had to be reduced in scale, and so that is why a 1:2 column was produced. In an industry context, with an extruder with a larger tube, columns would be printed at a larger scale and height, which would in turn add some more considerations to the fabrication process.

Structural testing was also beyond the scope of this research, and due to this being defined at the beginning of the thesis, it did not affect the design process. This however could be an interesting area to explore in further work if suitable equipment and appropriate time were available.

As outlined in the literature review, Māori architecture and carvings are an entirely justifiable area for this research to develop into. Although it was stated in the reflection that due to the high level of knowledge and delicate consideration needing in applying these traditional principles to ornament did not align with the explorative and parametric computational methods in this particular research; these principles could certainly be applied to digital fabrication and robotic printing in future studies.

Due to entirely unforeseen circumstances regarding COVID-19, the access to campus and the university workshops was delayed, and so the prototyping phase unfortunately could not commence until much later in the research process than intended. Although this did not hugely decrease the quality of the outcome of this research, it did however mean that there was less time to focus on the large-scale final fabricated prototypes.

Although these limitations altered some of the milestones for this research, they did however open up opportunities for other future research, and also strengthened and brought to light important considerations which in turn strengthened the quality of this testing. Now that a base workflow has been developed and established, there is an opportunity for more prototyping and script developments, which in turn means more opportunities for the testing of mass-customisation. These findings could be applied to other architectural elements, as well as the use of other architectural materials, such as concrete 3D printing. An increase in scale also would mean that there would be more aspects for testing, and therefore further opportunities for development. 


\subsection{FUTURE RESEARCH}

The limitations of this research, as well as the findings, provide various opportunities for future research. This includes opportunities to further refine the workflow, as well as applying the findings to larger scales, and other architectural elements. Applying these methods to a New Zealand context, particularly with Māori architecture and ornamental craft would be an influential future direction for this research.

Applying these scripting methods to other architectural elements mean that masscustomisable ornamentation could be applied to not only columns, but walls and even to the scale of full buildings. The versatility and the ability of adaptability of this technology mean that innovations can be developed and built upon.

An exploration with other additive manufacturing materials, such as the use of concrete is also another area of potential research. The exploration of this would further help to refine the processes, and also provide more opportunities for these methods to fit into the design and construction industry. 


\subsection{CONCLUSION}

This research aimed to explore and answer how contemporary computational design and fabrication techniques could work to reinvigorate and reimagine the use of ornamentation in contemporary architecture. Through the use of visual scripting and digital fabrication and prototyping, this thesis has shown that it is possible to design customisable ornamental columns, and digitally fabricate them using existing digital technology and materials.

The research outcomes from this thesis identify just one way of approaching the revitalisation of ornamentation in architecture. This research focused on robotics and additive manufacturing, specifically with using clay as a material, however there are many more tools that could have been used in place. Subtractive manufacturing such as CNC is another method that could provide a multitude of other design outcomes. This research reinforced the potential that this technology has, and by taking influence from nature and the classical orders, just one avenue of a range of possibilities has been explored.

\section{RESEARCH OBJECTIVE ONE:}

From the initial literature analysis, it became clear that this thesis is a small piece of a much larger picture. To get the best and most effective results, defining a clear research scope and design focus was an important step in making the progression of this research successful, which is why the classical orders and an organic style was chosen as a design focus. Because of the cultural, social and technological influences regarding this area, it was important to ground the project in a specific place to make effective progress.

\section{RESEARCH OBJECTIVE TWO:}

By using the classical orders as the initial starting point for the design phase, key ideas were able to be tested, and a workflow and understanding of the technology was established. A set of criteria was identified to provide an assessment of the successfulness of the scripts and their associated design iterations. This included a rating of the script, ease of use, level of customisation, and a reflection on the design outcomes. This use of parametric design in the conceptual phase, as well as the developed stages throughout the design process, reinforced the major part they have in redefining a new way of designing uniquely with variety, creating more than just mass-replicated designs. It was made clear that creating a straightforward script, that had a good level of adjustable components were key to creating successful designs. It was not only the singular outcome of one design that was the main focus, but rather level of adaptability the design had to create a variety of outcomes.

\section{RESEARCH OBJECTIVE THREE:}

The fabrication component of this research was an important milestone in providing a strong understanding of the entire workflow and process of this technology. The initial small filament prototypes were important in understanding how the digital models translated into physical prototypes, outlining important considerations. Additive manufacturing was proven to be an effective method of fabrication, however it became clear that wastage was a key factor, as well as the issues with overhangs and failure angles, and so adjustments along the way of fabrication were key in creating successful prototypes.

\section{RESEARCH OBJECTIVES THREE AND FOUR:}

Moving into large scale fabrication and the use of the robotic arm and clay extruder was an essential part of the project. The increase in scale of the designs, as well as the use of clay as material, allowed the research to be situated and realised much more closely to industry circumstances, and in an architectural sense. Coming to terms with the technology and understand the parameters and workflow meant that this design process was able to be established, and an understanding of how these technologies could fit into the industry. By testing the material and technology, new 
findings were able to be discovered, and adjustments to the designs were made to find successful outcomes. Applying the designs to full-scale architectural columns and a design context meant that an understanding as to how these could be produced in a real context added an extra layer of understanding to the research.

This research has shown how ornamentation can be reenvisaged in contemporary design in a mass-customisable way, and how digital fabrication can be a key driver in this. As the developments continued through this research process, understanding of the technology and key considerations meant that a workflow of visual scripting and then in turn digital fabrication could be established. The benefits of this outcome mean that with a single design script, designs can be adjusted and modified in real time and that with simple adjustments, each architectural element can have variation and uniqueness, instead of repetition. Making these kinds of processes a design focus is a critical component in integrating ornamentation back into contemporary architectural design. This research has highlighted the potential that these tools have to effectively and efficiently create customisable elements, and has opened up opportunities for further explorations of these findings, to understand how ornamentation can fit into contemporary design again, re-establishing its place back into architecture. 
0

$\ddot{\sim}$

L)

$\underline{u}$

L

ㄸ

L

Lا

L

$\alpha$ 


\subsection{REFERENCES}

3DWASP. (n.d.). Ceramic 3D Printing. World's Advanced Saving Project. Retrieved 2 October 2020, from https://www.3dwasp.com/en/ceramic-3d-printing-wasp-clay/

3DWASP. (2019, May 15). TECLA. 3DWASP. https://www.3dwasp.com/en/3d-printed-house-tecla/

Abondano, D. (2013). The Return of Nature as Operative Model: Decoding of Material Properties as Generative Inputs to the Form-Making Process. International Journal of Architectural Computing, 11(2), 267-283. https://doi.org/10.1260/1478-0771.11.2.267

Achten, H., Gomez-Zamora, P., Henriques, G. C., \& Sousa, J. P. (2020). Architecture in the age of the 4th industrial revolution. International Journal of Architectural Computing, 18(4), 317-319. https:// doi.org/10.1177/1478077120950939

Agkathidis, A. (2015). Generative Design. Laurence King Publishing.

Al-Douri, T. A. (2015). On Belief and the Making of All Things Beautiful and Sublime: Creation by Ordinance and Destruction by Chaos. Cybernetics and Systems, 46(6-7), 580-587. https://doi.org/1 $0.1080 / 01969722.2015 .1038480$

Anton, A., Bedarf, P., Dillenburger, B., Flatt, R. J., Reiter, L., Wangler, T., \& Yoo, A. (2020). Concrete Choreography: Prefabrication of 3D-Printed Columns. In Fabricate 2020: Making Resilient Architecture (pp. 286-293). UCL Press.

Balik, D., \& Allmer, A. (2016). A Critical review of ornament in contemporary architectural theory and practice. ITU Journal of Faculty of Architecture, 13(1), 157-159.

Bandyopadhyay, A., \& Bose, S. (Eds.). (2016). Additive Manufacturing. CRC Press. http://search. ebscohost.com/login.aspx?direct=true $\& d b=$ nlebk \&AN=1059051\&site=ehost-live

Banon, C., \& Raspall, F. (2020). 3D Printing Architecture: Workflows, Applications, and Trends. Springer Singapore Pte. Limited.

Banton, C. (2020, September 30). Mass Production. https://www.investopedia.com/terms/m/massproduction.asp

Bertol, D. (2011). Form Geometry Structure: From Nature to Design. Bentley Institute Press.

Bloomer, K. (2000). The Nature of Ornament: Rhythm and Metamorphosis in Architecture. W.W Norton \& Company.

Callaghan Innovation. (2020, November 16). Press Print. Callaghan Innovation. https://www. callaghaninnovation.govt.nz/customer-stories/press-print

Chitham, R., \& Loth, C. (2004). The Classical Orders of Architecture. Routledge. http://ebookcentral. proquest.com/lib/vuw/detail.action?doclD=286749

Cobusier, L. (1986). Towards a New Architecture (Reprint. Originally published: London: J. Rodker, 1931, Vol. 1). Dover Publications.

Coulton, J. J. (1977). Greek Architects at Work: Problems of Structure and Design. Elek Books Ltd.

Curl, J. S. (1992). Classical Architecture: An Introduction to its Vocabulary and Essentials, with a Selected Glossary of Terms (2nd ed.). W.W Norton \& Company. 
Daas, M., \& John Wit, A. (Eds.). (2018). Towards a Robotic Architecture. Applied Research and Design Publishing.

Davis, D., \& Peters, B. (2013). Design Ecosystems: Customising the Architectural Design Environment with Software Plug-ins. Architectural Design, 83(2), 124-131. https://doi.org/10.1002/ad.1567

Dillenburger, B., \& Hansmeyer, M. (2014). Printing Architecture: Castles Made of Sand. In FABRICATE: Negotiating design \& making (pp. 93-97). gta Verlag.

Dunn, N. (2012). Digital Fabrication in Architecture. Lawrence King Publishing.

Folkard, R. (2015). Plant Lore, Legends, and Lyrics Embracing the Myths, Traditions, Superstitions, and Folk-Lore of the Plant Kingdom. Library of Alexandria.

Food4Rhino. (n.d.). Anenome. Food4Rhino. Retrieved 6 May 2020, from https://www.food4rhino. com/app/anemone

Furjan, H. (2003). Dressing Down: Adolf Loos and the politics of ornament. The Journal of Architecture, 8(1), 115-130.

Garcia, M. (2014). Future Details of Architecture. John Wiley \& Sons Inc.

Glazier, R. (1899). A manual of Historical Ornament. Mayfield Press.

Gleiniger, A., Vrachliotis, G., Gleiniger, A., \& Vrachliotis, G. (2009). Muster - Ornament, Struktur und Verhalten: Ornament, Structure, and Behavior. Walter de Gruyter GmbH. http://ebookcentral. proquest.com/lib/vuw/detail.action?doclD=1020525

Gramazio, F., Kohler, M., \& Willmann, J. (2014). Authoring Robotic Processes. In Architectural Design (Vol. 84, pp. 14-22). WILEY.

Gurr, M., Ligon, S. C., Liska, R., Mulhaupt, R., \& Stampfl, J. (2017). Polymers for 3D Printing and Customized Additive Manufacturing. Chemical Reviews, 117(15), 10212-10290. https://doi. org/10.1021/acs.chemrev.7b00074

Gursoy, B. (2018). From Control to Uncertainty in 3D Printing with Clay. Computing for a Better Tomorrow, 21-30.

Hansmeyer, M. (n.d.-a). Digital Grotesque II. Michael Hansmeyer. http://www.michael-hansmeyer. com/digital-grotesque-II

Hansmeyer, M. (n.d.-b). Subdivided Columns. Michael Hansmeyer. http://www.michael-hansmeyer. com/subdivided-columns

Hell, J., Adams, J., Steinmetz, G., Schönle, A., \& Schönle, A. (2010). Ruins of Modernity. Duke University Press. http://ebookcentral.proquest.com/lib/vuw/detail.action?doclD=1170517

Hersey, G. (1988). The Lost Meaning of Classical Architecture: Speculations of ornament from Vitruvius to Venturi. MIT Press.

Hull, C. W. (2015). The Birth of 3D Printing. Research-Technology Management, 58(6), 25-29. https:// doi.org/10.5437/08956308X5806067 
Huntley, G. H. (1946). In Defense of Ornament. College Art Journal, 6(1), 29-36. https://doi.org/10.1 080/15436322.1946.10795169

Jabi, W. (2013). Parametric Design for Architecture (1st Edition). Lawrence King Publishing.

Jencks, C. (1991). The Language of Post-Modern Architecture (6th ed.). Rizzoli International Publications Inc.

Johnston, L. (2015). Digital Handmade: Craftmanship in the New Industrial Revolution. Thames and Hudson.

Jones, O. (2016). The Grammar of Ornament: A Visual Reference of Form and Colour in Architecture and the Decorative Arts-The complete and unabridged full-color edition. Princeton University Press.

Kolarevic, B. (2005). Architecture in the digital age: Design and Manufacturing. Taylor \& Francis.

Kontovourkis, O., \& Tryfonos, G. (2018). Integrating parametric design with robotic additive manufacturing for 3D clay printing: An experimental study. ISARC. Proceedings of the International Symposium on Automation and Robotics in Construction, 35, 1-8. https://doi.org/10.22260/ ISARC2018/0128

Kontovourkis, O., Tryfonos, G., \& Georgiou, C. (2019). Robotic additive manufacturing (RAM) with clay using topology optimization principles for toopath planning: The example of a building element. Architectural Science Review, 63(2), 1-14. https://doi.org/10.1080/00038628.2019.1620170

Leach, N. (2017). Size Matters: Why body architecture is the future of 3D printing. Architectural Design, 87(6), 76-83. https://doi.org/10.1002/ad.2241

Leah, N., \& Yuan, P. (2018). Computational Design. Tongji University Press.

Loos, A. (1997). Ornament and Crime: Selected Essays. Ariadne Press.

Loporcaro, G., \& Zhao, A. (2019). Exploring Opportunities and Limitations of 3D Concrete Printing Technology in New Zealand. Concrete NZ Conference 2019. https://cdn.ymaws.com/concretenz.org. $\mathrm{nz} /$ resource/resmgr/docs/conf/2019/s4b_p2.pdf

Manufacturing Material Effects-Rethinking Design and Making in Architecture. (2008). Routledge.

Margaret Maliszewki-Pickart. (1998). Architecture and Ornament: An Illustrated Dictionary. McFarland \& Co.

Mediated Matter Group. (n.d.). Wanderers. https://mediatedmattergroup.com/wanderers

Meijl, T. van. (2006). Maori Meeting-houses in and Over Time. In Inside Austronesian Houses: Perspectives on domestic designs for living (pp. 201-224). ANU Press.

MIT. (n.d.). Wanderers. MIT. https://www.media.mit.edu/projects/wanderers/overview/

Mitrache, A. (2012). Ornamental Art and Architectural Decoration. Procedia - Social and Behavioral Sciences, 51, 567-572. https://doi.org/10.1016/j.sbspro.2012.08.207

Molitch-Hou, M. (2018). Overview of additive manufacturing process. In Additive Manufacturing: Materials, Processes, Quantifications and Applications (pp. 1-38). Elsevier Science \& Technology. 
Moussavi, F., \& Kubo, M. (2006). The Function of Ornament. Harvard University, Graduate School of Design.

Oxman, N. (2018). Neri Oxman: About. Neri Oxman MIT. https://neri.media.mit.edu/neri-oxman.html

Pell, B. (2010). The Articulate Surface: Ornament and Technology in Contemporary Architecture. Basel: Birkhäuser.

Peters, B. (2014). Building Bytes: 3D-Printed Bricks. In Fabricate (pp. 112-119). gta Verlag.

Picon, A. (2013). Ornament: The politics of Art and Subjectivity. Wiley \& Sons, Incorporated.

Raaij, M. van. (2014). Building as Ornament: Iconography in Contemporary Architecture (C. Frink, Trans.). Nai010 Publishers.

Rael, R., \& Fratello, V. S. (2018). Printing Architecture: Innovative Recipes for 3D Printing (1st Edition). Princeton Architectural Press.

Rael, R., \& San Fratello, V. (2017). Clay Bodies: Crafting the Future with 3D Printing. Architectural Design, 87(6), 92-97. https://doi.org/10.1002/ad.2243

Retsin, G. (2019). Towards Distcrete Architecture: Automation Takes Command. 39th Annual Conference of the Association for Computer Aided Design in Architecture, 523-541.

Retsin, G., Jimenez, M., Claypool, M., \& Soler, V. (2019). Robotic Building: Architecture in the Age of Automation. Detail Business Information $\mathrm{GmbH}$, The.

Rosenbauer, W. (1947). The Function of Ornament. College Art Journal, 6(3), 222-225. JSTOR. https:// doi.org/10.2307/772972

Rossi, M., \& Buratto, G. (Eds.). (2017). Computational Morphologies: Design Rules Between Organic Models and Responsive Design. Springer International Publishing.

Roudavski, S. (2009). Towards Morphogenesis in Architecture. International Journal of Architectural Computing, 7(3), 345-374. https://doi.org/10.1260/147807709789621266

Rowland, T. (2020, November 26). Concrete 3D Printeran Innovative approach by Hamilton Construction Company. NZ Herald. https://www.nzherald.co.nz/waikato-news/news/concrete-3d-printer-aninnovative-approach-by-hamilton-construction-company/TYPIOLC4RQLOSAINZP2T5ZDPJY/

Saglam, H. (2014). Re-thinking the Concept of 'Ornament' in Architectural Design. Procedia - Social and Behavioral Sciences, 122, 126-133. https://doi.org/10.1016/j.sbspro.2014.01.1314

Sankovitch, A.-M. (1998). Structure/Orament and the Modern Figuration of Architecture. The Art Bulletin, 80(4), 687-717. https://doi.org/10.2307/3051319

Scahill, D. (2009). The Origins of the Corinthian Capital. In P. Schultz \& R. von den Hoff (Eds.), Structure, Image, Ornament (pp. 40-53). Oxbow Books; JSTOR. https://www.jstor.org/stable/j.ctt1cdOpht.7

Schumacher, T. L. (2005). Horizontality. Journal of Architectural Education, 59(1), 17-26. https://doi. org/10.1111/j.1531-314X.2005.00002.x 
Shea, K., Aish, R., \& Gourtovaia, M. (2005). Towards integrated performance-driven generative design tools. Automation in Construction, 14(2), 253-264. https://doi.org/10.1016/j.autcon.2004.07.002

Sissons, J. (2010). Building a house society: The reorganization of Maori communities around meeting houses. The Journal of the Royal Anthropological Institute, 16(2), 372-386. https://doi.org/10.1111/ j.1467-9655.2010.01630.x

Stasiuk, D. (2016). Cocoon. Bespoke Geometry. http://bespokegeometry.com/2015/07/22/cocoon/

Summerson, J. (1980). The Classical Language of Architecture. Thames and Hudson.

Szita, J. (2011). New Order. Frame(Amsterdam), 82, 228-231.

Trilling, J. (2003). Ornament: A Modern Perspective. University of Washington Press.

Unitec. (2019, September). Te Noho Kotahitanga Marae. Unitec. https://www.unitec.ac.nz/maori/ who-we-are/te-noho-kotahitanga-marae

Venturi, R., Brown, D. S., \& Izenour, S. (1977). Learning from Las Vegas (Revised Edition). The MIT Press.

Vitruvius, P. (20 C.E.). Ten Books On Architecture (F. Granger, Trans. 2014). Harvard University Press.

Walsh, N. P. (2019, July 23). ETH Zurich Develops 3D-Printed Concrete Columns. ArchDaily. https:// www.archdaily.com/921635/eth-zurich-develops-3d-printed-concrete-column

Walters, M. (2014). Marae-Te tatau pounamu: A journey around New Zealand's meeting houses. RHNZ Godwit.

Ward, J. (1896). The Principles of Ornament (G. Aitchison, Ed.). Charles Scriber's Sons.

WASP. (2021). TECLA - Press Release. WASP.

Weston, R. (2011). 100 Ideas that Changed Architecture (1st ed.). Laurence King Publishing.

Zhang, Y. (2020). Mass customization: The new path for luxury industry? https://hapticmedia.com/ blog/mass-customization-definition-goal-examples/ 


\subsection{LIST OF FIGURES}

Fig. 01: Classical Greek Columns, Athens, Greece.

Fig. 02: Greek Ornament Retrieved from https://www.gutenberg.org/files/60034/60034-h/images/ ill_pg_091c_sml.jpg

Fig. 03: Greek Doric Order. Retrieved from https://www.gutenberg.org/files/60034/60034-h/images/ ill_pg_148_lg.jpg

Fig. 04: Greek lonic Order. Retrieved from https://www.gutenberg.org/files/60034/60034-h/images/ ill_pg_152_lg.jpg

Fig. 05: Greek Corinthian Order. Retrieved from https://www.gutenberg.org/files/60034/60034-h/ images/ill_pg_158_lg.jpg

Fig. 06: Porch of the Maidens (south porch), Erechtheion, 421-406 BCE. Retrieved from https://www. artsy.net/artwork/acropolis-athens-greece-porch-of-the-maidens-south-porch-erechtheion https:// www.artsy.net/artwork/acropolis-athens-greece-porch-of-the-maidens-south-porch-erechtheion/ download/porch-of-the-maidens-south-porch-erechtheion-421-406-bce.jpg

Fig. 07: Corinthian Capital, Athens, Greece.

Fig. 08: Greek Ruins, Athens, Greece.

Fig. 09: Duck vs. Decorated shed. Retrieved from https://images.e-flux-systems.com/a41033671_238 282993699467_6407199882212267545_nb2ccbg.png,2000

Fig. 10: Second Industrial Revolution. Retrieved from https://www.history.com/.image/t_share/ MTYxNTEyNTkxOTg0Njk5MDM1/second_industrial_revolution_gettyimages-51632462.jpg

Fig. 11: Ludwig Mies van der Rohe, Philip Johnson, Kahn \& Jacobs. (1958). Seagram Building, exterior, street level. Retrieved from https://library.artstor.org/\#/asset/ASTOLLERIG_10311331052

Fig. 12: Contemporary façade design: New Eskenazi - Parking Garage. Indianapolis, Indiana, USA. Retrieved from https://www.rgcollaborative.com/projects/new-eskenazi-parking-garage/104/ Image1-optimized.jpg

Fig. 13: John Lewis Department Store and Cineplex, Leicester. By Farshid Moussavi. Retrieved from https://www.farshidmoussavi.com/node/25

Fig. 14: Digital Grotesque II. Retrieved from http://www.michael-hansmeyer.com/digital-grotesque-II Fig. 15: ABB Robotic Arm at Victoria University of Wellington.

Fig. 16: Interior of negative space. Retrieved from http://www.michael-hansmeyer.com/subdividedcolumns

Fig. 17: Subdivided Column 1 at ETH. Retrieved from http://www.michael-hansmeyer.com/subdividedcolumns

Fig. 18: Digital Grotesque I: De-sanding of printed elements. Retrieved from http://www.michaelhansmeyer.com/digital-grotesque-I

Fig. 19: Digital Grotesque II. Retrieved from http://www.michael-hansmeyer.com/digital-grotesque-II Fig. 20: TE NOHO KOTAHITANGA MARAE. Retrieved from https://pbs.twimg.com/media/BijlKhCIAApliE.jpg

Fig. 21: TE NOHO KOTAHITANGA MARAE. Retrieved from https://lh3.googleusercontent. com/proxy/HTnOYrnNPJ_2F_6vKubwkn5cFleFMkjdhJ5EJ87MxenRtqQh_bQSjpiHQhriOY_ nqftDEN2vbdxAfpIVPscoVBqboaiw0Xr1sl8eQ8TJDwpL8DLZHHz01NsOHI5f65wy_Mq78HWD

Fig. 22: 3D-Printed Wearable. Wanderers. Retrieved from https://mediatedmattergroup.com/ wanderers

Fig. 23: Digital Renders. Wanderers. Retrieved from https://mediatedmattergroup.com/wanderers

Fig. 24: Digital Renders. Retrieved from https://mediatedmattergroup.com/wanderers

Fig. 25: Robotically Printed concrete columns. Concrete Choreography. Retrieved from https:// static.dezeen.com/uploads/2019/07/concrete-choreography-3d-printed-columns-stage-eth-zurichstudents-switzerland_sq-c.jpg 
Fig. 26: ABS 3D Printed Prototypes

Fig. 27-29: Grasshopper/Rhino Workflow

Fig. 30: Summary of Process

Fig. 31: Corinthian Capital. Retrieved from https://favpng.com/png_view/column-corinthian-ordercolumn-doric-order-classical-order-architecture-png/btZASXbS

Fig. 32: Doric Capital

Fig. 33: Digital Process

Fig 34: Rhino Digital Models

Fig 35: ABS 3D-Printed Prototypes

Fig. 36: Greek lonic Order. Retrieved from https://www.gutenberg.org/files/60034/60034-h/images/ ill_pg_152_lg.jpg

Fig 37: Digital Process

Fig 38: Rhino Digital Models

Fig 39: ABS 3D-Printed Prototypes

Fig. 40: Digital Process

Fig. 41: ABS 3D-Printed Prototypes

Fig. 42: Digital Process

Fig. 43: ABS 3D-Printed Prototypes

Fig. 44: Corinthian Capital. Retrieved from https://favpng.com/png_view/column-corinthian-ordercolumn-doric-order-classical-order-architecture-png/btZASXbS

Fig. 45: Digital Process

Fig. 46: Rhino Digital Models

Fig. 47: ABS 3D-Printed Prototypes

Fig. 48: Digital Process

Fig. 49: ABS 3D-Printed Prototypes

Fig. 50: Further digital explorations

Fig. 51: Weaving Digital Diagram

Fig. 52: Digital Process

Fig. 53: Rhino Digital Models

Fig. 54: ABS 3D-Printed Prototypes

Fig. 55: Fired Clay Models

Fig. 56: TECLA 3D Printed house. Retrieved from https://www.3dwasp.com/en/3d-printed-housetecla/

Fig. 57: Building Bytes Ceramic Bricks. Retrieved from https://doi-org.helicon.vuw.ac.nz/10.2307/j. ctt1tp3c5w.18

Fig. 58: ABB Robotic arm \& Clay extruder at Victoria University of Wellington

Fig. 59: Robotic arm \& Clay extruder attachment

Fig. 60: Clay extruder parts

Fig. 61-62: Clay print iteration one

Fig. 63-64: Clay print iteration two

Fig. 65-67: Clay Print iteration three

Fig. 68-70: Clay Print iteration four

Fig. 71-73: Clay Print iteration five

Fig 74: Error One

Fig 75: Error Two

Fig 76: Digital Process 
Fig 77-78: Clay print iteration one Fig 79-81: Clay print iteration two Fig 82-84: Clay print iteration three Fig. 85: Portion of Grasshopper script \& Digital Process

Fig. 86: Clay Print Iteration one Fig 87-88: Clay print iteration two Fig 89: clay print iteration three Fig. 90: Clay print iteration four Fig. 91: Error one

Fig. 92: Error two

Fig. 93: Digital Process

Fig. 94-95: clay print iteration one Fig 96-97: clay print iteration two

Fig 98: Error one

Fig 99: error two

Fig 100: Portion of Grasshopper script \& Digital Process

Fig. 101: Sampled Image

Fig 102-103: Clay print iteration one

Fig 104: Sampled image

Fig 105-106: Clay print iteration two

Fig 107: Sampled image

Fig 108-109: Clay print iteration three

Fig 110: Error one

Fig 111: Error one

Fig. 112: 3D-Printed models

Fig 113: Leaves/crumpling. Retrieved from https://i.pinimg.com/564x/84/bc/a5/84bca5f3e429aaa0 671258e8ae86e51f.jpg

Fig 114: Coral Growths. Retrieved from https://i.pinimg.com/564x/c3/fd/7c/ c3fd7cf0963626831e028202f6cc8e9d.jpg

Fig 115: Lichen growing on bark. Retrieved from https://i.pinimg.com/564x/f8/86/22/ f886224a091ec8cbc75e318ea5f60b77.jpg

Fig 116: Retrieved from https://i.pinimg.com/originals/23/79/40/2379405f9c1294faaa6da1f9dc044 03b.jpg

Fig 117: Site: Wellington Waterfront

Fig 118: Site context. Retrieved from https://koordinates.com/

Fig 119: Column Layout

Fig 120: Digital Model One

Fig 121: Digital Model Two

Fig 122: Digital Model Three

Fig 123: Digital Model Four

Fig 124: Final render of column series

Fig 125: Digital Model \& Division Process

Fig 126-129: Compiled final column (unfired)

Fig. 130: Clay Printed model

Fig. 131: Concrete 3D Printed Bench, Retrieved from: https://www.nzherald.co.nz/resizer/qxVguaf ceOulsyOyjEFGO4Wq8pU=/1440x810/smart/filters:quality(70)/cloudfront-ap-southeast-2.images. arcpublishing.com/nzme/UUJNEH5FUSLFM2AVHJQIQMXQK4.jpg 
Fig 132: Concrete bench designs. Retrieved from: https://ourhamilton.co.nz/culture-events/hamiltonhosts-new-zealands-first-3d-printed-concrete-demonstration/

Fig 133: Robotics workshop \& other clay prints 
